\title{
Padrões de consumo alimentar \\ associados a outros fatores de risco \\ predisponentes a doenças cardiovasculares \\ em residentes da área urbana \\ do município de São Paulo
}

Africa Isabel de la Cruz Perez Neumann

Tese apresentada ao Programa de Pós-Graduação em Saúde Pública da Faculdade de Saúde Pública da Universidade de São Paulo para a obtenção do título de Doutor em Saúde Pública

Área de concentração: Nutrição

Orientadora: Prof ${ }^{a} r^{2}$ Ignez Salas Martins

São Paulo

2005

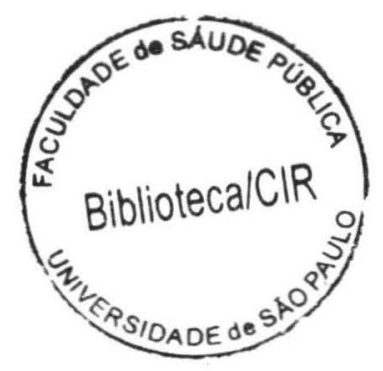




\section{Ficha catalográfica}

Neumann, Africa Isabel de la Cruz Perez

Padrões de consumo alimentar associados a outros fatores de risco predisponentes às doenças cardiovasculares em residentes da área urbana do município de São Paulo / Africa Isabel de la Cruz Perez Neumann - São Paulo, 2005. 165 p.

Tese (doutorado) - Faculdade de Saúde Pública da USP.

Orientadora: Ignez Salas Martins

$\begin{array}{lll}\text { 1. Padrão alimentar 2. Consumo de alimentos } 3 \text {. Doenças cardiovasculares } & \text { 2. }\end{array}$

4. Análise fatorial

Martins, Ignez Salas, orientadora

Autorizo, exclusivamente para fins acadêmicos e científicos, a reprodução total ou parcial desta tese, por processos fotocopiadores.

Assinatura:

Data:

$$
47135 / 2006 d x
$$




\section{DEDICO ESTE TRABALHO \\ A TODA MINHA FAMILIA, AMIEOS E, EM ESPECIAL ...}

... aos meus pais, Maria de los Angeles e Salvador,

por todos os sacrificios e renúncias que fizeram e ainda fazem para propiciar aos filhos oportunidades que eles nunca tiveram.

... aos meus fithos, Ana Laura, Deborah e Carlos Fernando,

minhas melhores "produçoes", por tantas horas "roubadas" do convivio com vocês... por privar vocês de comer padräo alimentar "cafeteria" ... ... espero que vocês me entendam, futuramente, quando puderem ler e compreender este trabalho.

... e ao meu marido, Carlos Fernando, meu melhor amigo

por todo o incentivo, compreensão, companheirismo, cumplicidade, carinho... amor... PACIÊNCIA... suporte financeiro... psicológico... constantemente recebido! 


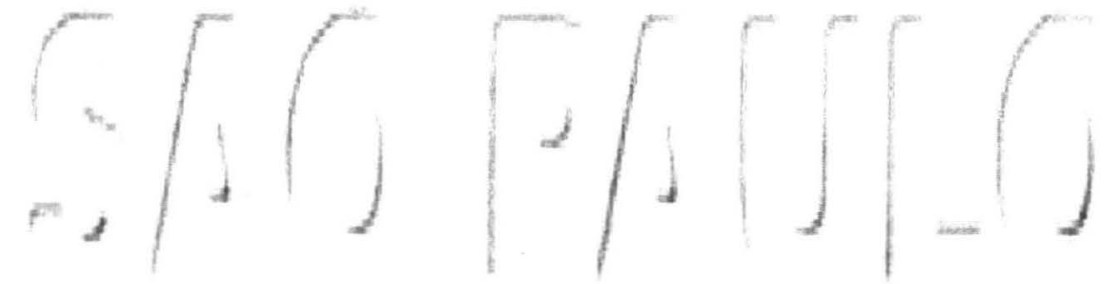

... "QUANDO EU TE ENCAREI FRENTE A FRENTE

E NÃO VI O MEU ROSTO

CHAMEI DE MAU GOSTO O QUE VI, DE MAU GOSTO, MAU GOSTO...

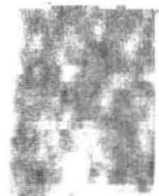

\$.<smiles>[Al]=[W]</smiles><smiles>[CH]=C</smiles>

FAVELAS DA FORÇA DA GRANA QUE ERGUE EDESTRÓI COISAS BELAS DA FEA FUMAÇA QUE SOBE

- APAGÁNDO AS ESTRELAS

Y i , EUVEJO SURGJR TEUSPOEIASDE CAMPOS 1. ... DO POVO OPRIMIDO NAS FILAS, NAS VILAS, FAVELAS,

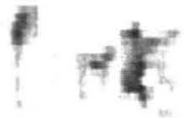
(VV) EIESPACOS

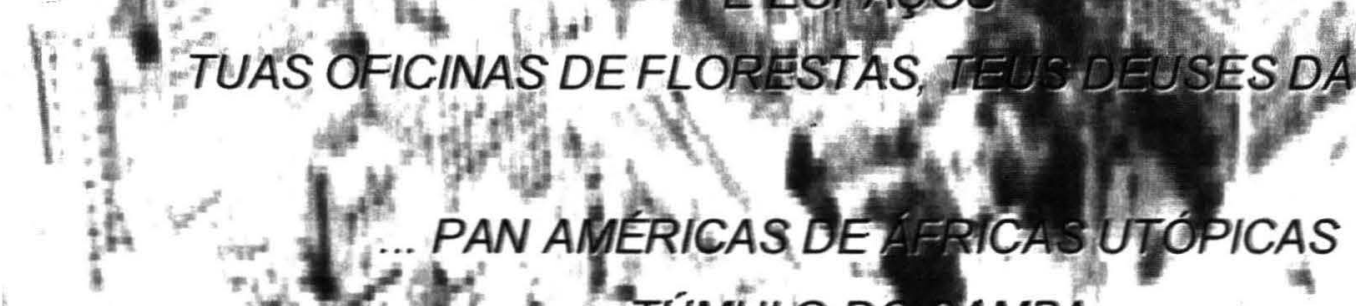

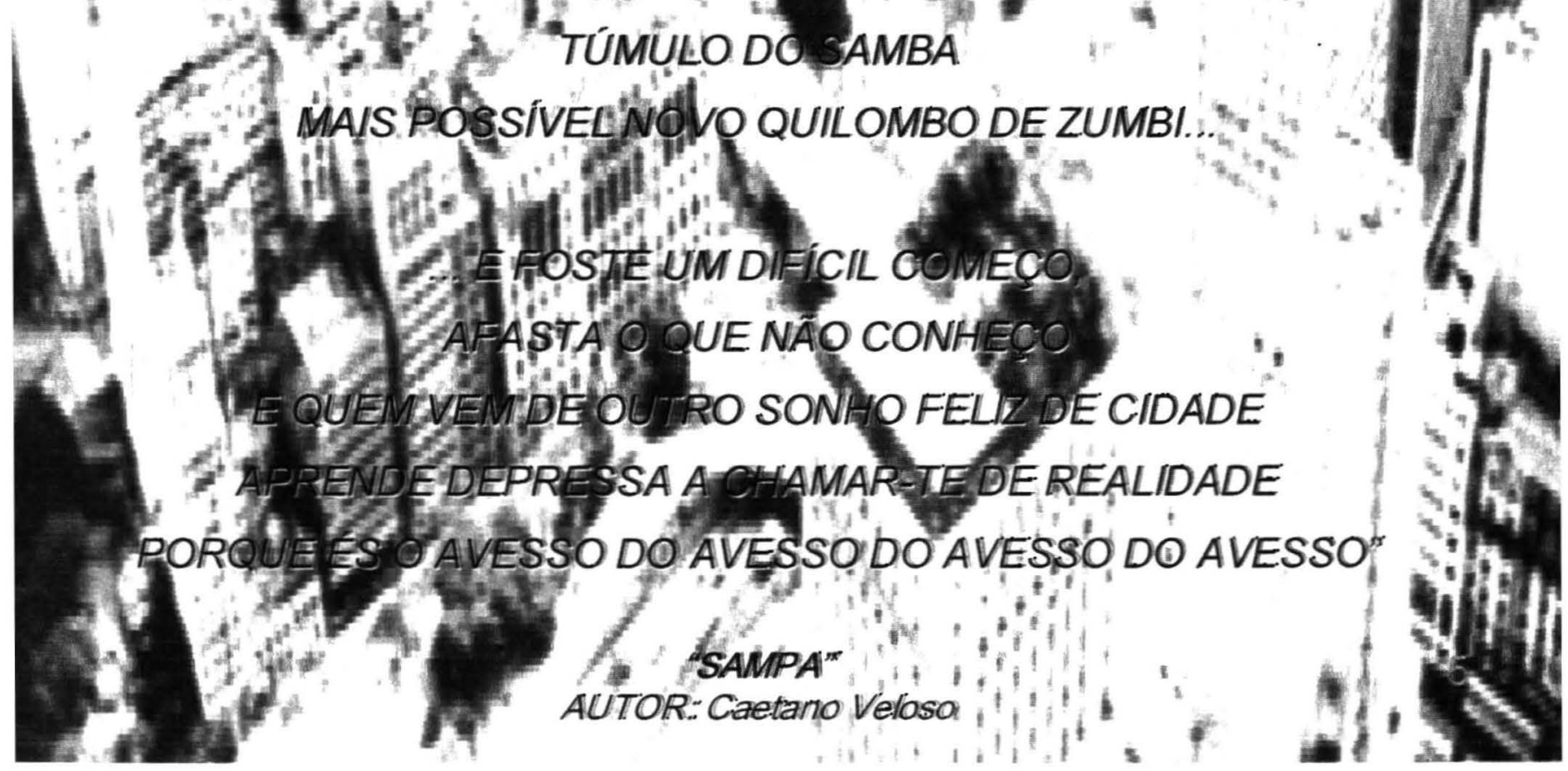




\section{AGRADECIMENTOS}

Este trabalho só pôde ser realizado graças a pessoas muito especiais que, direta ou indiretamente me ajudaram na sua elaboração. Quero aqui mencioná-las, demonstrando minha gratidão!

Profe. Dra. Ignez Salas Martins. Dizer OBRIGADA é muito pouco. Muitas portas se fecharam e achei que era a hora de desistir... Serei eternamente grata por ter me acolhido e, pacientemente, dispor de seu tempo e de seu conhecimento para me orientar.

Prof. Dr. José Alfredo Gomes Arêas. Como Presidente da Comissão de Pós Graduação desta Faculdade, quero agradecer por sua total compreensão, irrestrito apoio, disponibilidade, paciência e incentivo.

Prof. Dr. Luiz Francisco Marcopito. Agradeço o apoio recebido, paciência, disponibilidade, amizade e suas valiosas correçōes.

Aos habitantes da cidade de São Paulo. Sem a colaboração, disponibilidade em responder ao extenso questionário não seria possivel a realização deste estudo.

Equipe de planejamento e execução da pesquisa "Fatores de risco para doenças crônicas não-transmissiveis: inquérito domiciliar no Municipio de São Paulo".

Dr. Carlos Magno Castelo Branco Fortaleza, ex-diretor do Centro de Vigilância Epidemiológica da Secretaria de Estado da Saúde (CVE/SES) e atual diretor Centro de Controle de Doenças (CCD/SES) e Enf. Ana Paula Coutinho. Agradeço aos meus superiores todo o apoio recebido, proporcionando infra-estrutura e demais condições para a realização do trabalho. À Ana Paula Coutinho, pela amizade, apoio e compreensão de sempre.

Enf. Marco Antonio de Moraes, Enf Dalva M. O. Valencich, Dr. Rodolfo Brumini, Dr. Sérgio São Fins Rodrigues, Dr. Sidney Federmann. Membros da equipe técnica da DDCNT/CVE/CVE. Obrigada pela amizade, carinho, auxilio, pela paciência em me ouvir reclamar das dificuldades encontradas na elaboração deste trabalho. 
Lenilza Moura e Lúcia Prestes Salvi. Equipe de apoio da DDNCT/CVE/SES. Grata pela amizade, apoio e todo o carinho que recebo de vocês!

$D r^{a}$. Mírian Matsura Shirassu. Pela amizade de sempre, apoio, carinho e outras oportunidades de trabalho oferecidas.

$D r^{a}$. Maria Célia Guerra Medina. Por reconhecer a necessidade e importância do profissional nutricionista na Divisão de Doenças Crônicas Não Transmissiveis do Centro de Vigilância Epidemiológica da Secretaria de Estado da Saúde. Pela amizade, conselhos valiosos e todas as oportunidades proporcionadas.

Dr. Arthur Jacques Goldfeder. Pela amizade, preocupaçäo com a qualidade deste trabalho e disposição em ajudar sempre que necessário.

Dra. Ana Maria Sanches. Pela amizade, atenção, compreensão e toda colaboração oferecida, no inicio desta jornada.

Prof. Dr. Paulo Andrade Lotufo. Pela amizade, apoio e oportunidades que me proporcionou no início desta caminhada.

Prof . Dr. Regina Mara Fisberg. Por ter me proporcionado a oportunidade de realizar a pós graduação; pela orientação, compreensão, paciência e amizade.

Prof . Dr ${ }^{2}$.Dirce M. Lobo Marchioni. Por toda a atenção, correçōes, sugestōes, auxilio e amizade.

Prof. Dr. Moacyr R. Cuce Nobre. Por aceitar, de imediato, participar da banca. Pela disponibilidade e correções feitas no trabalho.

Prof. Dr. Bruno Caramelli. Grata por aceitar participar da banca. Dispor de seu tempo para ler e sugerir melhorias a este trabalho.

Prof . Dr . Anita Sachs. Agradeço sua atenção, críticas, sugestōes e amizade.

Dra. Eutália A. C. Araújo. Pelo auxílio estatístico e pela amizade que, naturalmente, foi surgindo ao longo dos meses de trabalho em conjunto. 
Mestre Andréa Gomes. Amiga de todas as horas! Grande incentivadora! Obrigada por todas as sugestōes e indicaçōes. Valeu, amiga!

Mônica Perez. É como irmã... é o ombro amigo... é aquela que chega para levantar o astral, reclamar, acudir, contar e mostrar as "novidades"... emprestar o açúcar e o ovo para terminar o bolo. Por isso dizem que vizinho é mais que parente.

Dra. Mônica Inês Elias Jorge. Agradeço muito suas sugestões, apoio e amizade que surgiu nessa etapa final e decisiva!

Maria Aparecida Mendes (Cidinha), Márcia A. Garcia da Silva e Renilda M. de Figueiredo Shimono - Comissão de Pós Graduação - CPG/FSP-USP. Não tenho palavras para agradecer todo o apoio, compreensão e amizade que vocês me deram... Muito obrigada por tudo!

Aos funcionários da Biblioteca da Faculdade de Saúde Pública, em especial à Márcia R. P. Ribeiro, Antonia V. do Nascimento e minha "quase" chara Afra R. de Lima. Sempre prontas a auxiliar e encontrar "aquele" livro, artigo ou revista!

Minha "equipe" de apoio familiar. Neide Brito e Ridalva Paulino, que me ajudam a tornar realidade as leis da nutrição no meu lar... sem o apoio, carinho, cuidado com meus filhos e minha casa e a amizade de vocês, não poderia ter saído um único dia de casa nos últimos anos !

E finalmente, ao Professor Dr. José Eduardo Dutra de Oliveira, a quem devo grande parte do meu aprendizado sobre a Ciência da Nutrição. Responsável pelo meu "despertar" para a importância da carreira cientíica. Por todos os ensinamentos e oportunidades que me proporciou! 


\title{
RELAÇÃO DAS ABREVIATURAS
}

\author{
AVCIACV - acidente vascular cerebral \\ BTS - Bartlett's Test of Sphericity \\ CDC - Centers for Disease Control and Prevention \\ CID X - Classificação estatística Internacional de Doenças - $10^{\mathrm{a}}$ revisão \\ CVE - Centro de Vigilância Epidemiológica \\ DAnT - doenças e agravos não transmissiveis \\ DATASUS - Departamento de Informação e Informática \\ DCA - doenças cardiovasculares ateroscleróticas \\ DCNT- doenças crônicas não transmissíveis \\ DCV - doença cardiovascular \\ DDCNT - Divisão de Doenças Crônicas Não Transmissíveis \\ DNAADN - ácido desoxirribonuclêico \\ DIC - doença isquêmica do coração \\ DM - diabetes mellitus ou diabete melito \\ ENDEF- Estudo Nacional de Despesa Familiar
}

FR - fator de risco

HA - hipertensão arterial

HAS - hipertensão arterial sistêmica

HDL-c - high density lipoprotein - cholesterol (lipoproteína de alta densidadecolesterol)

IBGE - Instituto Brasileiro de Geografia e Estatística

ICC - insuficiência cardiaca congestiva

IG - índice glicêmico

IMC - indice de massa corporal

INCA - Instituto Nacional do Câncer

IS - Instituto de Saúde

ISO - International Standards Organization

KMO - Kaiser-Meyer-Oblin

$\mathrm{Kg}$ - quilograma

LDL-c - low density lipoprotein- cholesterol

MANCOVA: análise multivariada de covariância 
$\mathrm{m}^{2}$ - metro quadrado

MS - Ministério da Saúde

MSP - municipio de São Paulo

OMS - Organização Mundial da Saúde

OPAS - Organização Panamericana da Saúde

PA - pressão arterial

PAD - pressão arterial diastólica

PAS - pressão arterial sistólica

PNSN - Pesquisa Nacional sobre Saúde e Nutriçāo

PNUD - Programa das Nações Unidas para o Desenvolvimento

POF - Pesquisas de Orçamento Familiar

$R C Q$ - razão cintura-quadril

QFA - questionário de freqüência alimentar

SBD - Sociedade Brasileira de Diabetes

SES - Secretaria de Estado da Saúde

SP - São Paulo

SPSS - Statistical Package for Social Sciences

SUS - Sistema Único de Saúde

USDA - United States Dietary Allowances

WHO - World Health Organization (Organização Mundial da Saúde) 


\section{RESUMO}

Neumann AICP. Padrões de consumo alimentar associados a outros fatores de risco predisponentes a doenças cardiovasculares em residentes da área urbana do município de São Paulo. São Paulo, 2005. [Tese de Doutorado Faculdade de Saúde Pública da USP].

Introdução. Estudos epidemiológicos têm mostrado que a alimentação é um dos fatores envolvidos na etiologia de doenças cardiovasculares (DCV). Identificar padrões alimentares, levando em conta a complexidade de correlações entre os alimentos, permite examinar o efeito da dieta com diferentes composiçōes de alimentos, podendo descrever associações com doenças de forma mais abrangente do que as descritas por nutrientes ou alimentos singulares. Objetivo. Identificar padrōes de consumo alimentar de residentes da área urbana do município de São Paulo e suas associações com fatores de risco para DCV. Metodologia. Realizou-se inquérito epidemiológico com delineamento transversal em amostra probabilistica de base populacional com pessoas entre 15-59 anos de idade, ambos os sexos, residentes no município de São Paulo, com aplicação de questionário em 782 pessoas para levantamento de dados socioeconômicos, culturais, comportamentais, além de aplicação de questionário de freqüência alimentar (QFA) e dosagens bioquímicas em 700 pessoas. Utilizou-se análise fatorial por componentes principais na identificação dos padrōes alimentares derivados do QFA; análise de covariância para verificar as associaçōes com FR sócio-demográficos e comportamentais e regressão linear múltipla, para avaliar a associação entre os escores fatoriais e os FR biológicos para DCV. Resultados. Foram identificados quatro padrōes alimentares: o padrão 1 "cafeteria" ou "fastfood", composto por alimentos que contém grandes quantidades de açúcares simples, farinhas refinadas e gorduras saturadas associou-se com a área sócio ambiental categorizada como média, escolaridade superior e com o consumo de álcool; com o aumento da pressão arterial sistólica e diastólica, com o índice de massa corporal (IMC) e com a diminuição do HDL-col. O padrão 2 "tradicional" (cereais, leguminosas, infusões) associou-se com o sexo feminino e com a idade superior a 50 anos; associou-se também com o consumo de álcool, com a renda mais alta e com a área sócio ambiental categorizada como média. Associou-se ainda com o aumento da glicemia e do peso corporal; com a diminuição dos 
triglicérides e da obesidade periférica. O padrão 3 "modemo" se caracterizou por conter alimentos com baixos teores de gorduras e açúcares simples e peixes; associou-se com a área sócio ambiental categorizada como alta. Associou-se também com o nível de renda e escolaridade superior e ocupação na categoria de empregador. Associou-se de modo significativo com a diminuição da pressão arterial sistólica e diastólica, do colesterol total e do LDL-col e da glicemia. O padrão 4 foi chamado de "aterogênico" por conter alimentos ricos em gorduras saturadas, além de sal e bebidas alcoólicas. Este padrão associou-se com o sexo masculino, escolaridade fundamental, com o tabagismo e consumo de álcool e com a área homogênea categorizada como média. Também associou-se significativamente com o aumento do colesterol total, dos triglicérides e da glicemia, com a obesidade central e periférica. Observou-se também o baixo consumo de todos padrōes alimentares nas áreas homogêneas categorizadas como baixa e muito baixa. Conclusões. Três dos padrões alimentares identificados ("fast-food", "tradicional" e "aterogênico") associaram-se significativamente com fatores sociodemográficos, comportamentais e biológicos para DCV. Apenas o padrão alimentar caracterizado por conter alimentos com baixos teores de gorduras e açúcares simples mostrou-se, efetivamente, associado a FR biológicos para reduzir riscos cardiovasculares.

Descritores. Padrão alimentar. Consumo alimentar. Doenças Cardiovasculares. Análise fatorial. 


\section{ABSTRACT}

Neumann AICP. Padrões de consumo alimentar associados a outros fatores de risco predisponentes a doenças cardiovasculares em residentes da área urbana do municipio de São Paulo. [Dietary patterns associated with other risk factors for cardiovascular disease in urban residents of São Paulo city]. São Paulo (BR), 2005. [Tese de Doutorado - Faculdade de Saúde Pública da USP].

Introduction. Recent epidemiologic publications pointed out that diet is one of the more important factors involved in the etiology of cardiovascular disease (CVD). Also was established that the intercorrelations among foods described better dietary paterns and their association with diseases than taking associations with nutrients or singular foods. Objective. The main purpose is to describe dietary patterns of urban residents of Sao Paulo city and their association with risk factors for CVD. Methodology. A cross-sectional household survey by randomzed sample including people aged 15-59 years in Sao Paulo City. The final sample was composed of more than 700 people with application of questionnaire for socio-economic, cultural and comportamental data-collecting, and also application of food frequency questionnaire (FFQ) and measures of blood samples.. Factor analysis was used to identify dietary patterns derived from FFQ; covariance analysis to verify the associations with socio-demographic and comportamental risks and multiple linear regression to evaluate the association between factorscore and risk for CVD. Results. Four dietary patterns were identified: pattem 1 "fast food" that contains great amounts of sugars, refined flours and saturated fats were associated with categorized social area as medium, higher educational level and alcoholic drinking intake; with higher sistolic and diastolic blood pressure and body mass index (BMI) and lower HDL-col concentrations. Pattern 2 "traditional" (refined grains, legumes, beverages) were associated with women and older age; also associated with alcoholic drinking intake, the income highest and categorized social area as medium. This pattern still associated with higher concentrations of glucose and body mass index (BMI); with lower concentrations of triglicerides and peripheral obesity. Pattern 3 "modern" characterized for containing low-fats foods, simple sugar and associated with categorized social area as high. Also associated with higher educational and income levels and employer occupation category. This pattern was strongly associated with lower sistolic and diastolic blood pressure, 
total cholesterol, LDL-col and the glucose levels. Pattern 4 called "aterogenic" for containing rich foods in saturated fats, salt and alcoholic beverages. This pattern associated with men, lower educational level, cigarette smoking, alcoholic drinking intake and categorized social area as medium. Also associated significantly with higher concentrations of total cholesterol, triglicerides and glucose levels and peripheral and central obesity. It was observed very low intake of food of all dietary patterns in categorized social areas as low and very low. Conclusions. Three dietary patterns ("fast-food", traditional" e "aterogenic") were strongly associated with sociodemographic, behavioral and biological CDV risk factor. Only the "modern" pattern characterized for containing low-fat and low-sugar foods was effectively associated with biological factor for reduce CVD risk.

Key words. Dietary patterns. Food consumption. Cardiovascular disease. Factor analysis. 
1 INTRODUÇÃO

1.1 As Doenças Cardiovasculares 02

1.1.1 Fatores de risco para Doenças Cardiovasculares 03

1.2 Alimentação e Doenças Cardiovasculares 12

1.3 Transição alimentar no Brasil 18

1.4 O estudo de padrōes de consumo alimentar 22

2 JUSTIFICATIVA 24

3 OBJETIVOS 26

4 MÉTODOS 27

4.1 Delineamento do estudo 27

4.2 População de estudo 27

4.3 Critérios de inclusão 27

4.4 Critérios de exclusão 27

4.5 Amostragem e procedimentos 27

4.5.1 Medidas da pressão arterial 33

4.5.2 Antropometria e índices derivados 34

4.5.3 Critérios diagnósticos específicos 35

4.5.4 Análise fatorial 39

4.5.5 Variáveis do estudo 43

4.5.6 Análise estatística dos dados 45

4.5.6.1 Programa estatístico 47

4.6 Ética 47

5 RESULTADOS $\quad 48$

5.1 Características gerais da amostra de estudo 48

5.2 Características gerais da amostra de estudo quanto 50 estilo de vida, estado nutricional e presença de doenças

5.3 Padrões alimentares da amostra de estudo 52 
ÍNDICE

5.4 Padrões alimentares e variáveis sociodemográficas e comportamentais

5.4.1 Sexo

5.4.2 Grupo etário

5.4.3 Escolaridade

5.4.4 Renda familiar $\quad 57$

5.4.5 Ocupação 58

5.4.6 Áreas homogêneas $\quad 58$

5.4.7 Hábito de fumar $\quad 59$

5.4.8 Consumo de álcool $\quad 59$

5.5 Padrōes alimentares e fatores de risco para DCV 60

6 DISCUSSÃO $\quad 66$

6.1 Características gerais da amostra de estudo 66

6.2 Características gerais da amostra de estudo quanto 67 estilo de vida, estado nutricional e presença doenças

6.3 Padrões alimentares da amostra de estudo 72

6.4 Padrões alimentares e variáveis sociodemográficas 77 e comportamentais

6.5 Padrões alimentares da amostra de estudo 80 associados aos fatores de risco para dcv

7 CONSIDERAÇÕES FINAIS $\quad 84$

8 CONCLUSÕES $\quad 86$

9 REFERÊNCIAS $\quad 87$

10 ANEXOS 114 
Figura 1. População selecionada por amostragem, individuos excluidos e

\section{ÍNDICE DE QUADROS}

Quadro 1. Alimentos/grupo de alimentos usados na análise de padrões alimentares.

\section{ÍNDICE DE TABELAS}

Tabela 1. Distribuição da amostra estudada, segundo características sóciodemográficas. São Paulo, 2002.

Tabela 2. Distribuição da amostra estudada, segundo características quanto ao estilo de vida, estado nutricional e presença de doenças. São Paulo, 2002.

Tabela 3. Distribuição dos componentes alimentares segundo matriz rotacionada. São Paulo, 2002.

Tabela 4. Médias dos escores fatoriais dos padrōes alimentares ajustadas, segundo sexo, grupo etário, escolaridade, quartis de renda, ocupação, áreas homogêneas, hábito de fumar e consumo de álcool. Município de São Paulo, 2002. gico e padrōes alimentares. Município de São Paulo, 2002. 

INTRODUÇĀO

As transformações sociais e econômicas ocorridas no Brasil durante o século passado provocaram mudanças importantes no perfil de ocorrência das doenças em nossa população. Na primeira metade do século 20 , as doenças infecciosas transmissíveis eram as mais freqüentes causas de mortes. A partir dos anos 60, as doenças e agravos não transmissiveis - as DAnTs - tomaram esse papel. Entre os fatores que contribuiram para essa transição epidemiológica estão: o processo de transição demográfica, com queda nas taxas de fecundidade e natalidade e progressivo aumento na proporção de idosos, favorecendo o aumento das doenças crônico-degenerativas (doenças cardiovasculares, câncer, diabetes, doenças respiratórias); e a transição nutricional, com diminuição expressiva da desnutrição e aumento do número de pessoas com excesso de peso (sobrepeso e obesidade). Soma-se a isso o aumento dos traumas decorrentes das causas externas: acidentes, violências e envenenamentos, etc. (BRASIL 2003).

Projeções para as próximas décadas apontam para um crescimento epidêmico das DAnTs na maioria dos países em desenvolvimento, em particular das doenças cardiovasculares, neoplasias e diabetes tipo 2 (OPAS 2003; BRASIL 2003).

Essa transição do quadro epidemiológico tem impactado a área de saúde pública no Brasil e demandado o desenvolvimento de estratégias para o controle das DAnT. A vigilância epidemiológica dessas doenças e dos seus fatores de risco é de fundamental importância para a implementação de políticas públicas voltadas para sua prevenção, controle e a promoção geral da saúde (BRASIL 2003). 


\subsection{As Doenças Cardiovasculares (DCV)}

As Doenças do Aparelho Circulatório constituem o capitulo IX da $10^{\mathrm{a}}$ Classificação Internacional de Doenças - CID-10, (OMS 1996) e são, preferentemente, denominadas na prática "doenças cardiovasculares" (BERTRAND 1997; LESSA 1998b).

Cerca de 17 milhões dos óbitos ocorridos no mundo são causados por doenças cardiovasculares, principalmente cardiopatias e acidentes vasculares cerebrais (OPAS 2003).

Entre as chamadas doenças cardiovasculares destacam-se, principalmente as doenças coronarianas (doença isquêmica ou infarto do miocárdio), doenças cérebro-vasculares (acidente vascular cerebral - AVC), hipertensão arterial (pressão alta) e constituem um conjunto de afecçōes com etiologias e manifestações clínicas diversas de grande importância na estrutura de morbi-mortalidade de todos os países, sendo as mais estudadas no Brasil, do ponto de vista populacional (LESSA 1998a; OPAS 2003).

Entre 1930 e 1985, a proporção de mortes por DCV aumentou em nosso pais em mais de $\mathbf{2 0 0 \%}$ e, segundo dados do Ministério da Saúde, essas doenças vitimam aproximadamente 300.000 brasileiros ao ano (BUSS 1993; BRASIL 1994; LESSA e col. 1996; LESSA 1998b; LOTUFO e LÓLIO 2000).

Apesar de ter sido observado nas últimas quatro décadas declínio na mortalidade por DCV, elas continuam sendo as principais causas de morte no Estado de São Paulo (SES 1997, 2000; LOTUFO e LÓLIO 2000).

No ano de 2002 a mortalidade proporcional por doenças do aparelho circulatório, ambos os sexos, todas as idades, no estado de São Paulo foi de $32,6 \%$ (SES 2004). A porcentagem de óbitos nesse mesmo período no município de São Paulo foi semelhante, sendo que, desse total (64.271), foi 
considerada como primeira causa as doenças isquêmicas do coração (8.452 $13,6 \%)$ e, em segundo lugar as doenças cerebrovasculares (5.484 - 8,8\%) (PMSP 2005).

\subsubsection{Fatores de Risco para Doenças Cardiovasculares}

No avanço do conhecimento sobre a etiologia das doenças cardiovasculares, grande número de características que aumentam a probabilidade de seu desenvolvimento foram identificadas por meio de estudos epidemiológicos (KANNEL 1988).

Os fatores de risco para DCV podem ser classificados em dois grandes grupos: incontroláveis ou não modificáveis e controláveis ou modificáveis. No primeiro grupo estão fatores biológicos, como idade, sexo, raça e hereditariedade. No segundo grupo estão fatores ambientais, subdivididos em fatores de risco biológicos (níveis séricos de lipídios e suas frações, níveis sangüíneos de glicose/insulina, fatores trombogênicos, pressão arterial, entre outros), fatores comportamentais ou estilo de vida (tabagismo, sedentarismo e hábitos alimentares). Fatores sócio-econômicos (renda, escolaridade, ocupação, condições ambientais) e psicossociais também contribuem para o aumento ou agravamento de situaçōes de risco (OMS 1994).

Didaticamente, os determinantes ou fatores de risco para DCV são separados em quatro grupos (BLOCH 1998):

características constitucionais: idade, sexo, raça e hereditariedade não passiveis de modificaçōes - mediadas pelo contexto socioeconômicocultural permitem a identificação de grupos especificos de risco em diferentes populaçōes;

caracteristicas socioeconômico-culturais: renda, escolaridade, ocupação, classe social, entre outras - passiveis de modificaçōes - só obtidas 
mediante transformações profundas da sociedade - auxiliam na identificação de grupos sob maior risco de adoecer;

doenças ou distúrbios metabólicos: hipertensão arterial (HA), obesidade, hiperlipidemia, diabetes mellitus (DM) - geradas por uma combinação de características genéticas e ambientais que aumentam o risco de DCV, isoladamente ou interagindo com outros fatores de risco cardiovascular. Podem ser reduzidos, controlados ou até eliminados, tendo impacto significativo na morbi-mortalidade cardiovascular.

características comportamentais: hábito de fumar, hábitos alimentares, atividade física, consumo de álcool e uso de anticoncepcionais passiveis de modificações - determinados pelo ambiente psicossocioeconômico dos indivíduos.

Os elementos mais importantes no processo de determinação das DCV e as inter-relaçōes entre os mesmos são complexas. Admite-se que estes fatores de risco tenham um efeito não apenas aditivo, mas potencializador quando ocorrem concomitantemente (JACKSON e col. 1993; CARRUTHERS 1993).

Tanto a morbidade como a mortalidade por doença cardiovascular aumenta com a idade em ambos os sexos. No estudo de Framingham, observou-se aumento de 10 vezes na incidência de eventos coronarianos em mulheres com mais de 55 anos, quando comparadas às mulheres na faixa etária de 35 a 54 anos. O aumento observado em homens, nesse mesmo período, foi de 4,6 vezes. A partir dos 55 anos as mulheres apresentaram taxas de morbidade próximas às das masculinas (LERNER e KANNEL 1986).

Entre as doenças e distúrbios metabólicos, a hipertensão arterial é um problema mundial. Em alguns paises industrializados, estima-se que até $25 \%$ da população adulta tenha pressão diastólica superior a $90 \mathrm{mmHg}$, sendo que nos paises em desenvolvimento estas taxas também sāo elevadas (WHO 2003). 
Sabe-se que a hipertensão arterial é altamente prevalente na população brasileira. Estima-se que 16 milhões de brasileiros tem pressão alta (LESSA 1993; LOTUFO e LÓLIO 2000).

A elevação da pressão arterial (PA) relaciona-se com o grau de desenvolvimento das sociedades: aumenta com a idade nas populações urbanizadas e industrializadas. A baixa prevalência de hipertensäo arterial em algumas comunidades, como as indigenas, indica que, em princípio, esta afecção pode ser prevenida. Essas diferenças são largamente atribuídas a diferenças nos padrões alimentares e de atividade física (LOLIO 1993; OMS 1994; WHO 2003).

O aumento da freqüência da obesidade com a idade é considerado o mais importante fator para a elevação de PA em individuos mais idosos. A forma de distribuição corporal da gordura parece estar mais fortemente associada com HA e com diabetes mellitus do que outros padrōes de obesidade (WHO 2003).

O aumento da pressão arterial, sistólica ou diastólica, em qualquer idade e sexo, resulta em substancial aumento da morbi-mortalidade por vários transtornos cardiovasculares e renais (JNC 1997; WHO 2003).

Componentes da alimentação, como o sódio, o potássio, o cálcio e o magnésio têm sido investigados e implicados na fisiopatologia da HA (JNC 1997; WHELTON e col. 1997; WHO 2003).

A obesidade está associada a vários efeitos adversos à saúde. A relação entre o grau de obesidade e incidência de doença cardiovascular tem sido vastamente descrita na literatura (WHO 1997, 2003; KIM e col. 2000).

A avaliação de homens e mulheres participantes do estudo de Framingham, em período de 26 anos, revelou que a obesidade é um fator de 
risco para a ocorrência de eventos cardiovasculares, especialmente doença coronariana, insuficiência cardiaca e acidentes vasculares cerebral, independentes da idade, pressão arterial, níveis de colesterol, tabagismo, intolerância à glicose e hipertrofia ventricular esquerda (HUBERT 1983).

A obesidade e/ou o sobrepeso podem resultar da ação isolada ou conjunta de diferentes fatores: genéticos, endócrinos, ambientais, culturais, socioeconômicos, psicossociais. Várias alterações biológicas determinadas pela senescência favorecem o ganho de peso. A diferença entre os sexos também influencia o acúmulo e a distribuição da gordura, que se apresenta distribuída, preferencialmente, na regiāo visceral abdominal nos homens e na região das coxas e do quadril nas mulheres (OMS 1997; ISSA e FRANCISCO 1996; WHO 2003).

Em intervalo de quinze anos, dois estudos de base populacional realizados no Brasil, abrangendo todo o território nacional, o Estudo Nacional de Despesa Familiar (ENDEF) e a Pesquisa Nacional sobre Saúde e Nutrição (PNSN) mostraram que houve nesse periodo aumento da obesidade na população, sendo maior entre as mulheres $(13,3 \%)$, na faixa etária entre os 25 64 anos (FIBGE 1977, 1991).

Em recente estudo realizado sobre a prevalência da obesidade no Brasil por meio da análise de três censos (1974-5, 1989 e 1996-7), os autores evidenciaram que a evolução da obesidade feminina no período 1989-1997 mostrou-se distintamente influenciada pela renda familiar, tanto na região Nordeste como na Sudeste. Na região Sudeste, a elevação do número de obesos foi nitidamente maior nas classes menos favorecidas e houve declínio na prevalência nos estratos intermediários e de alta renda (de 13,2\% para $8,2 \%)$. Já no Nordeste, constatou-se grande ascensão da obesidade entre as mulheres mais ricas, de $9,9 \%$ para $14,6 \%$. No caso dos homens, embora a prevalência da obesidade tenda a seguir aumentando nas duas regiōes, a 
elevação se dá de modo mais intenso na região Nordeste, aproximando-se da prevalência encontrada na regiāo Sudeste. (MONTEIRO e CONDE 1999).

Os primeiros resultados da Pesquisa de Orçamento Familiar (POF) 2002-2003 do Instituto Brasileiro de Geeografia e Estatística (IBGE) revelam que o excesso de peso atinge 38,8 milhōes de brasileiros adultos. Tal freqüência na população supera em oito vezes 0 déficit de peso entre as mulheres e em quinze vezes o da população masculina. No universo de $\mathbf{9 5 , 5}$ milhões de pessoas de 20 anos ou mais de idade há 3,8 milhões de pessoas $(4,0 \%)$ com déficit de peso e 38,8 milhões $(40,6 \%)$ com excesso de peso, das quais 10,5 milhões são considerados obesos. Esse padrão se reproduz, com poucas variações, na maioria dos grupos populacionais analisados no País (FIBGE 2004).

O desajuste entre o menor gasto energético, devido à inatividade física e o elevado consumo energético (excesso de calorias provenientes do açúcar, cereais refinados e/ou das gorduras) é o determinante principal da epidemia da obesidade. O aumento da atividade física e a redução no consumo de alimentos com alto teor de gorduras e de bebidas com alto teor de açucar podem impedir o aumento de peso nocivo (WHO 2003; OPAS 2003).

No que tange à relação cintura quadril (RCQ), estudos têm mostrado que tal índice revela quem são portadores de obesidade centralizada (abdominal, visceral - obesidade "andróide" ou "em forma de maçā") e quem apresenta deposição de gordura predominantemente no quadril (obesidade "ginóide" ou "em forma de pêra"). A obesidade de tipo central é a de maior risco para doenças do coração (STERN e HAFFNER 1986; RIMM e col. 1996; WHO 1997).

Cada vez mais, há maior consciência de que as intervenções preventivas são eficazes e de que o custo com o tratamento está aquém dos 
recursos financeiros das pessoas e dos sistemas de saúde pública de quase todos os países em desenvolvimento. As intervençōes para a prevenção e o controle da obesidade devem complementar-se com as iniciativas atuais para pôr fim à desnutrição e a outras carências nutricionais específicas, promovendo o crescimento e desenvolvimento da população para que as pessoas tenham uma vida longa e sadia. Assim, são necessários planos e programas integrados sobre a obesidade e as doenças crônicas não transmissiveis, dado que ambas têm causas comuns (WHO 2003; OPAS 2003).

Em relação às dislipidemias, verificou-se que os níveis de colesterol sérico total e de LDL-colesterol associam-se às coronariopatias. Estudos populacionais de incidência mostraram uniformemente que os níveis de colesterol predizem as ocorrências de morbidade e mortalidade por coronariopatia (NCEP 1993, 2001).

O risco de doenças cardiovasculares ateroscleróticas (DCA) aumenta significativa e progressivamente quando os valores sangüíneos de colesterol total e lipoproteínas de baixa densidade-LDL-c estão acima dos limites desejáveis. Para as lipoproteínas de alta densidade-HDL-c, a relação de risco é inversa: quanto mais elevado seu valor, menor o risco de DCA. (SBC 1996; WHO 2003).

A elevação dos níveis de LDL-c está diretamente relacionada com o início e manutenção do processo aterosclerótico. Tais partículas promovem a aterogênese, afetando o processo de influxo e efluxo de colesterol na parede dos vasos. Entre os mecanismos por meio dos quais o HDL-c exerce seu efeito protetor em relação à doença aterosclerótica, um dos mais importantes é a habilidade de iniciar o transporte reverso do colesterol, ou seja, a remoção do colesterol das células e seu transporte ao figado para posterior excreção (GRUNDY 1995; FURBERG e col. 1997; RABELO 1998). 
Estudos com migrantes mostram que eles tendem a adquirir os hábitos alimentares e com isso os padrões lipidicos e a freqüência de coronariopatia dos seus novos países (NCEP 1993; YANG 2005).

O diabetes mellitus e outras formas de intolerância à glicose representam fatores de risco para a hipertensão arterial, cardiopatia isquêmica, doença cerebrovascular e outras vasculopatias periféricas. São inúmeras as evidências de associação entre diabetes e doenças cardiovasculares (BLOCH 1998; COSTA 1998; WHO 2003).

O risco cardiovascular aumenta acentuadamente com a presença simultânea do diabetes e da hipertensão. $O$ diabetes duplica a mortalidade cardiovascular. Seu impacto relativo é maior entre as mulheres, diminui com a idade e varia amplamente segundo o nivel de outros fatores de risco existentes (BLOCH 1998; RABELO 1998; COSTA e ALMEIDA NETO 1998; WHO 2003).

São escassos os estudos realizados no Brasil, enfocando a morbimortalidade por DCV e seus fatores de risco. Dentre esses, destaca-se a pesquisa realizada por MARTINS e col. (1989), realizada no Município de São Paulo, que caracterizaram niveis lipêmicos e a presença de outros fatores de risco para DCV: obesidade, hipertensão, tabagismo, etilismo, antecedentes diabéticos e uso de contraceptivos orais. Tal estudo mostra que a obesidade isolada ou associada, com niveis lipêmicos elevados, apresenta-se como um dos fatores de risco mais freqüentes em todos os grupos etários e em ambos os sexos. Neste mesmo estudo, a obesidade, isolada ou associada à hipertensão e/ou alcoolismo, foi o fator de risco mais relevante.

Quanto aos fatores de risco comportamentais - tabagismo, etilismo, sedentarismo, anticoncepcionais orais e a alimentação - as pesquisas têm apontado que a morbi-mortalidade por DCV está associada a tais hábitos de vida. (MARMOT e ELLIOT 1992; REGO e col. 1990; VARTIAINEN e col. 1991; KANNEL 1992; BLOCH 1998; WHO 2003). 
O tabagismo é um fator independente de risco cardiovascular que interage com vários outros fatores, aumentando os riscos independentes. $\mathrm{O}$ hábito de fumar é responsável por, aproximadamente, $45 \%$ das mortes nos homens com menos de 65 anos de idade e por mais de $20 \%$ de todos os óbitos por doença coronariana nos homens com idade maior que 65 anos (LEONE 1995; ROSENBERG 1996). Alguns dos mecanismos pelos quais o tabagismo atua de modo lesivo no sistema cardiovascular são: aumento nos niveis de fibrinogênio e na agregação plaquetária, aumentando a aterosclerose; a diminuição da capacidade carreadora de oxigênio no sangue; a liberação de catecolaminas tornando o miocárdio mais irritável e o aumento da viscosidade do sangue (LAUSTIOLA 1991; RABELO 1998; BLOCH 1998).

Os estudos mais recentes de intervenção sobre o tabagismo mostram que a diminuição da prevalência do tabagismo tem papel significativo na diminuição das doenças cardiovasculares (ROSENBERG 2003).

O consumo de bebidas alcoólicas pode contribuir para a ocorrência de hipertensão arterial, hipertrigliceridemia, diabetes tipo 2, câncer, problemas psicossociais e comportamentais, hepatopatias, entre outras. Em quantidades excessivas pode lesar o miocárdio e torná-lo mais irritável (OMS 1994; WHO 2003).

O consumo moderado de álcool (até $30 \mathrm{~g}$ de etanol por dia) parece ter efeito protetor contra as doenças cardiovasculares, sendo que as taxas de mortalidade por cardiopatia coronariana são maiores entre as pessoas que não consomem álcool. Porém, pode ocorrer o contrário em relação ao acidente cerebrovascular, devido ao efeito adverso do álcool sobre a hipertensão (KANNEL 1992; OMS 1994; WHO 2003).

Os mecanismos pelos quais a atividade física se associa às cardiopatias podem ser separados em dois modelos: atividade fisica intensa, 
que agiria diretamente produzindo alterações no coração, melhorando a capacidade de bombeamento, resultando em condicionamento cardiovascular. Num segundo modelo - indireto - atua nos fatores de risco, alterando a composição corporal (diminuído a massa gorda e aumentando a massa magra), reduzindo a pressão arterial e aumentando a lipoproteína de alta densidade (HDL-col). Recomenda-se a prática regular, leve ou moderada, com freqũência de 30 minutos por dia, de forma contínua ou acumulada, por pelo menos quatro dias durante a semana (PAFFENBARGER e col. 1993; SBC 1996; LEON 1997; BLOCH 1998; WHO 2003).

Estudo realizado por BERTOLAMI e col. (1993) verificou maiores niveis de LDL-c quanto menor a atividade física no trabalho. Além disso, a atividade física está associada à aquisição e manutenção do peso desejável, reduzindo a gordura corpórea, com diminuição dos níveis pressóricos, aumento da tolerância à glicose e da sensibilidade à insulina. As modificaçōes no perfil lipídico são consideradas resultantes de adaptações induzidas pelo exercício físico na atividade das $\mathrm{HDL}-\mathrm{c}$ e da lipoproteína lipase - enzima que cataboliza as lipoproteínas ricas em triglicerídeos (OMS 1994; RABELO 1998).

No estudo de KEYS e col. $(1970,1984)$, observou-se que a atividade física na ilha de Creta na Grécia e outros fatores relacionados ao estilo de vida podem ter contribuído para o aumento da expectativa de vida e para a baixa incidência de doenças crônicas.

Nas modernas sociedades industrializadas a tecnologia eliminou largamente a necessidade de grandes esforços físicos no trabalho, em casa e como locomoção. Recentemente, preocupaçōes com a saúde ou apenas com a estética, levaram a aumento do interesse na atividade física em alguns países (OPAS 2003).

As usuárias de anticoncepcionais orais pertencem ao grupo de risco para as doenças do aparelho circulatório, visto que associaçōes positivas foram 
observadas tanto retrospectiva quanto prospectivamente. Verificou-se existência de risco, tanto para a cardiopatia isquêmica como para a hipertensão arterial e fenômenos tromboembólicos. Os efeitos adversos são mais freqüentes, sobretudo em mulheres fumantes e com mais de 35 anos ou detentoras de outros riscos cardiovasculares e tendem a aumentar com a idade embora o risco relativo em mulheres jovens também seja alto (KANNEL 1988; BLOCH 1998; ROSENBERG 2003).

A alimentação é um importante fator de risco para diversas DCNT. Nos últimos trinta anos, a atenção tem se voltado cada vez mais sobre a relação da dieta e nutrição com as DCV, os diversos tipos de câncer, diabetes, obesidade, entre outras. Inúmeros estudos epidemiológicos realizados nas últimas décadas têm demonstrado a estreita relação entre fatores dietéticos, sua causa e a prevenção (WHO 1990, 2003; WILLETT 1994, 1998).

\section{2 Alimentação e Doenças Cardiovasculares}

A alimentação contribui de várias formas na determinação do risco cardiovascular. Há estudos demonstrando que $30 \%$ dessas morbidades podem ser reduzidos com modificações na alimentação que, dependendo de sua composição, pode não apenas constituir um fator de risco, como também proteção (WILLETT 1998; BLOCH 1998; OPAS 2003).

HOPKING e WILIAMS (1981) identificaram 246 fatores de risco associados a DCV, sendo 44 relacionados à alimentação. Entre os mencionados, 21 apresentaram associação positiva com excessos dietéticos e 23 tiveram associação negativa com deficiências dietéticas. Evidencia-se, portanto, estreita relação entre características qualitativas da alimentação e a ocorrência de DCV entre outras doenças crônicas. 
São vários os estudos de associação entre o consumo de gorduras saturadas e a ocorrência de doença coronariana, diabetes tipo 2 e obesidade (WILLET 1990, 1998; HERTOG e col. 1993; NESS e POULES 1997; WHO 2003).

O estudo pioneiro que permitiu a observação da associação entre a alimentação e DCV foi realizado por KEYS e colaboradores que verificaram a associação de fatores dietéticos com a incidência de DCV em 15 populações de sete países. Tal estudo revelou haver associação positiva entre o consumo de gorduras saturadas e a incidência de DCV (KEYS e col. 1965; KEYS 1970, 1984b; KEYS e col. 1984a).

Outros estudos epidemiológicos têm evidenciado a associação entre o consumo regular de carnes vermelhas e o aumento dos riscos para DCV, por serem aquelas ricas em gorduras saturadas e colesterol (KUSHI e col. 1995; HOOPER e col 2001; WHO 2003).

FORNÉS (1998) realizou estudo com indivíduos adultos, ambos os sexos, de 20 anos ou mais, residentes na área metropolitana de São Paulo, por meio de entrevista direta, composta de inquérito sócio-demográfico, clínico, bioquímico, estilo de vida e inquérito dietético (freqüência de consumo). Testou as relações entre o consumo alimentar e o perfil lipídico de sua população e obteve correlação positiva e significante entre alimentos de origem animal e níveis de colesterol total e LDL-c. Mostrou também correlação inversa entre estes níveis e o consumo de frutas e hortaliças.

HU e col. (1999) examinaram as implicações específicas de ácidos graxos saturados, presentes na alimentação, relacionando-os ao risco de DCV em mulheres. Os resultados mostraram que a alimentação rica em ácidos graxos saturados de cadeia longa (incluindo 12:0, 14:0, 16:0 e 18:0) - carnes vermelhas e produtos lácteos integrais - estava associada a aumento do risco para DCV. Entretanto, o consumo de ácidos graxos de cadeia média e curta, 
presente em alimentos como peixes e produtos lácteos desnatados, estava associado com baixo risco.

Os ácidos graxos trans foram, recentemente, incluídos entre os lipídios dietéticos que atuam como fatores de risco para doença arterial coronariana, modulando a síntese do colesterol e suas frações e atuando sobre os eicosanóides (ARO e col. 1997; ASTRUP e col. 2000; NCEP 2001; WHO 2003; BARRETO e col. 2005). Esses ácidos estão presentes naturalmente em gorduras originadas de animais ruminantes, como resultado do processo de biohidrogenação de alguns tipos de rações na flora microbiana do rúmen (ARO 1997), e em produtos alimentícios industrializados que sofrem processo de hidrogenação parcial ou total de óleos vegetais ou marinhos (OKONEK 1996). Em produtos alimentícios manufaturados, são encontrados em margarinas duras e alguns cremosos, cremes vegetais, gordura vegetal hidrogenada, biscoitos, sorvetes, alguns pães, batatas fritas (fast food), pastelarias, bolos, massas, entre outros (OOMEN e col. 2001).

Nas últimas décadas, o consumo de margarina vem se elevando no Brasil, por meio da substituição da manteiga e do crescente aumento na manufatura e na ingestão de produtos alimentícios industrializados contendo gordura hidrogenada (MONDINI e MONTEIRO 1995; VALENZUELA e col. 1995).

Embora desde 1995 a Organização Mundial da Saúde venha recomendando a ingestão moderada deste tipo de gordura na prevenção e tratamento de doenças coronarianas, até o presente são desconhecidos os teores de ácidos graxos trans nos alimentos industrializados, prejudicando a orientação em relação ao seu consumo. No Brasil, uma portaria do Ministério da Saúde, datada de 17 de outubro de 1997, estabelece que a quantidade desses ácidos nos produtos deve estar computada como ácidos graxos 
saturados, permanecendo desconhecidos os teores específicos de ácidos graxos trans (BRASIL 1997b).

O sódio e o potássio são minerais essenciais para a regulação dos fluidos intra e extracelulares, atuando na manutenção da pressão sangüínea. $O$ sal de cozinha - cloreto de sódio - é a principal fonte de sódio, sendo composto por $40 \%$ desse elemento químico. Estudos epidemiológicos realizados com base populacional demonstram, de forma convincente, que o consumo diário de sódio está associado com a elevação da pressão arterial (LAW e col. 1991; MIDGLEY e col. 1996; APPEL e col. 1998; GIBBS e col. 2000; WHO 2003). A hipertensāo arterial explica $40 \%$ das mortes por acidente vascular encefálico e $25 \%$ daquelas por doenças arterial coronariana (LAW e col. 1991; WHO 2003).

Vários estudos de intervenção que avaliaram os efeitos da redução no consumo diário de sódio comprovaram sua associação com a diminuição dos níveis pressóricos em individuos hipertensos e normotensos (MIDGLEY e col. 1996; CUTLER e col. 1997; APPEL e col. 1998). Recomenda-se atualmente que o consumo de sal deve ser limitado a menos de cinco gramas de cloreto de sódio por dia (WHO 2003; BARRETO e col. 2005).

Recente publicação da OMS elaborado por especialistas no assunto, baseada nas melhores provas científicas atualmente disponiveis sobre a relação entre o regime alimentar, a nutrição, a atividade física e as DCNT, mostra que há evidências científicas convincentes de que os componentes da dieta que causam ao organismo efeitos adversos, ou seja, aumentam o risco de DCV, quando consumidos em grande quantidade e diariamente, são os alimentos e/ou preparações que contêm colesterol, ácidos graxos saturados 
(mirístico e palmítico), os ácidos graxos-trans e 0 alto consumo de sódio (CARDOSO e MARTINS 1998; WHO 2003).

Há também evidências científicas convincentes de que os elementos dietéticos que diminuem o risco de DCV sāo os alimentos que contêm ácidos graxos insaturados: poliinsaturados (ômega-3: $\alpha$-linolênico, eicosapentanóico, docosaexaenóico e ômega-6: linolênico, $\gamma$-linolênico, araquidômico) e monoinsaturados (ômega 9: oléico). Os alimentos fontes destas substâncias são os óleos vegetais - soja, milho, algodão, oliva, entre outros, os peixes salmão, cavala, atum, entre outros (WILLET 1994; BULLIYYA 1994; GRUNDY 1997; CRAIG 1997; SANTOS 1998; CARDOSO e MARTINS 1998; DE ANGELIS 1999; WHO 2003).

Estudos epidemiológicos também sugerem que o consumo de alimentos vegetais - cereais, leguminosas, frutas em geral, verduras e legumes - podem reduzir os riscos para tais doenças. Isto tem sido atribuido, em parte, à presença de fibras alimentares, potássio, componentes antioxidantes e fitoquímicos nestes alimentos (WHO 2003; KRINKSY 1993; WILLET 1998; GILMAN e col. 1995; GILMAN 1996; KUSHI e col. 1995; RIMM e col. 1996; HALLIWELL 1997; CRAIG 1997; DE ANGELIS 1999; SILVA e SILVA 1999; BAZZANO e col. 2002; BARRETO e col. 2005).

Cabe salientar que em relação às fibras alimentares, os achados sugerem que estas possam desempenhar um papel na prevenção e controle de doenças cardiovasculares. As fibras solúveis parecem ser eficientes na redução de níveis séricos de colesterol e seu consumo diário tem sido recomendado na quantidade de 15 a $30 \mathrm{~g}$ por dia (MCNAMARA 1994; WHO 2003; OPAS 2003; BARRETO e col. 2005). Sua inclusão é recomendada para reduzir a densidade calórica, promover saciedade por aumentar o tempo de esvaziamento gástrico e diminuir num pequeno grau a eficiência da absorção intestinal (AHA 1998; WHO 2003; OPAS 2003; BARRETO e col. 2005). 
O consumo diário de frutas e vegetais garante ao organismo a oferta adequada do mineral potássio. Vários estudos têm demonstrado haver uma associação inversa entre o consumo desse mineral e risco de AVC (WHELTON e col. 1997; ASCHERIO e col. 1998). O consumo adequado de potássio diminui os niveis pressóricos protegendo contra as DCV (WHO 2003).

As leguminosas - feijōes, soja, entre outras - apresentam vantagens em relação às outras fontes de proteína vegetal. Possuem elevado teor de proteínas (38\% a $42 \%$ ) de baixo custo e de excelente qualidade, como também as isoflavonas, que auxiliam na redução do colesterol sangüíneo. A redução pode ocorrer pelo aumento da excreção de sais biliares pelas fezes, principal forma de eliminação do colesterol, ou pelo aumento no metabolismo do colesterol, para compensar o aumento na eliminação de sais biliares. Além disso, o consumo de leguminosas diminui a relação insulina/glucagon, hormônios que estão envolvidos no metabolismo do colesterol. São fontes de ácidos graxos essenciais que, aliados às isoflavonas, atuam de maneira protetora sobre a camada interna que recobre as artérias, prevenindo a arteriosclerose e a trombose, que são processos de obstrução das artérias (WHO 2003).

A "dieta mediterrânea", por suas características nutricionais e por sua palatabilidade, tem sido propagada como um modelo de dieta ideal. Segundo especialistas em nutrição, caracteriza-se por uma abundante quantidade de alimentos de origem vegetal - frutas e vegetais (tomate, batata, pimentão, espinafre, alcachofra, berinjela, pepino, abobrinha, alho, cebola, limão, laranja, cereais, como o trigo e seus derivados, entre outros) -, elevado consumo de pescados, uso do azeite de oliva como principal fonte de gordura e o vinho, consumido moderadamente nas refeiçōes (KEYS 1970, 1995; WILLETT 1995; DE LORGERIL e col. 1994, 1999).

O interesse atual pela dieta mediterrânea originou-se na década de $\mathbf{5 0}$ quando se verificaram taxas muito baixas de morte por doenças cardiacas em 
regiōes que margeiam o Mar Mediterrâneo, motivando um estudo epidemiológico na Ilha de Creta. A pesquisa "Seven Countries Study", bastante detalhada no que diz respeito ao consumo alimentar e perfil epidemiológico das doenças cardiacas, levaram KEYS e colaboradores a realizarem um estudo na região junto a outras investigaçōes paralelas sobre a dieta e o risco de doença coronariana em sete países (KEYS e col. 1984a; KEYS 1995). Tal estudo serviu de protótipo para se estabelecer à política de recomendação dietética dos Estados Unidos e posteriormente constituiu a base para determinar a proporção de alimentos na Pirâmide da Dieta Mediterrânea (WLLETT 1995).

Vários estudos têm mostrado que o consumo de, pelo menos cinco porçōes ao dia de vegetais (frutas e hortaliças), fontes de minerais, vitaminas e fibras "protegem" o organismo de uma série de doenças crônicas. A OMS recomenda um consumo mínimo diário de $\mathbf{4 0 0}$ gramas de frutas e vegetais (WILLETT 1998; WHO 2003). Geralmente, nessas quantidades, é possível obter proteção cardiovascular (OPAS 2003; BARETO e col. 2005).

Ensaios clínicos randomizados mostram que dietas tradicionais cardioprotetoras, baseadas em alimentos vegetais pouco processados - pão integral, verduras, legumes, frutas, nozes ou assemelhados e óleos ricos em ácidos graxos poli e monoinsaturados - conferem proteção contra eventos isquêmicos cardiacos em indivíduos de alto risco (DE LORGERIL e col. 1994; SINGH e col. 2002; BARRETO e col. 2005).

\subsection{Transição Alimentar no Brasil}

As evidências sobre a evolução da disponibilidade de alimentos no Brasil indicam que a transição alimentar no pais tem sido, de modo geral, favorável do ponto de vista dos problemas associados à subnutrição (aumento na disponibilidade de calorias per capita e aumento da participação de alimentos de origem animal e açúcar na alimentação) e desfavorável no que 
se refere à obesidade e às demais DCNT (diminuição no consumo de cereais, leguminosas e frutas, verduras e legumes) (BARRETO e col. 2005).

As melhores fontes nacionais disponiveis sobre estimativa da disponibilidade de alimentos são o Estudo Nacional de Despesa Familiar (ENDEF) realizado em $1974 / 75$ e as Pesquisas de Orçamento Familiar (POF) 1961/63; 1987/88; 1995/96 e mais recentemente, 2002/3 (FIBGE 1977, 1991, 1997, 2000, 2004).

A POF investiga as aquisições de alimentos anuais per capita das famílias brasileiras. Suas informações servem de base para análise da dieta domiciliar e do estado nutricional dos adultos, apesar das limitaçōes inerentes a todas as pesquisas de orçamento familiar: o curto período de referência (uma semana) para a coleta de dados; a não consideração da fração dos alimentos adquiridos que não é consumida pelos moradores do domicílio.

As principais mudanças detectadas no padrāo alimentar ao longo dos três inquéritos anteriores, foram as seguintes (MONDINI e MONTEIRO 1994; MONTEIRO e col. 2000):

- aumento contínuo e intensificação do consumo relativo de carnes, leites e derivados (exceto manteiga) e declínio no consumo de ovos;

- ascensão do consumo (já excessivo) de açúcar refinado e refrigerante;

- redução do consumo de leguminosas, raízes e tubérculos; por conseguinte, diminuição da participação relativa de carboidratos complexos na dieta;

- substituição da banha, toucinho e manteiga por óleos vegetais e margarina. 
Os resultados da Pesquisa de Orçamentos Familiares 2002-2003 do IBGE (FIBGE, 2004) sobre a disponibilidade domiciliar de alimentos no Brasil (1974-2003) revelam características positivas e negativas do padrão alimentar, encontradas em todas as regiöes e em todas as classes de rendimento. Como características positivas destacam-se a adequação do teor protéico das dietas e o elevado aporte relativo de proteínas de alto valor biológico. As características negativas encontradas foram o excesso de açúcar e a presença insuficiente de fruta e hortaliças na dieta. Nas regiōes economicamente mais desenvolvidas (Sudeste e Sul e Centro-Oeste) e, de modo geral, no meio urbano e entre famílias com maior rendimento, além do consumo excessivo de açúcar, houve também consumo excessivo de gorduras em geral e de gorduras saturadas (LEVY-COSTA e col. 2005).

Os diferentes niveis de rendimento familiar são determinantes para a aquisição da maioria dos alimentos no país. Carnes, leite e derivados, frutas, verduras e legumes, bebidas alcoólicas, condimentos e refeições prontas são os grupos de alimentos cuja participação na dieta das famílias tende a aumentar uniformemente, de acordo com o nivel de rendimentos familiares. $O$ inverso inclui feijōes e raízes e tubérculos. A participação de cereais e derivados na dieta das familias mostra relativa constância até a faixa de dois salários-mínimos per capita de rendimento. Alguns alimentos se destacam na relação com os rendimentos, como o arroz, cujo consumo cai na medida em que aumenta a renda das famílias. $\mathrm{O}$ contrário acontece com pães e biscoitos, cuja participação na dieta tende a aumentar com o aumento dos rendimentos (FIBGE 2004).

A evolução da composição da dieta em macronutrientes evidenciou aumento do teor em gorduras e diminuição do teor em carboidratos. No caso dos carboidratos, chega-se muito próximo, no último inquérito, da contribuição mínima de $55 \%$ das calorias totais, com o agravante de que cerca de um quinto dos carboidratos da dieta ( $12 \%$ em $56 \%$ ) correspondem a açúcar. No caso das gorduras, no último inquérito, o limite máximo de $30 \%$ das calorias totais é 
ultrapassado. Gorduras saturadas tendem a aumentar intensa e continuamente entre os inquéritos, sendo que seu limite máximo na dieta (10\% das calorias totais) é virtualmente alcançado no último inquérito $(9,6 \%)$. O limite máximo de $10 \%$ para a proporção de calorias provenientes de açúcar é ultrapassado em todos os inquéritos ainda que tenha havido algum declínio entre os dois últimos. Embora o teor de proteínas na dieta mostre tendência de aumento, a proporção de calorias protéicas se mostrou adequada nos quatro inquéritos (FIBGE, 2004; LEVY-COSTA e col. 2005).

Foram detectadas tendências preocupantes quanto ao consumo de alguns alimentos, como por exemplo os refrigerantes e os biscoitos que tiveram aumento de $400 \%$ nas últimas três décadas (LEVY-COSTA e col. 2005).

A pesquisa também observou que entre as grandes regiōes, 0 consumo é bastante diversificado; a região norte supera a região sul no consumo de carnes bovinas. Nas classes de rendimento maior consome-se menos cereal, farinha, féculas, massas e leguminosas. As famílias que ganham mais adquirem mais bebidas alcoólicas (FIBGE 2004).

A POF 2002-2003 investigou pela primeira vez a despesa associada a cada item da alimentação fora de casa e o tipo de estabelecimento onde as refeiçōes foram realizadas. Apesar de não terem sido especificados o tipo e a quantidade dos alimentos adquiridos, foi possivel verificar que tais despesas crescem de forma consistente com os rendimentos (FIBGE, 2004; LEVYCOSTA e col. 2005).

Este panorama justifica o estabelecimento de um sistema de monitoramento da evolução de padrōes dietéticos por meio da execução periódica de inquéritos de consumo alimentar para que medidas possam ser tomadas em relação à associação dieta/saúde. 


\section{4 estudo de padrões de consumo alimentar}

De modo geral, a única fonte regular e padronizada de informações sobre a tendência da evolução de padrōes dietéticos tem sido aquela baseada em dados sobre disponibilidade de alimentos e indicam a quantidade potencial médio disponivel para consumo humano nos países, considerando produção, importação, exportação e desperdicio. A interpretação de tais dados deve ser feita com cautela, considerando a impossibilidade de se conhecer a distribuição do consumo nos diferentes estratos da população, a qualidade das estatísticas de produção e comercialização dos alimentos no pais, entre outros (HELSING 1991; MONDINI e MONTEIRO 1994; MONDINI e MONTEIRO 2000).

Os inquéritos dietéticos, realizados por meio de diferentes metodologias, apresentam como principal vantagem a possibilidade da medida direta do consumo de alimentos, propiciando condiçōes para se inferir com precisão maior a quantidade de alimentos efetivamente consumida por famílias ou indivíduos. Suas limitaçōes ficam por conta da dificuldade em se captar a grande variabilidade do consumo alimentar em um período curto de tempo e o custo elevado dos estudos domiciliares (MONDINI e MONTEIRO 1994).

A investigação direta do consumo alimentar é de suma importância, pois o periodo de indução de enfermidades referidas pode ocorrer muitos anos antes de sua manifestação clínica (WILLET 1998).

Avaliar os diferentes padrōes de consumo alimentar, mais que a ausência específica de nutrientes na dieta, refletem situações reais de disponibilidade de alimentos e de condiçōes diferenciadas de inserção das populações nos diferentes cenários sociais e a tendência a desenvolver maior ou menor capacidade de geração - ou não - de saúde. Posteriormente, podem ser relacionados ao risco de doenças (WILLET 1998; SICHIERI e col. 2003; MARCHIONI e col. 2005). 
A maioria dos trabalhos realizados em epidemiologia nutricional sobre avaliação do consumo alimentar de populações baseia-se no cômputo de micro e macronutrientes e respectivo consumo calórico (WILLETT, 1998; HANKINSON e col. 2001; SICHIERI e col. 2003). Mais recentemente, a Organização Mundial da Saúde vem sugerindo que as recomendações alimentares para populaçōes deve basear-se em alimentos ao invés de nutrientes, como geralmente é feito (WHO 1998), pois a alimentação consiste de uma variedade de alimentos que resulta em complexa combinação de nutrientes que, por sua vez, são misturas complexas de compostos químicos que podem ser antagônicos, competir ou alterar a biodisponibilidade de outros compostos químicos ou nutrientes (WILLETT 1998).

Vários estudos em diferentes partes do mundo tem utilizado o método de análise fatorial para caracterizar os padrōes alimentares de populaçōes e assim investigar as relações entre a dieta e as doenças (SLATTERY e col. 1998; HU e col. 1999a; FUNG e col, 2001; SHICHIERI e col. 2003; MARCHIONI 2003; CORDEIRO 2003; KERVER e col. 2003; VAN DAM e col 2003; QUATROMONI e col. 2002; LEDIKWE e col. 2004; KHANI e col. 2004; YANG e col 2005; JORGE 2005).

Levando em conta a complexidade de intercorrelaçōes entre os alimentos, a análise fatorial por componentes principais é uma técnica estatística de utiliza as correlações entre os alimentos ou grupos alimentares para descrever os padrões dietéticos gerais e que permite, posteriormente, examinar o efeito da dieta como um todo, podendo descrever associaçōes com doenças de forma mais abrangente do que as descritas por nutrientes ou alimentos singulares (WILLET 1998; HU e col. 1999a, 1999b; MARCHIONI e col. 2005). 
No Brasil e no mundo, o maior contingente de óbitos é o decorrente das doenças cardiovasculares.

Açōes de saúde pública para prevenção populacional das doenças crônicas não transmissíveis (DCNT) devem controlar os seus determinantes, diminuindo a média do nível dos fatores de risco (tabagismo, etilismo, estresse, obesidade, hipertensão arterial, hábitos alimentares, diabetes e dislipidemias), deslocando toda a diminuição de exposição na direção favorável.

Em 1987 o Instituto de Saúde da Secretaria de Estado da Saúde (SES) de São Paulo coordenou no município de São Paulo um estudo que visava conhecer a freqũência de alguns fatores de risco para doenças crônicas não transmissiveis (REGO e col. 1990).

Em 1999, decorridos 13 anos desse estudo pioneiro, a Divisão de Doenças Crônicas Não Transmissiveis (DDCNT) do Centro de Vigilância Epidemiológica (CVE) "Professor Alexandre Vranjac", em parceria com o Departamento de Medicina Preventiva da Universidade Federal de São Paulo, resolveu retomar essa linha de pesquisa com o estudo "Fatores de risco para doenças crônicas não-transmissíveis: inquérito domiciliar no Município de São Paulo" (MARCOPITO e col. 2005), no qual foi incluído também um inquérito sobre hábitos alimentares e foram feitas dosagens bioquímicas.

Tendo em vista a importância da alimentação na etiologia das DCV, o presente estudo visa primeiramente identificar os padröes de consumo alimentar de residentes da área urbana do município de São Paulo e, posteriormente, associá-los a outros fatores de risco (constitucionais, comportamentais, sócioeconômico-culturais, outras doenças ou distúrbios metabólicos), utilizando parte dos dados dessa pesquisa. 
A identificação de padrões alimentares busca colaborar com informações que podem subsidiar as áreas de planejamento e assistência à saúde do município de São Paulo e a implementação de programas de intervenção, com ênfase na mudança da conduta alimentar, controle e tratamento de agravos relacionados à nutrição. 


\subsection{Objetivo Geral}

- Identificar os padrões de consumo alimentar de residentes da área urbana do município de São Paulo e suas associações com fatores de exposição ao risco - constitucional, comportamental, sócioeconômicoculturais, outras doenças ou distúrbios metabólicos - para doenças cardiovasculares.

\section{2 Objetivos Específicos}

- Descrever as características gerais da amostra de estudo, quanto ao estilo de vida, estado nutricional e presença de doenças;

- Descrever e analisar as associações entre os padrões alimentares segundo as variáveis sociodemográficas (escolaridade, ocupação, renda, áreas homogêneas) e comportamentais (hábito de fumar, consumo de álcool), ajustados por sexo e idade;

- Descrever e analisar as associações entre os padrões alimentares e os fatores de risco biológicos - glicemia, perfil lipídico (colesterol total e frações e triglicérides), pressão arterial, índice de massa corporal e razão cintura-quadril - ajustados por sexo, idade, variáveis sociodemográficas (escolaridade, áreas homogêneas), comportamentais (hábito de fumar, consumo de álcool) e antecedentes familiares de doenças. 


\section{MÉTODOS}

\section{1 Delineamento do estudo}

Esta pesquisa corresponde a um estudo de delineamento transversal, realizado no município de São Paulo, entre 2001 e 2002.

\section{2 População de estudo}

$O$ presente trabalho foi realizado com pessoas de 15 a 59 anos de idade, de ambos os sexos, residentes no município de São Paulo (MSP), pertencentes à sub amostra do estudo "Fatores de risco para doenças crônicas não-transmissíveis: inquérito domiciliar no Município de São Paulo" (MARCOPITO e col. 2005).

\section{3 Critérios de inclusão}

- residir no domicílio selecionado;

- ter entre 15 e 59 anos;

- ter sido escolhido por sorteio.

\section{4 Critérios de exclusão}

- recusa, do indivíduo sorteado, em participar do estudo;

- mulheres com gravidez declarada ou perceptível ou puérperas.

\section{5 Amostragem e procedimentos}

Realizou-se inquérito domiciliário por amostragem probabilística para o estudo selecionando pessoas em quatro de seis áreas sócio-ambientais homogêneas (SPOSATI 1996) da cidade de São Paulo, Sudeste do Brasil. 
As áreas homogêneas são recortes territoriais onde os dados sobre a população tendem a ser mais homogêneos em relação às características sóciodemográficas dessa população e ao meio ambiente (CARSTAIRS 1981). Alguns autores nacionais apresentaram estudos propondo recortes territoriais da cidade de São Paulo com o objetivo de analisar a situação de saúde do município (LESER 1972; AKERMAN e col. 1996).

No presente estudo, as áreas homogêneas foram escolhidas a partir daquelas apresentadas no Mapa da inclusão/exclusão social da Cidade de São Paulo, que selecionou todas as informaçōes socioeconômicas e ambientais disponiveis que detectam a exclusão social e que permitiam, ao mesmo tempo, a desagregação pelos 96 distritos administrativos da cidade (SPOSATI 1996).

Estas áreas homogêneas foram definidas considerando as seguintes variáveis: autonomia (renda do chefe de família, emprego e indigência), qualidade de vida (qualidade ambiental, qualidade dos domicilios, propriedade, investimento imobiliário, deslocamento e oferta de serviços básicos), desenvolvimento humano (escolaridade do chefe da familia, educação infantil, concentração, longevidade, mortalidade e violência) e equidade (trabalho feminino). As metodologias detalhadas para a elaboração das áreas e seus resultados encontram-se em publicação específica (SPOSATI 1996).

A construção dos indicadores socioeconômicos e ambientais utilizou metodologia semelhante àquela desenvolvida pelo Programa das Nações Unidas para o Desenvolvimento. Assim, no Mapa da Cidade de São Paulo, os valores para a construção dos índices para cada distrito foram estabelecidos segundo a fixação de padrōes básicos de inclusão, a partir dos quais foram calculados os indicadores para os 96 distritos. Como resultado, o Mapa da 
Exclusão dividiu o território do município em áreas homogêneas, de acordo com a agregação socioeconômica dos distritos (SPOSATI 1996):

área do tipo 1 - distritos com as melhores condições sócio-ambientais $(3,2 \%$ da população), composta por 4 distritos.

área do tipo 2 - distritos com boas condiçōes sócio-ambientais $(10,5 \%$ da população), composta por 11 distritos.

área do tipo 3 - distritos com condições sócio-ambientais média-altas $(5,1 \%$ da população), composta por 8 distritos.

área do tipo 4 - distritos com condiçōes sócio-ambientais média-baixas $(43,1 \%$ da população), composta por 44 distritos.

área do tipo 5 - distritos com más condiçōes sócio-ambientais $(27,3 \%$ da população), composta por 20 distritos.

área do tipo 6 - distritos com as piores condições sócio-ambientais $(\mathbf{1 0 , 8 \%}$ da população), composta por 9 distritos.

O Anexo 1 traz mais detalhes sobre o mapa da exclusão/inclusão social, a distribuição geográfica desses distritos dentro do município, bem como os distritos que compõem cada área sócio-ambiental homogênea.

As duas áreas mais privilegiadas (áreas do tipo 1 e 2) não foram incluídas porque o estudo piloto revelou que cerca de $80 \%$ recusariam participar.

O presente estudo denominará as áreas estudadas da seguinte forma: área do tipo 3 - distritos com condições sócio-ambientais média-altas: ALTA área do tipo 4 - distritos com condiçōes sócio-ambientais média-baixas: MÉDIA área do tipo 5 - distritos com más condições sócio-ambientais: BAIXA área do tipo 6 - distritos com as piores condiçōes sócio-ambientais: MUITO BAIXA.

A população-alvo englobou, portanto, $88,6 \%(6.084 .824)$ do total de 6.869.224 residentes de 15-59 anos de idade de São Paulo. 
Selecionaram-se três distritos de cada uma das quatro áreas remanescentes, a fim de cobrir região geográfica semelhante àquela do inquérito de 1987 (REGO e col 1990).

O tamanho da amostra foi estipulado em 2.100 participantes, quase $40 \%$ maior que aquela do inquérito de 1987.

Dos 12 distritos escolhidos, seleciononaram-se por sorteio 96 setores censitários. Estes foram conferidos no ano 2001 - porque os dados do Censo 1991 estavam desatualizados e os dados do Censo 2000 ainda não estavam disponíveis - e uma lista com cerca de $\mathbf{2 5 . 0 0 0 ~ d o m i c i ́ l i o s ~ f o i ~ c o n s t r u i ́ d a . ~}$

Por amostragem sistemática selecionou-se número suficiente de domicílios para atingir o planejado tamanho da amostra, permitindo apenas uma substituição em caso de domicílios não ocupados ou comerciais e para casos de recusas.

Foram visitados 2.852 domicílios, dos quais 155 (5,4\%) estavam desocupados e $186(6,5 \%)$ tinham moradores com idade maior que 59 anos.

Os 2.511 domicilios remanescentes foram contatados com cartaconvite. Se os habitantes concordassem em participar do estudo, uma lista com todos os moradores entre 15 a 59 anos de idade era obtida por um visitador independente. A ordem dessa lista seguiu as recomendações de MARQUES e BERQUÓ (1976), relacionando dos mais velhos para os mais jovens, homens aparecendo primeiro.

Daqueles 2.511 domicilios elegíveis, os moradores de 401 (16,0\%) recusaram participação no estudo.

Prontas as listas domiciliares de moradores entre 15-59 anos de idade, uma pessoa em cada domicílio foi selecionada pelo escritório central do estudo 
por amostragem probabilística estratificada, utilizando selos adesivos précodificados (MARQUES e BERQUÓ 1976).

Como este processo tendeu a selecionar mais mulheres do que homens, ele foi periodicamente corrigido, a fim de aproximadamente atingir a razão populacional de 52:48 para mulheres: homens naquela faixa etária.

As entrevistas domiciliárias foram marcadas e/ou confirmadas por telefone. O total de 2.103 pessoas foi entrevistado no domicílio de março de 2001 a outubro de 2002, respondendo ao questionário geral (Anexo 2) aplicado por enfermeiros que foram devidamente capacitados, tendo sido feitas medidas de pressão arterial, peso, estatura, circunferências do abdome e do quadril. Todas as medidas realizadas foram feitas duas vezes, sendo a média das duas utilizada na análise.

A maioria $(70,9 \%)$ das entrevistas foi realizada nos fins-de-semana (42,7\% nos sábados, e $\mathbf{2 8 , 2} \%$ nos domingos), os restantes $\mathbf{2 9 , 1} \%$ distribuídos igualmente nos dias da semana. A integridade das entrevistas foi verificada por telefone em amostra aleatória de $10 \%$, e não mostrou discrepância com os dados originais.

Cerca de um terço dos participantes foi, aleatoriamente, selecionado para responder ao questionário de freqüência alimentar (QFA) - 782 pessoas (Anexo 3) e amostra de seu sangue venoso coletado no domicilio por laboratório com certificação ISO-9002. De 759 convidados para realizar a coleta de sangue, $59(7,8 \%)$ recusaram, de modo que o procedimento foi realizado em 700 pessoas. 


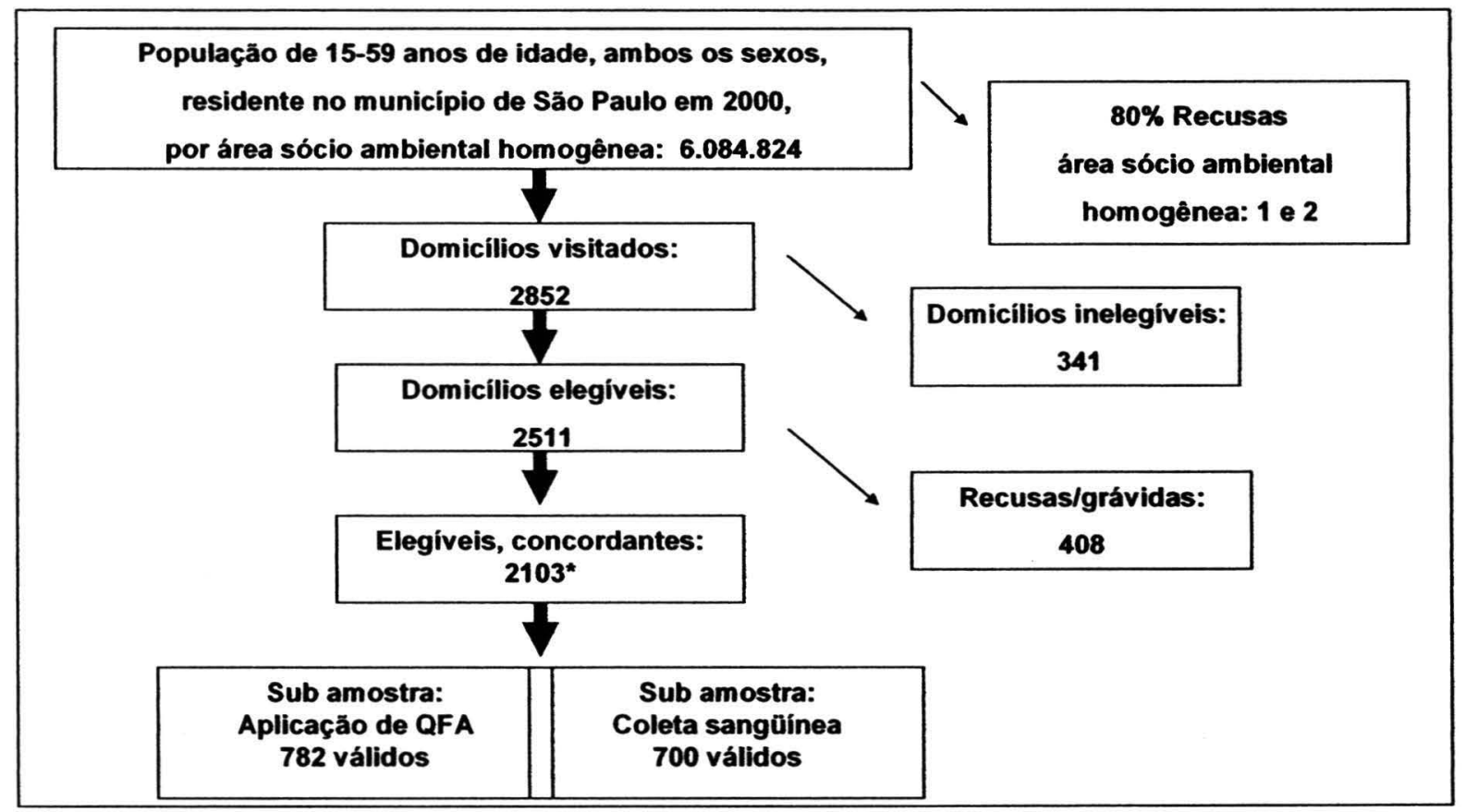

Figura 1. População selecionada por amostragem, indivíduos excluídos e amostra final do estudo. São Paulo, 2002.

* entrevistas: mar/2001 a out/2002

A fim de minimizar a interferência do excesso de alimentação nos finsde-semana, a coleta de sangue não foi marcada para os domingos, evitando-se também as segundas-feiras: a maioria ocorreu aos sábados $(44,0 \%)$ e quartasfeiras $(35,4 \%)$, o restante acontecendo as quintas $(11,1 \%)$, sextas $(7,6 \%)$, segundas $(1,0 \%)$ e terças-feiras $(0,9 \%)$. $O$ tempo mediano decorrido entre a entrevista e a coleta de sangue foi de 6,0 dias (média: 7,6 dias).

O sangue foi processado para a determinação de glicose plasmática e colesterol total, HDL-colesterol e triglicérides séricos.

Para verificar se os participantes obedeceram à recomendação de jejum, fez-se a tabulação cruzada de valores de glicemia $\geq 126 \mathrm{mg} / \mathrm{dl}$ e de trigliceridemia $\geq 200 \mathrm{mg} / \mathrm{dl}$, que resultou em apenas 13 pessoas em ambas as categorias, 11 das quais sabiam ter diabetes e/ou dislipidemia. 
Os participantes receberam uma carta do escritório central com as medidas neles realizadas, e aqueles que necessitavam assistência foram encaminhados ao centro de saúde mais próximo (Anexo 4).

\section{5. 1 Medidas da pressão arterial}

A pressão arterial foi tomada duas vezes: a primeira, ao final do bloco $\mathrm{E}$ do questionário; a segunda, ao término do bloco I do questionário. A média aritmética dessas duas medidas foi utilizada depois, na análise dos dados.

Em cada uma das duas medidas da pressão arterial, o individuo examinado estava confortavelmente sentado, com 0 antebraço direito ligeiramente fletido e totalmente apoiado sobre uma superfície dura (uma mesa, por exemplo), na altura do coração, com a palma da mão voltada para cima. As pernas não podiam estar cruzadas, e os pés estavam completamente apoiados no chão. O braço direito estava despido de qualquer vestimenta de manga longa.

Nos cinco minutos que antecediam cada medida, 0 indivíduo permaneceu sentado no local onde foi examinado, nos trinta minutos anteriores a cada medida se absteve de fumar, ingerir bebida alcoólica, comer, ou realizar qualquer esforço físico - exceto o de caminhar pela casa.

A medida propriamente dita foi feita com esfigmomanômetro de coluna de mercúrio, composto por um manguito inflável e um manômetro com escala de valores numéricos, cuja aferição foi realizada semanalmente.

Os observadores/entrevistadores que fizeram as medidas foram treinados com a fita sonora da London School of Hygiene and Tropical Medicine (ROSE 1965). A pressão sistólica correspondeu à primeira fase de Korotkoff (surgimento das bulhas) e, à diastólica, a quinta (desaparecimento) - 
ou a quarta (abafamento), se os batimentos permanecerem audiveis até a marca de pressão zero. Essas três marcas foram anotadas, em $\mathrm{mm} \mathrm{Hg}$, no bloco $\mathrm{J}$ do questionário (FOLSOM e col. 1984).

\section{5. 2 Antropometria e indices derivados}

As medidas foram todas obtidas em duplicata, com base nas recomendações de CALLAWAY e col. (1988). Foi considerada a média dos dois valores.

O peso foi medido com uma balança portátil (tipo de banheiro), com mostrador digital, calibrada ao final de cada dia com pesos conhecidos. $\mathrm{O}$ examinado estava descalço e usando apenas roupas leves, de preferência as intimas.

A altura foi determinada com fita métrica inextensivel fixada em parede lisa da residência, sem rodapé, formando ângulo de $90^{\circ} \mathrm{com}$ o piso. $O$ examinado estava descalço, com os pés bem juntos, e os calcanhares encostados na parede. Durante a medida, permaneceu em pé, ereto, olhando para o horizonte imaginário. Sobre sua cabeça e a fita métrica foi encostado cada um dos dois catetos de um esquadro. $\mathrm{O}$ examinador fez a leitura estando com os olhos à distância não superior a $30 \mathrm{~cm}$ da fita métrica.

O perímetro do abdome foi determinado com fita métrica inextensível colocada sobre o plano horizontal que passa sobre a cicatriz umbilical do examinado. Já o perímetro do quadril foi medido no plano que passa pelos trocanteres maiores de ambos os fêmures.

O índice de massa corpórea (IMC, em $\mathrm{kg} / \mathrm{m}^{2}$ ) foi calculado como a razão entre o peso e o quadrado da altura. $A$ razão cintura-quadril (RCQ) foi calculada pela divisão do perímetro do abdome pelo perímetro do quadril (OMS 1995; 1997). 
4. 5.3 Critérios diagnósticos específicos

Pressão arterial - no caso de o(a) entrevistado(a) não estar em uso de prescrição anti-hipertensiva, foram utilizados para a análise a classificação de pressão arterial normal (>18 anos) PAS $<130$ ou PAD $<85 \mathrm{mmHg}$ (IV Diretrizes Brasileiras de Hipertensão Arterial 2004)

Glicemia - no caso de o(a) entrevistado(a) não estar em uso de prescrição anti-diabética, foram utilizados para a análise os critérios da American Diabetes Association [SBD 2003], a saber:

glicemia jejum < $99 \mathrm{mg} / \mathrm{dl}$.

Perfil lipídico - a interpretação dos resultados das dosagens seguiu as recomendações da III Diretrizes Brasileiras sobre Dislipidemias e Diretriz de Prevenção da Aterosclerose, 2001.

- Colesterol total: $<200 \mathrm{mg} / \mathrm{dl}$

- LDL colesterol: $<100 \mathrm{mg} / \mathrm{dl}$

- HDL colesterol: > $40 \mathrm{mg} / \mathrm{dl} \mathrm{em}$ homens e $>50 \mathrm{mg} / \mathrm{dl} \mathrm{em}$ mulheres

- Triglicérides: < $\quad 150 \mathrm{mg} / \mathrm{dl}$

Antropometria - os dados de peso e estatura foram utilizados para 0 cálculo do Índice de Massa Corporal (IMC) - peso/altura ${ }^{2} \mathrm{em} \mathrm{kg} / \mathrm{m}^{2}$. Foram utilizados para a análise os critérios da Organização Mundial da Saúde (WHO 1995, 2000), a saber:

- Baixo peso: $<18,5 \mathrm{~kg} / \mathrm{m}^{2}$;

- Normal (peso desejável): $18,5-24,9 \mathrm{~kg} / \mathrm{m}^{2}$;

- Sobrepeso (pré-obeso): 25 - 29,9 kg/m;

- Obesidade: $\geq 30 \mathrm{~kg} / \mathrm{m}^{2}$ (obesidade grau l: $30-34,9 \mathrm{~kg} / \mathrm{m}^{2} ;$;)

(obesidade grau II: $35-39,9 \mathrm{~kg} / \mathrm{m}^{2}$; obesidade grau III: $\geq 40 \mathrm{~kg} / \mathrm{m}^{2}$ ). 
Razão cintura/quadril (RCQ), estabelecida pela divisão: perímetro da cintura / perímetro do quadril. Valores superiores a 0,80 para as mulheres e 0,95 para os homens, significam obesidade central (abdominal, visceral ou andróide). Valores inferiores a 0,75 em mulheres e 0,85 em homens, considera-se que a distribuição da gordura é ginóide.

O IMC e a RCQ são indicadores de obesidade global e de obesidade central (STERN e HAFFNER 1986; WHO 1995; HAFFNER e col 1996).

Hábito de fumar - considerou-se não fumante, os participantes que responderam: nunca fumou ou não fuma mais e fumante os que responderam fuma às vezes ou diariamente.

Consumo de álcool - considerou-se o consumo médio de álcool em grama por dia, de acordo com o consumo de bebida relatado pelo indivíduo no QFA, utilizando-se a seguinte correspondência - $g$ álcoo//litro:

-cerveja: $\mathbf{4 0}$ g; vinho, $96 \mathrm{~g}$; cachaça e demais bebidas destiladas: $\mathbf{3 0 0} \mathrm{g}$ (IARC 1988).

Hábitos alimentares - o inquérito alimentar foi aplicado em 782 entrevistados, por meio de aplicação de questionário de freqüência alimentar (QFA) semiquantitativo, contendo 74 itens alimentares e perguntas objetivas.

O QFA é um método retrospectivo, no qual o entrevistado informa sobre os alimentos usualmente consumidos e com que freqüência (diária, semanal, mensal) [CDAM-II 1997; FISBERG e col. 2005].

No presente estudo, um questionário previamente validado (CARDOSO e STOCCO 2000; CARDOSO e col. 2001) foi adaptado para ser utilizado em estudos de intervenção e/ou programas de prevenção de doenças crônicas, cuja lista de alimentos selecionada visou abranger as principais fontes alimentares de alguns nutrientes, de acordo com estimativa de consumo do 
grupo de indivíduos estudado (obtida por meio de inquérito recordatório de 24 horas). A lista de alimentos do QFA atingiu mais de $90 \%$ da ingestão total de energia e nutrientes da população do estudo. Todo o processo de construção desse questionário de freqüência alimentar, metodologia, seleção e composição da amostra encontra-se publicado em trabalho anterior (RIBEIRO e CARDOSO 2002).

Para este trabalho, foram utilizadas as informações referentes a freqüência média usual de consumo de cada componente do QFA no último ano. As análises foram focalizadas no consumo dos alimentos relatados e na identificação de grupos de alimentos e não em analisar o conteúdo de nutrientes.

Os 74 itens alimentares do QFA foram agrupados várias vezes e de várias formas, de acordo com a semelhança de conteúdo nutritivo ou composição botânica, de modo a evitar algum tipo de viés. O Quadro 1 mostra os alimentos re-agrupados (29 grupos).

O QFA obteve informaçōes que são de interesse para o estudo e mostraram ter consumo elevado: bebidas alcoólicas, refrigerantes, café e outras infusões, adoçante e sal (adição na comida após o preparo). 
Quadro 1. Alimentos/grupo de alimentos usados na análise de padrões alimentares

\begin{tabular}{|c|c|}
\hline GRUPO DE ALIMENTOS & $\begin{array}{l}\text { ALIMENTOS DO QUESTIONÁRIO } \\
\text { DE FREQÜÊNCIA ALIMENTAR }\end{array}$ \\
\hline 1-LÁCTEOS - INTEGRAIS & leite integral, iogurte, iogurte com frutas, requeijão \\
\hline 2-LÁCTEOS - DESNATADOS & leite desnatado,queijo fresco ou ricota \\
\hline 3- PÁES & $\begin{array}{l}\text { pão francês, de forma, integral, , sovado, doce, croissant, } \\
\text { de queijo, biscoito salgado, doce, torradas, bolos }\end{array}$ \\
\hline $\begin{array}{l}\text { 4-ARROZ, OUTROS CEREAIS } \\
\text { E RAIZES }\end{array}$ & $\begin{array}{l}\text { arroz, aveia, granola, batata, mandioca, inhame, cará, } \\
\text { batata doce, cará,farofa, farinha de milho }\end{array}$ \\
\hline 5-MASSAS & macarronada, lasanha, nhoque, pizza, panqueca \\
\hline 6-PASTELARIAS, SALGADOS & coxinha, pastel, torta salgada, chips \\
\hline 7-MAIONESE & maionese, salada maionese \\
\hline 8-ÓLEOS E GORDURAS & oleaginosas, oleos para cozinhar, margarinas, manteiga \\
\hline 9-DOCES & $\begin{array}{l}\text { geléia, mel, açúcar, chocolates, sorvetes, pudins,doces } \\
\text { de frutas }\end{array}$ \\
\hline 10-FEWŌES & feijāo, ervilha, grăo de bico, soja, lentilha \\
\hline 11-FEIJOADA & feijoada \\
\hline 12-FOLHOSOS & $\begin{array}{l}\text { alface, rúcula, escarola, agriăo, almeirão, repolho, couve- } \\
\text { flor, acelga, couve, brócolos, espinafre }\end{array}$ \\
\hline $\begin{array}{l}\text { 14-LEGUMES (NĀO } \\
\text { FOLHOSOS + SOPAS) }\end{array}$ & $\begin{array}{l}\text { cenoura, tomate, beringela, beterraba, vagem, chuchu, } \\
\text { abobrinha, milho verde, sopas de legumes }\end{array}$ \\
\hline 14-FRUTAS & $\begin{array}{l}\text { laranja, mexerica, banana, maçã, pera, mamão, melancia, } \\
\text { melão, uva, abacaxi, goiaba, abacate, figo, morango }\end{array}$ \\
\hline 15-SUCOS NATURAIS & laranja, outras frutas \\
\hline $\begin{array}{l}\text { 16-CARNES - BOVINA E } \\
\text { MIÚDOS }\end{array}$ & carne de boi, miúdos \\
\hline 17-PORCO & carne de porco \\
\hline 18-FRANGO & carne de frango, perú, chester \\
\hline 19-PEIXES/FRUTOS DO MAR & peixe fresco, congelado, frutos do mar \\
\hline $\begin{array}{l}\text { 20-EMBUTIDOS 1: } \\
\text { LINGÜIÇASALSICHA }\end{array}$ & lingüiça, salsicha \\
\hline $\begin{array}{l}\text { 21-EMBUTIDOS } \\
\text { 2:PRESUNTO/MORTADELA }\end{array}$ & presunto, mortadela \\
\hline 22-OVOS & ovos \\
\hline 23-CAFÉ/INFUSŌES & café, chá preto, chá de ervas \\
\hline 24-BEBIDAS ALCOÓLICAS & cerveja, pinga, uisque, vodca, conhaque, vinho \\
\hline 25-SUCOS ARTIFICIAIS & sucos artificiais \\
\hline 26-REFRIGERANTES DIET & refrigerante diet \\
\hline 27-ADOÇANTE (NO CAFÉ) & adoçante, no café \\
\hline $\begin{array}{l}\text { 28-REFRIGERANTES } \\
\text { COMUNS }\end{array}$ & refrigerante normal \\
\hline 29-SAL - DE ADIÇÃO & acréscimo de sal na comida, depois de pronta \\
\hline
\end{tabular}

Neste estudo optou-se por resumir as freqüências de consumo dos alimentos ou grupo de alimentos em um único valor, independente das quantidades consumidas, sendo esta uma maneira simples para a verificar a "qualidade" da alimentação, independentemente do tamanho da porção 
consumida. Tal metodologia também foi empregada em outros estudos (KANT e col. 2000; ARAÚJO 2002; JORGE 2005).

A construção da medida-resumo obedeceu ao seguinte critério de agrupamento - após várias combinaçōes - e codificação das freqüências dos alimentos para cada indivíduo (SWEETING 1994; ARAÚJO 2002):

- nunca consumido ............................................................. $=0$

- consumo: 1 - 8 vezes ao ano.......................................... = 1

- consumo: 1 - 4 vezes ao mês............................................. = 2

- consumo: 1 - 4 vezes na semana...................................... = 3

- consumo: 5 -7 vezes na semana e $1-2$ vezes ao dia............ $=4$

- consumo: 3 vezes ao dia ou mais .................................. $=5$

$\mathrm{Na}$ etapa seguinte, somam-se as categorizações correspondentes aos alimentos efetivamente consumidos pelo indivíduo em cada grupo alimentar, o que constitui o numerador da medida-resumo. $\mathrm{O}$ denominador corresponde aos números máximos de consumo, que é obtido multiplicando-se a soma dos valores das categorizações por 5 - o máximo que poderia ser consumido no grupo - pelo indivíduo. Foram obtidas medidas-resumo para cada indivíduo integrante da amostra. Verificou-se a consistência interna dos escores alimentares por meio do coeficiente $\infty$-Cronbach, que resultou em 0,825 , ou seja, mostrando boa confiabilidade.

\section{5. 4 Análise Fatorial}

Este estudo utilizou a análise fatorial por componentes principais, visando a identificar padrões alimentares a partir das medidas-resumo, derivados do QFA.

Tal técnica exige modelagem estatística e tem por objetivo transformar um grande conjunto de variáveis correlacionadas em um conjunto menor de 
variáveis não-correlacionadas, que são chamadas componentes principais. $\mathrm{Na}$ análise fatorial, ao invés de se arbitrar um indicador da dieta, os dados apontam objetivamente como os alimentos se agrupam. Busca-se com esta técnica identificar a estrutura subjacente a uma matriz de dados, reduzindo-os, de modo a propiciar uma medida sintética da dieta (SLATTERY e col. 1998; HU e col. 2000a, 2000b; FUNG e col. 2001; MARTíNEZ e col. 1998; HOFFMANN 2004).

Obter uma solução fatorial por componentes principais é um processo interativo que geralmente requer repetição do procedimento de análise fatorial um certo número de vezes até se alcançar um resultado satisfatório.

A análise fatorial por componentes principais requer que as variáveis devam ser métricas e o tamanho da amostra deve ser maior que 50. A razão número de casos/número de variáveis deve ser de 5 para 1 (HAIR e col. 1998). No presente estudo, obtivemos 29 variáveis. Portanto, a razão $=782 / 29=26,96$ que excede o requerimento para a razão casos/variáveis.

A matriz de correlação de variáveis deve conter duas ou mais correlações de 0,30 ou mais (HAIR e col. 1998). No presente estudo, encontramos vinte e seis variáveis com correlação > que 0,300 .

Foram aplicados os testes Kaiser-Meyer-Oblin (KMO) e Bartlett's test of sphericity (BTS), que indicaram o grau de ajuste dos dados à análise fatorial, isto é, qual é o nível de confiança que se pode esperar dos dados, quando o seu tratamento pelo método multivariado de análise fatorial for empregado com sucesso (HAIR e col. 1998).

O KMO apresenta valores entre 0 e 1,0 e mostra qual é a proporção da variância que as variáveis apresentam em comum ou proporção daquela que são devidas a fatores comuns. Valores próximos de 1,0 indicam que o método 
de análise fatorial é perfeitamente adequado para o tratamento dos dados (HAIR e col. 1998; SPSS 1999).

O valor obtido para o KMO dos dados deste trabalho foi de 0,84 , indicando bom ajuste à análise fatorial.

O BTS é baseado na distribuição estatística do qui-quadrado e testa a hipótese de nulidade $\left(\mathrm{H}_{0}\right)$ : a matriz de correlação é uma matriz identidade (cuja diagonal é 1 e todas as outras iguais a zero), isto é, não há correlação entre as variáveis. Valores maiores que 0,100 indicam que os dados não são adequados para o tratamento com análise fatorial, isto é, a hipótese de nulidade não pode ser rejeitada. Já valores menores que 0,100 permitem rejeitar a hipótese de nulidade (HAIR e col. 1998; SPSS 1999).

O valor do BTS aqui obtido foi de $p=0,000$ (o que permitiu mais uma vez confirmar a possibilidade e a adequação do método de análise fatorial para o tratamento dos dados). A primeira fase da análise de componentes principais está voltada para tais verificações.

A seguir verificou-se a adequação de cada variável à análise fatorial, utilizando-se a matriz de correlação anti-imagem. O software utilizado (SPSS 1999) aloca as medidas de adequação das variáveis na diagonal da matriz de correlação anti-imagem, representada pela letra minúscula "a". A medida de adequação deve ser maior que 0,50 para cada variável (Anexo 6).

Há tantos componentes extraídos na análise de componentes principais quantas forem as variáveis do modelo.

Os autovalores são as variâncias dos componentes principais. Como a análise foi realizada com a matriz de correlação, as variáveis são padronizadas, isto é, cada variável tem variância 1 e a variância total é igual ao número de variáveis usadas na análise. 
Para determinar o número de fatores a serem extraídos na análise por componentes principais, utilizou-se o método de simulação de Lébart (LÉBART e DREYFUS 1972) da seguinte forma: elaborou-se uma matriz de números aleatórios do mesmo tamanho da matriz original, apresentando a mesma média e desvio-padrão de cada variável original. Em seguida, realizou-se a análise fatorial por componentes principais, obtendo-se os autovalores. Repetiu-se esse processo " $p$ " vezes. A cada vez, retém-se o maior autovalor nas $p$ repetiçōes. Esses autovalores máximos constituem o limite inferior que deve ser ultrapassado para que um componente principal passe a ser considerado. A probabilidade de se obter um autovalor maior que o autovalor máximo durante as p-1 repetições precedentes é de 1/p. Portanto, existe probabilidade $1 / p$ de se observar um autovalor que seja superior a este limite de confiança. No presente trabalho, 20 simulaçōes permitiram alcançar um nível de significância de $5 \%$.

A verificação adicional da adequação do número de fatores extraídos consiste em efetuar a diferença entre a matriz de correlação observada e a matriz de correlação reproduzida. Esta diferença constitui a matriz de correlação dos resíduos. Desse modo, os resíduos são computados entre as correlações observadas e as reproduzidas. É desejável que as contagens de resíduos $>0,05$ ou $5 \%$ estejam em menos de $50 \%$ dos dados.

O objetivo principal de rotacionar a matriz de componentes é obter um padrão de cargas mais claro para interpretação dos fatores. Os valores variam de $-1 a+1$, pois se trata de correlações. Valores inferiores a 0,200 foram eliminados, pois não contribuiam significativamente para o modelo. Quanto maior a correlação dos componentes, maior a contribuição do alimento para o fator. Desse modo, emprega-se a rotação que maximiza a variância dos novos eixos, obtendo-se um padrão de cargas em cada fator que é tão diferente quanto possivel do outro, facilitando a interpretação. 
Entre as diversas estratégias de rotação, empregou-se a rotação denominada Varimax, que é a mais usada e constitui um método de rotação ortogonal que minimiza o número de variáveis que cada fator terá (HAIR e col 1998).

No presente estudo, foram definidos 4 fatores que representam $35,6 \%$ da variância total (Anexo 7). Existem 165 não redundantes resíduos (40\%) maiores que 0,05 . Cada indivíduo do estudo tem um escore dos quatro fatores identificados.

\subsubsection{Variáveis do estudo}

\section{$\underline{\text { Sociodemográficas - } \quad \text { Categorias }}$}

$\begin{array}{ll}\text { Sexo - } & \text { Mulheres } \\ & \text { Homens } \\ \text { Idade (anos) - } & 15-29 \\ & 30-39 \\ & 40-49 \\ & 50-59 \\ & \text { Nenhuma } \\ \text { Escolaridade - } & \text { Fundamental - completo/incompleto } \\ & \text { Médio - completo/incompleto } \\ & \text { Superior - completo/incompleto } \\ & \text { Até } 500,00 \\ \text { Renda - } & 501,00-1.000,00 \\ & 1001,00-2.000,00 \\ & >2.000,00\end{array}$


Sóciodemográficas

Estado civil -

Número de pessoas na

família -

Áreas homogêneas -

Ocupação -

\section{Estilo de vida -}

Consumo de álcool -

Hábito de fumar -

\section{Categorias (continuação)}

casado

Viúvo

separado/divorciado

Solteiro

1 a 3

4 a 7

8 a 13

Alta (área do tipo 3 - média alta)

Média (área do tipo 4 - média baixa)

Baixa (área do tipo 5 - má)

Muito baixa (área do tipo 6 - pior)

Assalariado

Empr comis/prof liberal

Empregador

Autônomo

Outros

\section{Categorias}

não consome

Consome

Nuncafumou/não fuma mais

Fuma 


\begin{tabular}{ll} 
Estado nutricional - & $\begin{array}{l}\text { Categorias } \\
\text { BMC - }\end{array}$ \\
& $\begin{array}{l}\text { Baixo peso } \\
\text { Eutrófico } \\
\text { Sobrepeso } \\
\text { Obesidade } \\
\text { NCQ - }\end{array}$ \\
& $\begin{array}{l}\text { Normal } \\
\text { Elevado }\end{array}$ \\
Presença de doencas & Categorias \\
\hline Pressão arterial & Normal \\
& Alterada \\
Glicemia & Normal \\
Colesterol total & Alterada \\
& Normal \\
HDL-col & Alterado \\
& Normal \\
LDL-col & Alterado \\
& Normal \\
Triglicérides & Alterado \\
& Normal \\
& Alterado
\end{tabular}

\section{5.6 Análise estatística dos dados}

- Análise descritiva dos dados sociodemográficos, comportamentais e biológicos;

- Análise fatorial por componentes principais a partir das medidasresumos, derivadas do QFA. A análise fatorial reduz a dimensionalidade dos dados e identifica novas variáveis subjacentes significativas (HAIR e col 1998) 
- Cálculo das médias, ajustadas por sexo e idade, dos escores fatoriais, derivados dos padrões alimentares, segundo variáveis sócio-demográficas e comportamentais, foi obtido empregando a análise de covariância. Os escores fatoriais e idade foram modelados como variáveis contínuas. Todos os " $\mathrm{p}_{\mathrm{s}}$ " foram bicaudais;

- Regressão linear múltipla para avaliar a associação entre os escores fatoriais, que são combinações lineares dos padrões alimentares, atribuídos a cada observação e os fatores biológicos considerando três modelagens, com os seguintes ajustes:

- sócio-demográfica: sexo, idade, áreas homogêneas;

- multivariada; escolaridade, hábito de fumar, consumo de álcool ( $g / d i a)$, história de doença na família;

- multivariada com índice de massa corporal (IMC) ou razão cintura quadril (RCQ).

Os escores fatoriais foram modelados como variáveis contínuas. $\mathrm{O}$ nível de significância adotado foi $5 \%$.

As variáveis qualitativas, como sexo, hábito de fumar, áreas homogêneas, parente na família com hipertensão e/ou com diabete, foram transformadas em variáveis indicadoras, recebendo valores 0 e 1 , para identificar as categorias.

Quando se emprega o coeficiente de regressão padronizado, as interpretações baseiam-se no desvio-padrão (DP) das variáveis. A variação de um DP na variável independente produz a variação de B DPs na variável dependente, mantendo-se as outras variáveis constantes. $\mathrm{O}$ sinal (+ ou -) do coeficiente $B$ indica se a variável dependente aumenta ou diminui, quando a variável independente aumenta. 


\subsubsection{Programa estatístico}

As análises foram realizadas utilizando-se o software Statistical Package for Social Sciences - SPSS 10.0 - (SPSS, 1999) e S-Plus (versão 4,5).

\section{6 Ética}

O potencial participante, uma vez informado (consentimento esclarecido, de acordo com a Resolução 196/96 do Conselho Nacional de Saúde) sobre as razões e os objetivos do estudo, foi então convidado a dele fazer parte.

Garantiu-se ao convidado o direito de recusa ou desistência em qualquer momento do estudo. Garantiu-se também que o participante se abstivesse de responder a qualquer pergunta do questionário que julgasse incompatível com suas crenças ou princípios.

As informações obtidas foram utilizadas apenas para finalidades científicas, preservando-se indevassável sigilo quanto à identidade do participante.

O protocolo do estudo do projeto temático "FATORES DE RISCO PARA DOENÇAS CRÓNICAS NÃO-TRANSMISSIVEIS: INQUÉRITO DOMICILIAR NO MUNICÍPIO DE SÃo PAULO", do qual estão sendo extraídos os dados para o presente estudo, foi aprovado pelo Conselho de Ética em Pesquisa da Universidade de São Paulo - UNIFESP - (Anexo 5).

O projeto de pesquisa que gerou o presente trabalho foi analisado e aprovado pelo Comitê de Ética em Pesquisa da Faculdade de Saúde Pública da Universidade de São Paulo - FSP/USP - (Anexo 5). 


\section{RESULTADOS}

\subsection{Características gerais da amostra estudada}

A Tabela 1, descreve as variáveis sócio-demográficas - número e jorcentagem, por sexo, grupo etário, escolaridade, renda, estado civil, número de jessoas na família, ocupação e áreas homogêneas - dos participantes.

Verifica-se que a amostra foi composta por $54 \%$ de pessoas do sexo Feminino e, aproximadamente, $46 \%$ do sexo masculino. Observa-se que $29 \%$ jertencia ao grupo etário compreendido entre 15 e 29 anos; $28 \%$ tinham entre 30 ə 39 anos, $25 \%$ com idade entre 40 e 49 anos e $18 \%$, entre 50 e 59 anos.

Quanto ao nível de escolaridade, predominou o nivel fundamental (46\%). $32 \%$ tinham nível médio e $18 \%$ nível superior.

Quanto à renda familiar, $27 \%$ tinham renda até $\mathrm{R} \$ 500,00 ; 20 \%$ com enda entre $R \$ 500,00$ e $R \$ 1.000,00 ; 28 \%$ com renda até $R \$ 2.000,00$ e $25 \%$ zom renda acima de $R \$ 2.000,00$.

A maioria $(56 \%)$ era casada e $30 \%$ eram solteiros; $10 \%$ eram separados e $7 \%$, viúvos. Em $45 \%$ dos domicílios visitados, havia até 3 pessoas na família e em $53 \%$ - de 4 a 7 pessoas.

Quanto à distribuição por áreas homogêneas, predominou a média, pois se trata da área sócio ambiental onde há maior concentração de pessoas (35\%). Quanto às áreas categorizadas como "baixa" e "muito baixa", o percentual de jessoas que participaram do estudo em cada uma delas, ficou ao redor de $25 \%$.

Quanto à ocupação, predominou a categoria dos assalariados $(43,2 \%)$. 
Tabela 1. Distribuição da amostra estudada, segundo características sóciodemográficas. São Paulo, 2002.

\begin{tabular}{|c|c|c|c|c|}
\hline VARIÁVEIS & CATEGORIAS & $\mathbf{N}^{\circ}$ & $\%$ & TOTAL \\
\hline Sexo & $\begin{array}{l}\text { Mulheres } \\
\text { Homens }\end{array}$ & $\begin{array}{l}425 \\
357\end{array}$ & $\begin{array}{l}54,3 \\
45,7\end{array}$ & 782 \\
\hline $\begin{array}{l}\text { Grupos etários } \\
\text { (idade em anos) }\end{array}$ & $\begin{array}{l}15-29 \\
30-39 \\
40-49 \\
50-59\end{array}$ & $\begin{array}{l}224 \\
216 \\
199 \\
143\end{array}$ & $\begin{array}{l}28,6 \\
27,6 \\
25,4 \\
18,3\end{array}$ & 782 \\
\hline Escolaridade & $\begin{array}{l}\text { Nenhuma } \\
\text { Fundamental - compl/incomp } \\
\text { Médio - compl/incompl } \\
\text { Superior compl/incompleto }\end{array}$ & $\begin{array}{r}28 \\
360 \\
253 \\
141\end{array}$ & $\begin{array}{r}3,5 \\
46,0 \\
32,4 \\
18,0\end{array}$ & 782 \\
\hline Renda familiar & $\begin{array}{l}\text { Até } 500,00 \\
501,00-1.000,00 \\
1001,00-2.000,00 \\
>2.000,00\end{array}$ & $\begin{array}{l}214 \\
155 \\
216 \\
197\end{array}$ & $\begin{array}{l}27,4 \\
19,8 \\
27,6 \\
25,2\end{array}$ & 782 \\
\hline Estado civil & $\begin{array}{l}\text { Casado } \\
\text { Viúvo } \\
\text { separado/divorciado } \\
\text { Solteiro }\end{array}$ & $\begin{array}{r}437 \\
35 \\
71 \\
239\end{array}$ & $\begin{array}{l}55,9 \\
04,5 \\
09,8 \\
30,5\end{array}$ & 782 \\
\hline $\begin{array}{l}\text { Número de pessoas } \\
\text { na familia }\end{array}$ & $\begin{array}{l}1 \text { a } 3 \\
4 \text { a } 7 \\
8 \text { a } 13\end{array}$ & $\begin{array}{r}350 \\
412 \\
20\end{array}$ & $\begin{array}{l}44,7 \\
52,7 \\
02,6\end{array}$ & 782 \\
\hline Áreas homogêneas & $\begin{array}{l}\text { Alta } \\
\text { Média } \\
\text { Baixa } \\
\text { Muito baixa }\end{array}$ & $\begin{array}{l}121 \\
276 \\
192 \\
193\end{array}$ & $\begin{array}{l}15,5 \\
35,3 \\
24,5 \\
24,7\end{array}$ & 782 \\
\hline Ocupação & $\begin{array}{l}\text { Assalariado } \\
\text { Empr comis/prof liberal } \\
\text { Empregador } \\
\text { Autônomo } \\
\text { Outros }\end{array}$ & $\begin{array}{r}338 \\
34 \\
20 \\
118 \\
272 \\
\end{array}$ & $\begin{array}{r}43,2 \\
4,3 \\
2,6 \\
15,1 \\
34,8 \\
\end{array}$ & 782 \\
\hline
\end{tabular}


5.2 Características gerais da amostra estudada quanto ao estilo de vida, estado nutricional e presença de doenças

A Tabela 2 mostra a distribuição do número e porcentagem de participantes, quanto ao estilo de vida (consumo de álcool e hábito de fumar), estado nutricional (por meio dos indicadores índice de massa corporal e razão cintura quadril) e presença de distúrbios metabólicos (hipertensão arterial, hiperglicemia e dislipidemias).

Verifica-se que, quanto ao hábito de fumar, cerca de $72 \%$ nunca fumaram ou não fumam mais. Entretanto, pouco mais de $28 \%$ declararam que tem o hábito de fumar. Quanto ao consumo de bebidas alcoólicas, 45,5\% declararam não consumi-las.

Pôde-se observar que, praticamente, $50 \%$ dos indivíduos apresentou sobrepeso/obesidade e menos de $3 \%$ apresentou baixo peso. $43 \%$ tinham RCQ alterada.

Em torno de $60 \%$ dos indivíduos apresentaram níveis pressóricos normais, entretanto, $40 \%$ apresentaram niveis alterados.

Quanto aos niveis de colesterol e frações, cerca de $35 \%$ apresentaram colesterol total e LDL-col acima dos niveis normais e, aproximadamente, $44 \%$ apresentaram HDL-col abaixo dos parâmetros considerados adequados. 27\% apresentaram hipertrigliceridemia e, cerca de $25 \%$ apresentaram hiperglicemia. 
Tabela 2. Distribuição da amostra estudada, segundo características quanto ao estilo de vida, estado nutricional e presença de doenças.

São Paulo, 2002.

\begin{tabular}{|c|c|c|c|c|}
\hline VARIÁVEIS & CATEGORIAS & No & $\%$ & TOTAL \\
\hline Álcool - consumo & $\begin{array}{l}\text { não consome } \\
\text { consome }\end{array}$ & $\begin{array}{l}384 \\
398\end{array}$ & $\begin{array}{l}49,1 \\
50,9\end{array}$ & 782 \\
\hline Hábito de fumar & $\begin{array}{l}\text { Nuncafumou/năo fuma mais } \\
\text { Fuma }\end{array}$ & $\begin{array}{l}559 \\
223\end{array}$ & $\begin{array}{l}71,5 \\
28,5\end{array}$ & 782 \\
\hline IMC & $\begin{array}{l}\text { Baixo peso } \\
\text { Eutrófico } \\
\text { Sobrepeso } \\
\text { Obesidade }\end{array}$ & $\begin{array}{l}022 \\
381 \\
237 \\
142\end{array}$ & $\begin{array}{l}02,8 \\
48,7 \\
30,3 \\
18,2\end{array}$ & 782 \\
\hline RCQ & $\begin{array}{l}\text { Normal } \\
\text { Alterado }\end{array}$ & $\begin{array}{l}445 \\
336\end{array}$ & $\begin{array}{l}56,9 \\
43,1\end{array}$ & 781 \\
\hline Pressão arterial & $\begin{array}{l}\text { Normal } \\
\text { Alterada }\end{array}$ & $\begin{array}{l}458 \\
324\end{array}$ & $\begin{array}{l}58,6 \\
41,4\end{array}$ & 782 \\
\hline Glicemia & $\begin{array}{l}\text { Normal } \\
\text { Alterada }\end{array}$ & $\begin{array}{l}524 \\
175\end{array}$ & $\begin{array}{l}75,0 \\
25,0\end{array}$ & 669 \\
\hline Colesterol total & $\begin{array}{l}\text { Normal } \\
\text { Alterado }\end{array}$ & $\begin{array}{l}451 \\
248\end{array}$ & $\begin{array}{l}64,5 \\
35,5\end{array}$ & 699 \\
\hline HDL-col & $\begin{array}{l}\text { Normal } \\
\text { Alterado }\end{array}$ & $\begin{array}{l}384 \\
298\end{array}$ & $\begin{array}{l}56,3 \\
43,7\end{array}$ & 682 \\
\hline LDL-col & $\begin{array}{l}\text { Normal } \\
\text { Alterado (> } 100 \mathrm{mg} / \mathrm{dl} \text { ) }\end{array}$ & $\begin{array}{l}235 \\
447\end{array}$ & $\begin{array}{l}34,5 \\
65,5\end{array}$ & 682 \\
\hline Triglicérides & $\begin{array}{l}\text { Normal } \\
\text { Alterado }\end{array}$ & $\begin{array}{l}513 \\
186\end{array}$ & $\begin{array}{l}73,4 \\
26,6\end{array}$ & 699 \\
\hline
\end{tabular}




\section{3 Padrões alimentares da amostra estudada}

O passo final da análise fatorial é a interpretação dos fatores, baseada na análise das correlações observadas na matriz fatorial rotacionada, (Tabela 3) onde foram obtidos quatro fatores. Os alimentos que contribuíram para cada um dos padrões obtidos:

Fator 1 - contribuíram de forma significativa: leite integral, pães, massas, salgados, doces, gorduras, presunto, sucos artificiais, refrigerante comum - e em menor proporção: feijoada, sucos naturais e frango. Este fator foi denominado de padrão "cafeteria" ou "fast-food".

Fator 2 - cereais, feijōes, folhosos, não folhosos e sopas, maionese, infusão em menor proporção: gorduras, frutas, frango. Denominou-se "padrão tradicional".

Fator 3 - leite desnatado, frutas, sucos naturais, peixes, refrigerante diet, adoçantes artificiais - em menor proporção: pães, não folhosos e sopas. A este fator, denominou-se de "padrão moderno".

Fator 4 - feijoada, carne boi e miúdos, porco, frango, lingüiça, ovo, bebidas alcoólicas, sal, denominado de "padrão aterogênico" .

Visando a avaliar a estabilidade dos quatro padrões alimentares, que emergiram da amostra como um todo, procedeu-se à análise fatorial em dois subgrupos: por sexo e por áreas homogêneas. Identificaram-se também, em geral, quatro padrōes alimentares em cada subgrupo. Os padrões alimentares obtidos por áreas homogêneas serão mostrados e analisados em futura publicação.

Verificou-se as médias dos escores fatoriais dos padrōes alimentares, segundo características sociodemográficas e comportamentais. 
Tabela 3. Distribuição dos componentes alimentares, segundo matriz rotacionada*. São Paulo, 2002.

\begin{tabular}{|c|c|c|c|c|}
\hline 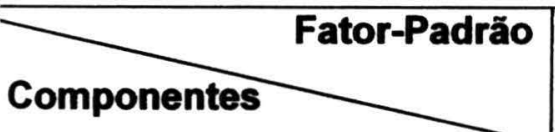 & 1 & 2 & 3 & 4 \\
\hline 1-lácteos - integrais & 0,583 & 0,185 & 0,139 & $-0,135$ \\
\hline 2-lácteos - desnatados & $-0,028$ & 0,174 & 0,495 & $-0,174$ \\
\hline 3- pães & 0,621 & 0,131 & 0,288 & $-0,125$ \\
\hline 4-arroz, outros cereais e raízes & 0,194 & 0,602 & $-0,058$ & 0,099 \\
\hline 5- massas & 0,422 & 0,017 & 0,014 & 0,083 \\
\hline 6- pastelaria, salgados & 0,642 & $-0,027$ & 0,096 & 0,200 \\
\hline 7- maionese & 0,163 & 0,441 & 0,090 & 0,167 \\
\hline 8- óleos e gorduras & 0,420 & 0,341 & $-0,089$ & 0,179 \\
\hline 9 -doces & 0,615 & 0,182 & 0,131 & 0,158 \\
\hline 10 -feijōes & 0,188 & 0,635 & $-0,115$ & 0,171 \\
\hline 11-feijoada & 0,355 & $-0,087$ & 0,079 & 0,462 \\
\hline 12-folhosos & $-0,047$ & 0,651 & 0,152 & $-0,010$ \\
\hline 13-legumes (n folhosos/sopas) & 0,030 & 0,649 & 0,349 & 0,073 \\
\hline 14-frutas & 0,188 & 0,381 & 0,554 & 0,010 \\
\hline 15 -sucos naturais & 0,315 & 0,008 & 0,497 & 0,013 \\
\hline 16-carnes - bovina e miúdos & 0,083 & 0,154 & $-0,030$ & 0,618 \\
\hline 17-porco & 0,100 & $-0,080$ & 0,130 & 0,554 \\
\hline 18-frango & $-0,125$ & 0,143 & 0,160 & 0,230 \\
\hline 19-peixes/frutos do mar & 0,178 & 0,135 & 0,550 & 0,087 \\
\hline 20-embutidos 1: lingüiça/salsicha & 0,221 & 0,055 & $-0,200$ & 0,432 \\
\hline 21-embutidos 2:presunto/mortad. & 0,507 & 0,198 & 0,149 & 0,200 \\
\hline 22-ovos & 0,018 & 0,198 & $-0,156$ & 0,395 \\
\hline 23-café/infusões & 0,045 & 0,513 & 0,032 & 0,064 \\
\hline 24 -bebidas alcoólicas & 0,001 & $-0,019$ & 0,161 & 0,585 \\
\hline 25-sucos artificiais & 0,302 & 0,033 & $-0,87$ & 0,135 \\
\hline 26-refrigerantes diet & $-0,148$ & 0,189 & 0,390 & $-0,013$ \\
\hline 27-adoçante (no café) & $-0,042$ & $-0,017$ & 0,144 & 0,030 \\
\hline 28-refrigerantes comuns & 0,570 & $-0,006$ & $-0,201$ & 0,117 \\
\hline 29- sal - de adiçăo & 0,094 & 0,048 & $-0,062$ & 0,262 \\
\hline \% variância & 18,1 & 7,5 & 5,2 & 4,8 \\
\hline$\%$ var. acumulada & 18,1 & 25,6 & 30,8 & 35,6 \\
\hline
\end{tabular}

$\left.{ }^{*}\right)$ Significativos para o modelo - valores maiores que 0,220 . 
5. 4 Padrões alimentares e variáveis sociodemográficas e comportamentais

A Tabela 4 mostra as médias dos escores fatoriais dos padrões alimentares, segundo características sociodemográficas e comportamentais.

Tabela 4. Médias dos escores fatoriais dos padrões alimentares ajustadas, segundo sexo, grupo etário, escolaridade, quartis de renda, ocupação, áreas homogêneas, hábito de fumar e consumo de álcool. Município de São Paulo, 2002.

\begin{tabular}{|c|c|c|c|c|c|}
\hline VARIÁVEIS & CATEGORIAS & PADRĀO 1 & PADRĀO 2 & PADRĀO 3 & PADRÃO 4 \\
\hline $\begin{array}{l}\text { SEXO } \\
\text { ajustado por } \\
\text { idade }\end{array}$ & $\begin{array}{c}\begin{array}{c}\text { Feminino } \\
\text { Masculino }\end{array} \\
p\end{array}$ & $\begin{array}{r}-0,03 \\
0,03 \\
0,404\end{array}$ & $\begin{array}{r}0,09 \\
-0,11 \\
0,005\end{array}$ & $\begin{array}{r}0,01 \\
-0,01 \\
0,716\end{array}$ & $\begin{array}{r}-0,10 \\
0,13 \\
0,001\end{array}$ \\
\hline $\begin{array}{l}\text { GRUPO ETÁRIO } \\
\text { ajustados por } \\
\text { sexo }\end{array}$ & $\begin{array}{c}15-29 \\
30-39 \\
40-49 \\
50-59 \\
p\end{array}$ & $\begin{array}{r}0,09 \\
-0,02 \\
-0,01 \\
-0,10 \\
0,351\end{array}$ & $\begin{array}{r}-0,14 \\
0,02 \\
0,06 \\
0,10 \\
0,019\end{array}$ & $\begin{array}{r}-0,10 \\
0,10 \\
-0,03 \\
0,04 \\
0,403\end{array}$ & $\begin{array}{r}-0,07 \\
0,03 \\
0,10 \\
-0,06 \\
0,526\end{array}$ \\
\hline $\begin{array}{l}\text { ESCOLARIDADE } \\
\text { ajustados por } \\
\text { sexo e idade }\end{array}$ & $\begin{array}{l}\text { Nenhuma } \\
\text { Fundamental } \\
\text { Médio } \\
\text { Superior } \\
\text { p }\end{array}$ & $\begin{array}{r}-0,47 \\
-0,04 \\
0,07 \\
0,08 \\
0,032\end{array}$ & $\begin{array}{r}-0,26 \\
0,02 \\
-0,04 \\
0,09 \\
0,322\end{array}$ & $\begin{array}{r}-0,41 \\
-0,08 \\
-0,02 \\
0,32 \\
0,000\end{array}$ & $\begin{array}{r}-0,16 \\
0,11 \\
-0,07 \\
-0,12 \\
0,039\end{array}$ \\
\hline $\begin{array}{l}\text { QUARTIS } \\
\text { DE RENDA } \\
\text { ajustados por } \\
\text { sexo e idade }\end{array}$ & $\begin{array}{l}\text { Até } 500,00 \\
501,-1.000 \\
1001,-2.000, \\
>2.000,00 \\
p\end{array}$ & $\begin{array}{r}-0,03 \\
-0,07 \\
0,03 \\
0,06 \\
0,602\end{array}$ & $\begin{array}{r}-0,11 \\
0,06 \\
-0,08 \\
0,15 \\
0,032\end{array}$ & $\begin{array}{r}-0,22 \\
-0,10 \\
-0,01 \\
0,33 \\
0,000\end{array}$ & $\begin{array}{r}-0,03 \\
0,08 \\
0,07 \\
-0,10 \\
0,224\end{array}$ \\
\hline $\begin{array}{l}\text { OCUPAÇÃO } \\
\text { ajustados por } \\
\text { sexo e idade }\end{array}$ & $\begin{array}{l}\text { Assalariado } \\
\text { Prof liberal } \\
\text { Empregador } \\
\text { Autônomo } \\
\text { Outros } \\
p\end{array}$ & $\begin{array}{r}0,03 \\
0,17 \\
-0,04 \\
-0,13 \\
0,01 \\
0,534\end{array}$ & $\begin{array}{r}-0,03 \\
0,04 \\
-0,10 \\
0,05 \\
0,01 \\
0,941\end{array}$ & $\begin{array}{r}0,06 \\
-0,15 \\
0,58 \\
0,07 \\
-0,13 \\
0,007\end{array}$ & $\begin{array}{r}0,02 \\
0,00 \\
0,06 \\
0,14 \\
-0,09 \\
0,275\end{array}$ \\
\hline
\end{tabular}




\begin{tabular}{|c|c|c|c|c|c|}
\hline VARIÁVEIS & CATEGORIAS & PADRĀO 1 & PADRĀO 2 & PADRĀO 3 & $\begin{array}{c}\text { continuação) } \\
\text { PADRAOO }\end{array}$ \\
\hline \multirow{5}{*}{$\begin{array}{l}\text { ÁREA } \\
\text { HOMOGÊNEA } \\
\text { ajustadas por } \\
\text { sexo e idade }\end{array}$} & Alta & 0,13 & 0,12 & 0,21 & $-0,11$ \\
\hline & Média & 0,20 & 0,13 & 0,12 & 0,12 \\
\hline & Baixa & $-0,07$ & $-0,04$ & 0,02 & 0,00 \\
\hline & Muito baixa & $-0,30$ & $-0,21$ & $-0,32$ & $-0,10$ \\
\hline & $p$ & .000 &, 002 & .000 &, 044 \\
\hline \multirow{3}{*}{$\begin{array}{l}\text { HÁBITO } \\
\text { DE FUMAR } \\
\text { ajustadas por } \\
\text { sexo e idade }\end{array}$} & Não & 0,01 & 0,01 & 0,01 & $-0,05$ \\
\hline & Sim & $-0,02$ & $-0,01$ & $-0,02$ & 0,12 \\
\hline & $p$ & 0,750 & 0081 & 0,754 & 0,041 \\
\hline \multirow{3}{*}{$\begin{array}{l}\text { CONSUMO DE } \\
\text { ÁLCOOL (g/dia) } \\
\text { ajustadas por } \\
\text { sexo e idade }\end{array}$} & Não & $-0,07$ & $-0,13$ & $-0,61$ & $-0,14$ \\
\hline & Sim & 0,07 & 0,13 & $-0,06$ & 0,14 \\
\hline & $p$ & 0,042 & 0,000 & 0,073 & 0,000 \\
\hline
\end{tabular}

\section{4. 1 Sexo}

As médias dos escores fatoriais (padrões 2 "tradicional" e 4 "aterogênico") ajustadas por idade se diferenciam quanto ao sexo ( $p=0,005$ e 0,001, respectivamente). Há maior consumo do padrão 2 por mulheres e do padrão 4 por homens.

Já, as médias dos escores fatoriais (Padrões 1 "cafeteria" e 3 "moderno") ajustadas por idade não se diferenciam quanto ao sexo $(p=0,404$ e 0,716, respectivamente).

Observa-se também que as médias dos escores fatoriais do sexo feminino em relação ao padrão 2 "tradicional" são bem mais altas, em comparação com o sexo masculino. Acontece justamente o contrário, em relação ao padrão 4 "aterogênico". Entre as mulheres predomina o consumo de arroz, feijão, entre outros alimentos presentes no padrão "tradicional" e entre os homens predomina o consumo de carnes, bebidas alcoólicas e sal. 
Não houve diferença estatisticamente significativa entre as médias dos escores fatoriais entre os sexos, em relação aos padrōes 1 "cafeteria" e 3 "moderno". Entretanto, observando-se o gráfico, verifica-se que as médias mais altas do padrão 1 estão entre os homens.

\section{4. 2 Grupo etário}

As médias dos escores fatoriais (Padrōes 2 "tradicional") ajustadas por sexo se diferenciam quanto aos grupos etários $(p=0,019)$. Há menor consumo do padrão 2 por pessoas com idade entre 15-29 anos.

As médias dos escores fatoriais (padrões 1 "cafeteria", 3 "moderno" e 4 "aterogênico") ajustadas por sexo. não se diferenciam quanto aos grupos etários $(p=0,351 ; 0,403$ e 0,526 , respectivamente).

Apesar de não haver diferença estatisticamente significativa entre as médias dos escores fatoriais, em relação aos grupos etários dos padrões 1 "cafeteria", 3 "moderno" e 4 "aterogênico", observa-se que as médias mais altas do padrão 1 estão entre os indivíduos do grupo etário compreendido entre 15 e 29 anos e as médias mais baixas, entre os indivíduos acima de 50 anos.

As médias mais altas do padrão 3 estão entre os indivíduos do grupo etário compreendido entre 30 e 39 anos e as médias mais baixas, entre os indivíduos entre 15 e 29 anos. Quanto ao padrão 4, as médias mais altas estão entre os indivíduos do grupo etário compreendido entre 40 e 49 anos.

Tais resultados mostram que os mais jovens consomem mais alimentos tipo "fast-food" e menos alimentos "tradicionais". Tais padrões se modificam e se invertem, conforme aumenta a idade. 


\section{4. 3 Escolaridade}

Existe diferença estatisticamente significativa entre as médias dos escores dos padrões 1, 3 e 4 por escolaridade, ajustadas por sexo e idade.

As médias mais elevadas dos escores do padrão 1 "cafeteria", estão entre os indivíduos com os níveis de escolaridade médio e superior.

Verifica-se também que as médias mais elevadas dos escores do padrão 3 "moderno" estão entre os indivíduos com os níveis de escolaridade superior.

Quanto ao padrão 4 "aterogênico" as maiores médias estão os de escolaridade fundamental.

Verifica-se que, as médias dos escores fatoriais dos padrōes alimentares, segundo a escolaridade, aumentam, conforme aumenta a escolaridade.

\section{4. 4 Renda familiar}

Existe diferença estatisticamente significativa entre as médias dos escores dos padrōes 2 e 3 por renda, ajustadas por sexo e idade.

As médias mais elevadas dos escores dos padrões 2 "tradicional" e 3 "moderno", estão entre os indivíduos com renda superior a R\$2.000,00.

Verifica-se também que as menores médias dos escores do Padrão 3 "moderno" estão entre os indivíduos com o nivel de renda até $\mathrm{R} \$ 500,00$ e estam aumentam, segundo aumenta o nivel de renda.

Apesar de não ter apresentado significância estatística, as médias dos escores fatoriais do padrão 1 , cujos alimentos predominantes são ricos em 
gorduras e açúcares e pobre em fibras, são similares, independente do nível de renda. Ou seja, o padrão alimentar 1 "cafeteria" é consumido pelos indivíduos entrevistados, independentemente do nível de renda familiar.

\section{4.5 Ocupação}

As médias dos escores fatoriais do padrão 3 "moderno", segundo ocupação, ajustadas por sexo e idade se diferenciam $(p=0,007)$. Há maior consumo do padrão 3 por empregadores (empresários, entre outros).

Verifica-se também que as menores médias dos escores fatoriais do padrão 3 estão entre os profissionais liberais e, também as maiores médias do padrão 1. Os profissionais autônomos são os que têm as maiores médias do padrão 4 e as menores médias do padrão 1.

\section{4. 6 Áreas homogêneas}

Existe diferença estatisticamente significativa entre as médias dos escores dos padrões por áreas homogêneas, ajustadas por sexo e idade.

As médias mais elevadas dos escores dos padrões 1 "cafeteria" e 2 "tradicional" estão entre os indivíduos das áreas homogêneas categorizadas como média e alta, respectivamente.

Quanto ao padrão 3 "moderno", estão entre os indivíduos da área considerada alta.

O padrão 4 "aterogênico" as menores médias estão entre os indivíduos da área homogênea alta e as maiores médias, entre os de área da categoria média. 
Verificou-se o intervalo de confiança das médias dos escores fatoriais dos padrōes alimentares, segundo as áreas homogêneas, ajustadas por sexo e idade. Observou-se que as menores médias dos escores fatoriais do padrão 4 "aterogênico" estão entre os individuos da área categorizada como alta e as maiores médias do padrão 3 "moderno" também estão entre os indivíduos dessa categorização. Notou-se também que, as menores médias dos escores fatoriais dos padrões estão entre os indivíduos da área homogênea classificada como muito baixa.

Observa-se que as médias dos padrões vão decrescendo, conforme as áreas sócio-ambientais vão apresentando piores condiçōes, ou seja, a exclusão social associa-se também aos padrões alimentares.

As maiores médias dos padrōes 1 e 4 estão entre os indivíduos da área categorizada como média - de maior densidade populacional na cidade de São Paulo.

\section{4. 7 Hábito de fumar}

Existe diferença estatisticamente significativa entre as médias dos escores dos padrões por hábito de fumar, ajustadas por sexo e idade.

As médias mais elevadas dos escores do padrão 2 "tradicional" estão entre os individuos que não fumam, enquanto que no padrão 4 "aterogênico" as maiores médias estão entre os indivíduos que fumam.

\section{4. 8 Consumo de álcool}

Verifica-se que existe diferença estatisticamente significativa entre as médias dos escores dos padrões por consumo de álcool (g/dia), ajustadas por sexo e idade. 
As médias mais elevadas dos escores dos padrões 1 "cafeteria", 2 "tradicional" e 4 "aterogênico" estão entre os individuos consomem álcool.

A única variável que apresentou diferença significativa por gênero (homens e mulheres) foi o consumo de álcool. Verificou-se que as maiores médias dos escores do padrão 2 "tradicional" estão entre os indivíduos que consomem álcool de ambos os sexos. As maiores médias do padrão 4 estão entre os indivíduos que consomem álcool, do sexo masculino.

\section{5 Padrões alimentares e fatores de risco para doenças cardiovasculares}

A associação entre fatores de risco biológicos - pressão arterial sistólica e diastólica, IMC, RCQ, colesterol total, LDL-colesterol, HDL-colesterol, triglicérides e glicemia - controladas por sexo, idade, áreas homogêneas, escolaridade, hábito de fumar, consumo de álcool, história familiar de hipertensão (na análise da pressão arterial), história familiar de diabetes (na análise da glicemia), estão apresentadas na Tabela 5.

Apresenta-se uma análise confirmatória sobre a dieta como fator de risco para doença cardiovascular, amplamente demonstrada pela literatura científica. Entretanto, tendo em vista a importância dos padrões alimentares detectados pela análise fatorial por componentes principais, optou-se por realizar uma análise entre esses padrōes e dislipidemias, controladas por variáveis referentes ao indivíduo, áreas homogêneas e seus antecedentes familiares. 
Tabela 5. Análise de Regressão Linear Múltipla entre fatores de risco biológico e padrões alimentares.

Municipio de São Paulo, 2002.

\begin{tabular}{|c|c|c|c|c|c|c|c|c|c|}
\hline $\begin{array}{l}\text { VARIAVEIS } \\
\text { PAS }(\mathbf{m m H g})\end{array}$ & \multicolumn{2}{|c|}{$\begin{array}{l}\text { PADRAO 1 } \\
\text { "Cafeteria" }\end{array}$} & \multicolumn{2}{|c|}{$\begin{array}{l}\text { PADRĀO } 2 \\
\text { "Tradicional" }\end{array}$} & \multicolumn{2}{|c|}{$\begin{array}{l}\text { PADRĀO } 3 \\
\text { "Moderno" }\end{array}$} & \multicolumn{2}{|c|}{$\begin{array}{c}\text { PADRĀO } 4 \\
\text { Aterogênico }\end{array}$} & $\mathbf{R}^{2}(\%)$ \\
\hline $\begin{array}{l}\text { PAS (mmHg) } \\
\text { 0- Sem ajuste } \\
\text { 1- Sexo, idade, áreas homogêneas } \\
\text { 2- Multivariado** } \\
\text { 3- Multivariado+ IMC***}\end{array}$ & $\begin{array}{c}B^{\star} \\
0,082 \\
0,076 \\
0,082 \\
0,077\end{array}$ & $\begin{array}{c}p \\
0,015 \\
0,030 \\
0,027 \\
0,031\end{array}$ & $\begin{array}{c}B^{*} \\
0,015 \\
0,028 \\
0,019 \\
-0,002\end{array}$ & $\begin{array}{l}p \\
0,684 \\
0,428 \\
0,585 \\
0,062\end{array}$ & $\begin{array}{c}B^{*} \\
-0,052 \\
-0,057 \\
-0,048 \\
-0,040\end{array}$ & $\begin{array}{c}P \\
0,058 \\
0,017 \\
0,028 \\
0,025\end{array}$ & $\begin{array}{c}B^{*} \\
0,042 \\
0,008 \\
0,013 \\
0,005\end{array}$ & $\begin{array}{c}p \\
0,263 \\
0,812 \\
0,735 \\
0,894\end{array}$ & $\begin{array}{l}17,9 \\
14,8 \\
16,2\end{array}$ \\
\hline $\begin{array}{l}\quad \text { PAD (mmHg) } \\
\text { 0- Sem ajuste } \\
\text { 1- Sexo, idade, áreas homogêneas } \\
\text { 2- Multivariado** } \\
\text { 3- Multivariado+ IMC }\end{array}$ & $\begin{array}{l}0,149 \\
0,132 \\
0,156 \\
0,151\end{array}$ & $\begin{array}{l}0,000 \\
0,000 \\
0,000 \\
0,000\end{array}$ & $\begin{array}{l}-0,010 \\
-0,009 \\
-0,010 \\
-0,028\end{array}$ & $\begin{array}{l}0,771 \\
0,772 \\
0,794 \\
0,405\end{array}$ & $\begin{array}{l}-0,116 \\
-0,121 \\
-0,099 \\
-0,111\end{array}$ & $\begin{array}{l}0,001 \\
0,000 \\
0,008 \\
0,002\end{array}$ & $\begin{array}{l}0,045 \\
0,012 \\
0,030 \\
0,014\end{array}$ & $\begin{array}{l}0,210 \\
0,718 \\
0,422 \\
0,699\end{array}$ & $\begin{array}{c}19,6 \\
7,5 \\
14,1\end{array}$ \\
\hline $\begin{array}{l}\text { COLESTEROL TOTAL } \\
\text { 1- Sexo, idade, áreas homogêneas } \\
\text { 2- Multivariado"* } \\
\text { 3- Multivariado+ IMC }\end{array}$ & $\begin{array}{l}-0,037 \\
-0,049 \\
-0,049\end{array}$ & $\begin{array}{l}0,284 \\
0,199 \\
0,182\end{array}$ & $\begin{array}{l}0,001 \\
0,033 \\
0,018\end{array}$ & $\begin{array}{l}0,988 \\
0,375 \\
0,628\end{array}$ & $\begin{array}{l}-0,104 \\
-0,133 \\
-0,120\end{array}$ & $\begin{array}{l}0,003 \\
0,001 \\
0,001\end{array}$ & $\begin{array}{l}0,042 \\
0,034 \\
0,024\end{array}$ & $\begin{array}{l}0,038 \\
0,025 \\
0,034\end{array}$ & $\begin{array}{c}21,2 \\
- \\
-\end{array}$ \\
\hline
\end{tabular}

$\beta^{*}=$ coeficiente de regressão padronizado.

Participantes sob tratamento com anti-hipertensivos foram excluídos da análise da PAD e PAS ( $n=709)$;

Participantes sob uso de antilipêmico foram excluídos da análise do colesterol total, HDL-col, LDL-col, triglicérides $(n=775)$. Devido a estas exclusões e missing (=85), os dados referem-se a 690 participantes.

Participantes sob tratamento com antiglicêmicos foram excluidos da análise de glicemia ( $n=761)$.

2- ajuste multivariado**: escolaridade (número de séries completadas), fuma (sim, não), consumo de álcool (gramas/dia) e história familiar de hipertensão na análise da pressão arterial ou história familiar de diabete na análise de glicemia;

3- ajuste multivariado com IMC ${ }^{\star \star \star}$ (pressão arterial, glicemia, lipemias e RCQ);

Ocupaçăo e renda não foram incluidas no ajuste multivariado porque apresentaram alto grau de colinearidade com escolaridade.

(CONTINUA) 
Tabela 5. Análise de Regressão Linear Múltipla entre fatores de risco biológico e padrões alimentares. Município de São Paulo, 2002 (continuação)

\begin{tabular}{|c|c|c|c|c|c|c|c|c|c|}
\hline VARIAVEIS & $\begin{array}{l}\text { PAD } \\
\text { "Cal }\end{array}$ & & $\begin{array}{l}\text { PA } \\
\text { "Tra }\end{array}$ & $\begin{array}{l}02 \\
\text { onal" }\end{array}$ & $\begin{array}{l}\text { PA } \\
\text { "Mc }\end{array}$ & & $\begin{array}{l}\text { PA } \\
\text { Ate }\end{array}$ & \begin{tabular}{|l}
54 \\
ico
\end{tabular} & $\mathbf{R}^{2}(\%)$ \\
\hline $\begin{array}{l}\text { HDL-colesterol } \\
\text { 1- Sexo, idade, áreas homogêneas } \\
\text { 2- Multivariado"k } \\
\text { 3- Multivariado+ IMC }\end{array}$ & $\begin{array}{c}B^{*} \\
-0,040 \\
-0,061 \\
-0,061\end{array}$ & $\begin{array}{c}\boldsymbol{P} \\
0,022 \\
0,045 \\
0,032\end{array}$ & $\begin{array}{c}B^{*} \\
0,011 \\
0,037 \\
0,049\end{array}$ & $\begin{array}{l}p \\
0,777 \\
0,339 \\
0,189\end{array}$ & $\begin{array}{c}B^{\star} \\
0,035 \\
0,043 \\
0,053\end{array}$ & $\begin{array}{c}p \\
0,355 \\
0,271 \\
0,185\end{array}$ & $\begin{array}{c}B^{\star} \\
0,032 \\
0,004 \\
0,012\end{array}$ & $\begin{array}{l}p \\
0,400 \\
0,923 \\
0,753\end{array}$ & $\overline{-}$ \\
\hline $\begin{array}{l}\text { LDL-colesterol } \\
\text { 1- Sexo, idade, áreas homogêneas } \\
\text { 2- Multivariado** } \\
\text { 3- Multivariado+ IMC }\end{array}$ & $\begin{array}{l}-0,007 \\
-0,023 \\
-0,022\end{array}$ & $\begin{array}{l}0,841 \\
0,557 \\
0,558\end{array}$ & $\begin{array}{l}-0,004 \\
-0,024 \\
-0,018\end{array}$ & $\begin{array}{l}0,915 \\
0,532 \\
0,782\end{array}$ & $\begin{array}{l}-0,093 \\
-0,130 \\
-0,120\end{array}$ & $\begin{array}{l}0,011 \\
0,001 \\
0,002\end{array}$ & $\begin{array}{l}0,014 \\
0,019 \\
0,011\end{array}$ & $\begin{array}{l}0,692 \\
0,623 \\
0,773\end{array}$ & $\overline{-}$ \\
\hline $\begin{array}{l}\text { TRIGLICÉRIDES } \\
\text { 1- Sexo, idade, áreas homogêneas } \\
\text { 2- Multivariado** } \\
\text { 3- Multivariado+ IMC }\end{array}$ & $\begin{array}{l}-0,064 \\
-0,059 \\
-0,044\end{array}$ & $\begin{array}{l}0,068 \\
0,099 \\
0,184\end{array}$ & $\begin{array}{l}-0,156 \\
-0,270 \\
-0,151\end{array}$ & $\begin{array}{l}0,000 \\
0,000 \\
0,000\end{array}$ & $\begin{array}{l}0,038 \\
0,034 \\
0,027\end{array}$ & $\begin{array}{l}0,332 \\
0,341 \\
0,525\end{array}$ & $\begin{array}{l}0,137 \\
0,223 \\
0,151\end{array}$ & $\begin{array}{l}0,000 \\
0,000 \\
0,000\end{array}$ & $\begin{array}{c}23,3 \\
- \\
33,6\end{array}$ \\
\hline $\begin{array}{l}\quad \text { IMC } \\
\text { 1- Sexo, idade, áreas homogêneas } \\
\text { 2- Multivariado** } \\
\text { 4- Multivariado+ RCQ }\end{array}$ & $\begin{array}{l}0,089 \\
0,098 \\
0,056\end{array}$ & $\begin{array}{l}0,005 \\
0,000 \\
0,067\end{array}$ & $\begin{array}{l}0,137 \\
0,236 \\
0,142\end{array}$ & $\begin{array}{l}0,000 \\
0,000 \\
0,000\end{array}$ & $\begin{array}{r}0,032 \\
0,048 \\
-0,056\end{array}$ & $\begin{array}{l}0,333 \\
0,142 \\
0,032\end{array}$ & $\begin{array}{l}0,186 \\
0,190 \\
0,150\end{array}$ & $\begin{array}{l}0,000 \\
0,000 \\
0,000\end{array}$ & $\begin{array}{c}18,5 \\
39,2 \\
-\end{array}$ \\
\hline $\begin{array}{l}\text { RCQ } \\
\text { 1- Sexo, idade, áreas homogêneas } \\
\text { 2- Multivariado** } \\
\text { 3- Multivariado+ IMC }\end{array}$ & $\begin{array}{l}0,006 \\
0,007 \\
0,007\end{array}$ & $\begin{array}{l}0,020 \\
0,022 \\
0,016 \\
\end{array}$ & $\begin{array}{l}-0,006 \\
-0,008 \\
-0,010 \\
\end{array}$ & $\begin{array}{l}0,038 \\
0,015 \\
0,000 \\
\end{array}$ & $\begin{array}{l}-0,003 \\
-0,001 \\
-0,003\end{array}$ & $\begin{array}{l}0,215 \\
0,641 \\
0,257\end{array}$ & $\begin{array}{l}0,002 \\
0,005 \\
0,004\end{array}$ & $\begin{array}{l}0,028 \\
0,022 \\
0,034 \\
\end{array}$ & $\begin{array}{c}31,0 \\
- \\
24,1\end{array}$ \\
\hline
\end{tabular}

$B^{*}=$ coeficiente de regressão padronizado.

Participantes sob tratamento com anti-hipertensivos foram excluídos da análise da PAD e PAS ( $n=709$ ). Participantes sob uso de antilipémico foram excluídos da análise do colesterol total, HDL-col, LDL-col, triglicérides $(n=775)$. Participantes sob tratamento com antiglicémicos foram excluídos da análise de glicemia ( $n=761)$.

Devido a estas exclusões e missing $(=85)$, os dados referem-se a 690 participantes.

2- ajuste multivariado**: escolaridade (número de séries completadas), fuma (sim, não), consumo de álcool (gramas/dia) e história familiar de hipertensão na análise da pressão arterial ou história familiar de diabete na análise de glicemia. ajuste multivariado com IMC (pressão arterial, glicemia, lipemias e RCQ);

3- ajuste multivariado com IMC (pressão arterial, glicemia, lipemias e RCQ);

4- ajuste multivariado com RCQ (IMC). Ocupação e renda não foram incluídas no ajuste multivariado porque apresentaram alto grau de colinearidade com escolaridade. 
Na regressão linear múltipla bruta (sem ajustes), os escores fatoriais do padrão 1 "cafeteria" associaram-se de modo significativo e positivamente com PAS, PAD e RCQ; de modo significativo e negativamente, com HDL-col.

Os escores fatoriais do padrão 2 "tradicional" associaram-se significativamente após os ajustes e de modo positivo com a glicemia e o IMC e, de modo negativo com os triglicérides e RCQ.

Os escores fatoriais do padrão 3 "moderno" associaram-se negativamente com PAS e PAD, colesterol total, LDL-col e glicemia e também com o IMC no modelo multivariado com RCQ.

Os escores do padrão 4 "aterogênico" associaram-se significativamente e de modo positivo com colesterol total, triglicérides, glicemia, IMC e RCQ.

Essas associações (B) modificaram-se em menos de $10 \%$ após os ajustes sociodemográficos, multivariado e multivariado com IMC, permanecendo porém, significativas.

A pressão sistólica e a diastólica associaram-se positivamente com o padrão 1 "cafeteria" e inversamente com o padrão 3 "moderno", mantendo-se o sinal da associação e a significância, após os ajustes.

O colesterol total mostrou-se inversamente associado com o padrão 3 "moderno" e diretamente com o padrão 4 "aterogênico", mantendo o sinal da associação e significância, após os ajustes.

Os niveis de glicemia mostraram-se associados, inversamente, com o padrão 3 "moderno" e, positivamente, com os padrōes 2 "tradicional" e 4 "aterogênico". 
O HDL-col associou-se de modo inverso com o padrão 1 "cafeteria" após os ajustes. Quanto ao LDL-col, apresentou relação inversa com o padrão 3 "moderno".

Os triglicérides associaram-se de modo negativo com o padrão 2 "tradicional" e positivo com o padrão 4 "aterogênico".

O IMC associou-se de modo positivo com os padrões 1 "cafeteria", padrão 2 "tradicional" e 4 "aterogênico". Apresentou associação negativa com o padrão 3 "moderno" no modelo multivariado com RCQ.

O RCQ associou-se, positivamente, com o padrão 4 "aterogênico" e, de modo negativo com o padrão 2 "tradicional".

Considerando o padrão 1 e a PAS, $O B=0,076$ para o ajuste sóciodemográfico, tem-se que a variação de 1 desvio-padrão no padrão alimentar 1 produz aumento de 0,076 desvio-padrão na PAS.

Considerando o padrão 3 "moderno" e colesterol total, $O B=-0,133$ para o ajuste multivariado (escolaridade, hábito de fumar, consumo de álcool (g/dia), história de doença na família), a variação de um desvio padrão no padrão alimentar 3 produz diminuição de 0,133 desvio-padrão no colesterol total.

Quanto ao HDL-col, para o ajuste multivariado (escolaridade, hábito de fumar, consumo de álcool (g/dia), história de doença na família), a variação de um desvio padrão no padrão alimentar 1 produz diminuição de 0,061 desviopadrão no HDL-col.

Em relação aos triglicérides, a variação de 1 desvio padrão do padrão alimentar 4 produz aumento de 0,223 desvio-padrão. 
Os padrões alimentares explicam $12,9 \%$ da variação dos triglicérides e em $14,1 \%$ a variação da glicemia.

Considerando os valores do $\mathrm{R}^{2}$ (porcentagem de variação na variável dependente que é explicada pela variação na variável independente em análise), observou-se que os padrões alimentares ajustados aos aspectos sociodemográficos (sexo, idade, área homogênea) explicam:

- 21,2\% da variação do colesterol,

- 23,3\% a variação dos triglicérides e da glicemia,

- $17,9 \%$ a variação da PAS e em $19,6 \%$ a variação da PAD,

- 18,5\% a variação do IMC e em $31,0 \%$ o RCQ.

Os padrões alimentares após o ajuste multivariado* explicam $39,2 \%$ a variação do IMC e $33,6 \%$ a variação do triglicérides**.

*ajuste multivariado: escolaridade (número de séries completadas), fuma (sim, não), consumo de álcool (gramas/dia)

*^ajuste multivariado com IMC (pressão arterial, glicemia, lipemias e RCQ). 
O estudo buscou-se identificar padrões de consumo alimentar e verificar associaçōes com reconhecidos fatores de risco para as doenças cardiovasculares, principal causa de morte entre residentes da área urbana do município de São Paulo.

\subsection{Características gerais da amostra estudada}

Segundo dados oficiais (PMSP 2004) a cidade de São Paulo tem população estimada em mais de dez milhōes de habitantes, sendo que aproximadamente $52 \%$ são mulheres e $48 \%$ são do sexo masculino. Está dividida em regiōes: Leste (mais de dois milhões e oitocentos mil habitantes), Norte e Sul (aproximadamente dois milhōes de habitantes, cada uma); Centro (aproximadamente, um milhão e oitocentos mil habitantes) e Oeste (aproximadamente, um milhão e setecentos mil habitantes).

Estudo realizado por MARQUES e TORRES (2005) sugere que a região metropolitana de São Paulo é ocupada por vários grupos sociais muito distintos entre si. Isso vale para grupos mais ricos e para os mais pobres, assim como para a classe média. Os resultados também reforçam a hipótese de que existem várias formas de pobreza. A localização de cada grupo social Ihe confere diferentes oportunidades em termos de acesso - ao mercado de trabalho, às políticas estatais, aos alimentos, bem como o impacto, sobre os habitantes, de diversos elementos ambientais (riscos ambientais, violência, poluição, entre outros).

Deve-se destacar que neste estudo houve muita resistência e recusa em participar por parte dos entrevistados das duas áreas mais privilegiadas, por isso não puderam ser incluídas. Essa foi uma limitação importante. 
6.2 Características gerais quanto ao estilo de vida, estado nutricional e presença de doenças

O estudo verificou as variáveis quanto ao estilo de vida (hábito de fumar, consumo de álcool), antropométricas (IMC, RCQ) e biológicas (pressão arterial, glicemia, triglicérides, colesterol total e frações), por serem importantes fatores de risco para DCV (REGO e col 1990; DUNCAN 1993; FÓRNES, 1998; VAN DAM, 2003).

\subsubsection{Estilo de vida \\ (hábito de fumar e consumo de bebidas alcoólicas)}

Verificou-se que importante parcela dos entrevistados tem o hábito de fumar e consomem bebidas alcoólicas, regularmente.

No estudo de MARCOPITO e col. (2005) os resultados referentes à amostra total (2100 pessoas, ambos os sexos), a prevalência total - ajustada por idade - para o tabagismo foi de $22,6 \%$. Comparados aos resultados do inquérito de 1987 (REGO e col. 1990), a porcentagem de fumantes diminuiu significativamente, porém, continua mais prevalente em homens do que em mulheres.

Segundo dados do Ministério da Saúde (BRASIL 2003) cerca de 33\% da população adulta brasileira fuma, a grande concentração de fumantes tem, entre 20 e 49 anos e os homens fumam em maior proporção que as mulheres em todas as faixas etárias. O consumo de cigarros tendia a ser menor nas classes de maior renda familiar per capita e maior nas de menor rendimento. Dados da Pesquisa Nacional sobre Saúde e Nutrição de (PNSN, 1989) evidenciaram que a prevalência do tabagismo na "baixa renda" - os $25 \%$ mais pobres do país - excede em $50 \%$ a freqüência do tabagismo na "alta renda" os $25 \%$ mais ricos, valendo a afirmação tanto para homens quanto para 
mulheres. Essa diferença se deve em grande parte à maior desinformação das classes sociais economicamente mais pobres, da mesma forma que ocorre em outros paises. Portanto, os dados obtidos em nossa população de estudo quanto ao hábito de fumar, renda e escolaridade são similares aos dados nacionais.

NEUMANN e col. (2005a) realizaram estudo com servidores públicos de sedes de secretarias estaduais do município de São Paulo, ambos os sexos, acima de 18 anos, obtendo-se informaçōes socioeconômicas, de estilo de vida e consumo alimentar, bem como morbidades referidas. Verificaram que $27 \%$ eram fumantes.

Em recente pesquisa realizada pelo Instituto Nacional do Câncer (INCA) e Secretaria de Vigilância em Saúde do Ministério da Saúde - Inquérito Domiciliar sobre Comportamentos de Risco e Morbidade Referida de Doenças e Agravos não Transmissíveis no Brasil - 15 capitais e distrito federal (BRASIL 2004) verificou, entre outros, no município de São Paulo, $20 \%$ de fumantes regulares de cigarro. Entre os homens o percentual foi de $23 \%$.

No Brasil, a prevalência do uso de bebidas alcoólicas é maior em homens, em todas as faixas etárias, segundo estudo realizado por CARLINI e col. (2002) em cento e sete cidades com mais de duzentos mil habitantes. $86 \%$ dos homens relataram uso de álcool, contra $68 \%$ de mulheres entre 25 e 34 anos.

No levantamento realizado com amostra probabilística em vinte e quatro cidades do estado de São Paulo constatou-se que o álcool e o tabaco foram as drogas com maiores prevalências de uso, $53,2 \%$ e $39,0 \%$, respectivamente. As estimativas quanto à dependência de álcool estiveram em torno de $6 \%$, valores próximos aos estudos de outros paises (CARLINI e col 2002). 
Este estudo ficou limitado quanto à utilização de importante variável sobre o estilo de vida. A classificação do nível de atividade física, segundo os critérios adotados pela OMS (PAFFENBARGER 1993; MATSUDO 1997), utilizando as questōes do bloco J: $\mathrm{J} 67$ e $\mathrm{J72}$, resultaram em informaçōes incoerentes, não sendo possível utilizar tal variável.

\subsubsection{Estado nutricional e presença de doenças} (peso corporal, pressão arterial, perfil lipídico e glicemia)

Os resultados encontrados foram, no minimo, preocupantes. Verificouse que mais de $30 \%$ dos participantes apresentaram sobrepeso e mais de $18 \%$, obesidade; menos de $3 \%$ de pessoas com déficit de peso. Outra informação preocupante: $43 \%$ das pessoas eram portadoras de obesidade central, dada pela relação cintura quadril.

No estudo realizado por REGO e col. (1990) no município de São Paulo em 1987, foi observada prevalência de obesidade para homens de $14,2 \%$ e de $21,4 \%$ para mulheres, totalizando $18 \%$, em média.

No estudo de MARCOPITO e col. (2005) as prevalências totais ajustada por idade, na faixa etária de 15-59 anos, foram de 13,7\% para obesidade e $19,7 \%$ para circunferência abdominal aumentada.

CERVATO e col. (1997) e FÓRNES (1998) observaram prevalência de obesidade em $38 \%$ dos indivíduos em área metropolitana de São Paulo, bem como a obesidade centralizada.

Dados do Ministério da Saúde (BRASIL 2003) revelaram que existem no Brasil vinte e sete milhões de indivíduos adultos com sobrepeso e obesidade (IMC superior a $25 \mathrm{~kg} / \mathrm{m}^{2}$ ), correspondendo a $32 \%$ da população adulta, sendo dezesseis milhões no sexo feminino (38\%) e onze milhões no 
sexo masculino (27\%). A freqũência do sobrepeso e da obesidade nos adultos eleva-se gradativamente com a idade até os 54 anos de idade. A maior prevalência de excesso de peso encontra-se na faixa etária entre 45 a 54 anos, sendo $37 \%$ dos homens e $55 \%$ das mulheres (FIBGE 2004; COSTA-LEVY 2005). Portanto, os resultados obtidos neste estudo têm certa concordância com os resultados nacionais, no sentido de que nossa população vem, continuamente, aumentando o peso corporal ao longo das últimas décadas.

No estudo de NEUMANN e col (2005a), realizado com servidores públicos estaduais do municipio de São Paulo, verificou-se a presença de sobrepeso/obesidade em $36 \%$ na amostra estudada.

No presente estudo foram utilizados para a análise os critérios mais recentes estabelecidos por organismos nacionais e internacionais, como os valores para pressão arterial (SBC, 2004), para a glicemia (ADA 2003; SBD, 2003) e dosagens de triglicérides, colesterol total e fraçōes (SBC 2001). Portanto, comparações externas com resultados de outros estudos brasileiros são dificeis de serem feitas porque as estatísticas comparáveis foram obtidas em diferentes áreas urbanas e em diferentes pontos do tempo. Assim, os resultados deste estudo tornam-se dificeis de serem comparados com outros estudos realizados no Brasil.

No estudo de MARCOPITO e col (2005), as prevalências totais, ajustadas por idade, foram: pressão arterial não controlada, 24,3\%; obesidade, 13,7\%; RCQ aumentada, 19,7\%; colesterol total $\geq 240 \mathrm{mg} / \mathrm{dl}, 8,1 \%$; HDL-col $\leq$ $40 \mathrm{mg} / \mathrm{dl}, 27,1 \%$; triglicérides $\geq 200 \mathrm{mg} / \mathrm{dl}, 14,4 \%$ e glicemia $\geq 110 \mathrm{mg} / \mathrm{dl}, 6,8 \%$. Pressão arterial não controlada, colesterol elevado, HDL-col diminuído e triglicérides elevados foram significantemente mais prevalentes em homens do que em mulheres. Comparados aos resultados do inquérito de 1987 (REGO e col 1990), a porcentagem de pressão arterial não controlada permaneceu semelhante. 
Alguma comparação também pode ser feita com estudos realizados em população da área metropolitana de São Paulo. No estudo de FÓRNES (1998) uma parcela importante apresentou níveis lipêmicos séricos acima do desejado, correspondendo a $35 \%$ para colesterol total e $33 \%$ para LDL-col. Mais de $\mathbf{2 0} \%$ apresentou níveis de HDL-col abaixo dos valores recomendados.

Dados do Ministério da Saúde (BRASIL 2003) revelaram também que existem no Brasil mais de $\mathbf{4 0} \%$ de pessoas com pressão arterial alterada; $25 \%$ de pessoas com hiperglicemia; $35 \%$ colesterol alto; mais de $40 \%$ HDL-col abaixo dos niveis considerados ideais; mais de $65 \%$ com LDL-col acima dos níveis normais e, cerca de $27 \%$ com triglicérides altos.

Verificou-se, portanto, que os participantes do estudo apresentam altas proporções de fatores de risco bem definidos na etiologia das dislipidemias e, conseqüentemente, fatores de risco para DCV.

O crescimento da incidência de DCNT observado nas últimas décadas relaciona-se, em grande parte, com os hábitos de vida adquiridos nesse período. Entre eles, destacam-se os comportamentos que desequilibram o balanço energético, induzindo ganho excessivo de peso. Estima-se que, para cada $5 \%$ de aumento de peso acima daquele apresentado aos 20 anos de idade, ocorre aumento de $200 \%$ no risco de desenvolver a síndrome metabólica na meia idade (EVERSON e col. 1998). Esse complexo metabólico, inflamatório e hemodinâmico - caracterizado por associar obesidade abdominal, resistência à insulina, hipertensão arterial, hipertrigliceridemia e níveis séricos baixo de HDL-col - por sua vez, está associado ao desenvolvimento da doença cardiovascular, entre outras DCNTs (SHIMIDT e col. 2003; LORENZO e col. 2003). 


\section{3 Padrões de alimentação}

Vários estudos em epidemiologia nutricional têm utilizado, mais recentemente, a metodologia de identificação de padrões de consumo com base na técnica de análise de componentes principais (SLATTERY e col. 1998; HU e col. 1999a; FUNG e col. 2001a, 2001b; MILLEN e col. 2001; SHICHIERI e col 2003; MARCHIONI, 2003; MARCHIONI e col 2005; CORDEIRO 2003; KERVER e col. 2003; VAN DAM 2003; QUATROMONI e col 2002; LEDIKWE e col 2004; KHANI e col 2004; YANG e col 2005; JORGE, 2005).

Quando se estuda a alimentação, deve-se levar em consideração que as pessoas consomem os nutrientes que necessitam a partir da escolha dos alimentos. Tal escolha é influenciada por fatores culturais, sociais e demográficos. Portanto, a verificação do conjunto de alimentos que formam a dieta - mistura complexa de compostos bioquímicos que podem competir entre si ou até alterar a biodisponibilidade de outros compostos químicos - é de importância fundamental (WILLETT 1998; SLATTERY e col. 1998).

O presente estudo permitiu caracterizar quatro padrōes de consumo entre os indivíduos amostrados, por meio da análise de componentes principais de residentes da cidade de São Paulo - formada por migrantes e imigrantes de todas as partes do Brasil e do mundo - que contribuíram para a formação dos hábitos alimentares, costumes e tradições paulistanas (PMSP 2004).

No padrão 1 - "cafeteria" ou "fast-food" houve predomínio de alimentos fonte de gorduras saturadas e sal (alimento/grupo: leite integral, presunto, massas, salgados, feijoada, frango, gorduras), carboidratos simples e amido (doces, sucos artificiais, refrigerante comum, pães, massas, salgados). Tais alimentos são, em geral, de alta densidade calórica, altamente processados e, geralmente, pobres em micronutrientes. O consumo de alimentos de excepcional densidade energética, tipicamente oferecidos por serviços de fast food, promove o aumento de peso corporal e, conseqüentemente permitem o 
desenvolvimento da obesidade (PRENTICE e col. 2003; WHO 2004; BARRETO e col. 2005). Não há evidência de que alimentos ricos em gordura mereçam maior atenção na prevenção da obesidade do que outros alimentos com alta densidade energética, como aqueles ricos em amido ou carboidratos simples (ASTRUP e col. 2000; WILLETT e col. 2002).

Em oposição a esses alimentos, estão aqueles de baixa densidade calórica, ricos em água, fibras e micronutrientes (potássio, magnésio, ácido fólico, entre outros) como frutas, verduras e legumes. $O$ aumento na ingestão de frutas e vegetais reduz a densidade energética e aumenta a quantidade de alimentos que pode ser consumida para um determinado nivel de calorias, aumentando a saciedade (ROLLS e col. 2004).

Além disso, frutas e vegetais tem baixo índice glicêmico (IG). Em hipótese, aumentariam a saciedade, mas esse efeito ainda não está comprovado de forma convincente. O IG é alto, por exemplo, para certos tipos de amido, como os presentes no pão branco, cereais matinais, batata, arroz branco, massas (COSTA e ALMEIDA NETO 1998; WHO 2004; BARRETO e col. 2005).

Alimentos com alto IG têm sido apontados como possivel co-fator da obesidade. Estudos preliminares sugerem que esses alimentos provocam mais fome após as refeiçōes. A hipótese é de que niveis diferentes de glicemia provocariam diferentes respostas hormonais na regulação do apetite (DILIBERTI e col. 2004).

O consumo freqüente de refrigerantes também tem sido associado ao ganho de peso, que pode ser explicado pelos efeitos fisiológicos da ingestão de energia sobre a saciedade, que são diferentes para líquidos e para alimentos sólidos (COSTA e col. 1998; LUDWIG e col. 2001). 
O padrão 2 - "tradicional" agrupou alimentos "tradicionais" da alimentação do povo brasileiro: arroz, feijão, verduras, legumes e café, fontes de energia, proteínas micronutrientes, fibras. Cabe salientar que neste padrão também estão presentes maioneses e outras gorduras.

Estudo experimental conduzido no Brasil sobre a utilização do amido de leguminosas mostrou que um tempo maior de cocção poderá facilitar a hidrólise e velocidade de absorção dos carboidratos, aumentando seu IG. Além do feijão o rompimento da estrutura da casca de outros alimentos, como os cereais (milho em forma de pipoca e aveia), vem sendo apontado com fator modificador de seu IG, sugerindo a necessidade de se considerar a integridade dos grãos (MENEZES e LAJOLO 1995; VENN e MANN 2004).

A disponibilidade domiciliar de alimentos no Brasil, cuja principal base de dados são as POF (FIBGE 1977, 1991, 1997, 2000, 2004), evidenciam o predomínio de consumo de arroz polido, desprovido da casca, cujo IG é maior quando comparado ao arroz e outros cereais integrais (WHO 2003; BARRETO e col. 2005).

O padrão 3 - "moderno" (leite desnatado, frutas, sucos naturais, peixes, refrigerante diet, adoçantes artificiais - em menor proporção: pães, não folhosos e sopas) é caracterizado por alimentos com menor teor de gorduras saturadas e açúcares simples e maior teor de gorduras insaturadas (ômega 3 peixes), fibras e micronutrientes. O QFA empregado neste estudo, não permitiu a verificação do consumo de pães e ou produtos confeccionados com cereais integrais. É provável que os indivíduos com este padrão alimentar façam uso dos alimentos citados, aumentando assim o teor de fibras e outros micronutrientes.

Faz parte das recomendações da estratégia global relativa à alimentação o alcance do balanço energético e peso saudável, a redução de alimentos de alta densidade calórica, o aumento da ingestão de fibras, de 
frutas e vegetais, limitar o consumo total de gorduras e redirecionar o consumo de gordura não saturadas, eliminar o consumo de gorduras hidrogenadas, entre outra recomendaçōes (WHO 2003; BARRETO e col. 2005).

O padrão 4 - "aterogênico" (feijoada, carne de boi e miúdos, porco, frango, lingūiça, ovo, bebidas alcoólicas, sal), caracteriza-se por conter alimentos com alto teor de gorduras saturadas, colesterol, igualmente ricos em sódio e o álcool; baixo ou nenhum teor de fibras e outros micronutrientes, encontrados em alimentos vegetais. Existe evidencias convincentes de que tais alimentos aumentam o risco de DCV (WHO 2003)

Em estudo prévio utilizando este mesmo banco de dados (NEUMANN 2005b), verificou-se o consumo de frutas e vegetais pela população urbana do município de São Paulo. Os resultados mostram que, considerando a população amostra de 782 indivíduos, $55, \%$ consomem frutas; aproximadamente $47 \%$ consomem verduras e apenas $41 \%$ consomem legumes - 5 vezes ou mais por semana. Dentre as verduras, o grupo mais consumido é aquele em que aparece a alface $-53,3 \%$ da população estudada. Dentre os chamados "legumes", $37,9 \%$ referem consumir tomate e $33,3 \%$, a cenoura. Entre as frutas, as mais consumidas são, respectivamente, a laranja $(37,9 \%)$, banana $(30,1 \%)$ e maçã $(10,8 \%)$. As demais frutas (mamão, melancia, melão, goiaba, abacate abacaxi, etc.) são consumidas por menos de $10 \%$ da população.

SICHIERI e colaboradores (2003) avaliaram os fatores que explicariam diferentes padrōes de consumo alimentar da população urbana brasileira, com base na Pesquisa sobre Padrões de Vida (PPV), utilizando a metodologia de análise de componentes principais. Obteve dois padrōes de consumo: misto (tubérculos, legumes, verduras, frutas, pães, bolos, macarrão, biscoitos,açúcar, leite e derivados, frango, carnes) e tradicional (arroz e outros cereais, feijão, farinha mandioca, açúcar, macarrão). Uma das conclusōes a que chegaram é que a caracterização de padrões de consumo reforça a idéia de que os fatores 
determinantes das doenças surgem da forma combinada com que os diversos nutrientes interagem entre si.

FUNG e col. (2001b) em estudo utilizando metodologia semelhante, identificaram entre as enfermeiras americanas um padrão de dieta chamado de "prudente" e "ocidental". O "padrão ocidental" - caracterizou-se por apresentar consumo elevado de carnes vermelhas, produtos lácteos integrais e cereais refinados; o "prudente" - caracterizou-se por conter grande quantidade de frutas e vegetais, cereais integrais e aves. Tais padrōes de consumo alimentar foram associados com a obesidade e com risco cardiovascular. Uma das conclusōes a que chegaram é que a identificação de padrões auxilia na avaliação do risco de doenças e servem para subsidiar a elaboração de guias alimentares para consumo de alimentos saudáveis.

Estudo realizado por VAN DAM e col. (2003) na população holandesa identifica três padrōes alimentares: "cosmopolita" (consumo de grande quantidade de vegetais fritos, saladas, arroz, frango, peixe e vinho); padrão "tradicional" (consumo de grande quantidade de carne vermelha e batatas, pequenas quantidades de produtos lácteos pobres em gordura e frutas); padrão "alimentos refinados" (consumo de grandes quantidades de batatas fritas, bebidas açucaradas, pão branco e pequenas quantidades de pães feitos com cereais integrais e vegetais cozidos). Tais padrōes alimentares associaram-se com vários outros fatores de risco para DCV, que serão discutidos adiante.

O estudo realizado por KERVER e col. (2003) sobre padrões alimentares (utilizando também análise fatorial) associados com fatores de risco para DCV em população adulta sadia norte-americana identificou, a principio, seis padrōes alimentares, porém dois padrōes mostraram-se mais predominantes: o "padrão ocidental" - caracterizado por consumo de grande quantidade de carnes processadas, ovos, carnes vermelhas e alto consumo de produtos lácteos integrais - e o "padrão americano saudável" - caracterizado 
por consumo de grande quantidade de vegetais verdes folhosos, molhos para salada, tomates e outros vegetais (ervilhas e outros grãos, milho, pimenta), vegetais cruciferos e chás. Concluiu também que a identificação de padrões de consumo alimentar mostrou-se adequada para caracterizar grupos populacionais de alto risco entre os cidadãos americanos e um método adequado para avaliar consumo alimentar quando associado a outros fatores de risco para DCV.

\section{4 Padrões alimentares e variáveis sociodemográficas e comportamentais}

Ao comparar resultados entre estudos, não se pode perder de vista as diferenças existentes entre os métodos usados para a coleta e classificação dos dados de inquéritos dietéticos, pois variam muito. Algumas comparaçōes são pertinentes à medida que reforçam tendências de consumo.

Os resultados mostraram predominância de consumo do padrão alimentar "fast-food" entre aqueles com escolaridade média e superior e que residem em local com boas condiçōes sócio ambientais, assim como o padrão tradicional. A associação com a renda familiar não foi significativa, porém é bem provável que este grupo tenha rendimentos familiar mais altos.

Tais achados estão parcialmente de acordo com os resultados da POF 2002-2003 (COSTA-LEVY e col. 2005), que evidenciaram padrōes distintos de relação entre os rendimentos e o grupo açúcar e refrigerantes. No caso do açúcar, há aumento ligeiro com os rendimentos até um salário-minimo per capita e depois um forte declínio, de modo que o consumo de açúcar na classe de maiores rendimentos foi $\mathbf{5 0 \%}$ inferior ao observado na classe de menores rendimentos. No caso dos refrigerantes, houve aumento intenso e contínuo com os rendimentos, de modo que a participação de refrigerantes na dieta foi cinco vezes maior na classe de maiores rendimentos do que na classe de 
menores rendimentos. A evolução nas áreas metropolitanas do País evidenciou aumentos de até $400 \%$ no consumo de produtos industrializados, como biscoitos e refrigerantes, persistência do consumo excessivo de açúcar e insuficiente de frutas e hortaliças e aumento no teor da dieta em gorduras em geral e gorduras saturadas.

$O$ resultados da POF (FIBGE, 2004) também evidenciaram que alguns alimentos se destacam na relação com os rendimentos, como o arroz, cujo consumo cai na medida em que aumenta a renda das famílias. O contrário acontece com pães e biscoitos, cuja participação na dieta tende a aumentar com o aumento dos rendimentos.

O padrão moderno associou-se com a idade entre 30-39 anos; também associou-se com a escolaridade e renda superior, local de residência com melhores condições sócio ambientais. Segundo MONDINI e MONTEIRO (2000), uma hipótese seria atribuir o declínio no consumo desses alimentos a uma atitude consciente da população das áreas mais desenvolvidas em prol de uma dieta mais saudável. A restrição a frituras e a redução no consumo de alimentos ricos em colesterol são duas das mais freqüentes mensagens educativas que vêm sendo divulgadas por profissionais de saúde e por meios de comunicação de massa.

Já o padrão aterogênico que mostrou-se predominante entre aqueles com idade entre 40-49 anos, com menor escolaridade, local de residência com condições sócio ambientais relativas, com o hábito de fumar e consumo de bebidas alcoólicas, parece concordar, em parte com o estudo realizado por VAN DAM e col. (2003) na população holandesa, citado anteriormente. Os mais altos escores do padrão "tradicional" desse estudo estavam associados com os indivíduos com idade mais avançada e os mais altos escores do padrão "alimentos refinados" se associaram os individuos mais jovens, porém ambos estavam associados com nivel educacional mais baixo, hábito de fumar, menor atividade física e IMC elevado. 
Nota-se neste estudo que as áreas sócio-ambientais categorizadas como baixa ( $27,3 \%$ da população, composta por 20 distritos) e muito baixa (10,8\% da população, composta por nove distritos) obtiveram as menores médias dos escores dos padrões de consumo. Tais áreas são compostas por grupos sociais com menores possibilidades de escolha em razão da pobreza e da exclusão social.

Em recente publicação sobre segregação, pobreza e desigualdades sociais na cidade de São Paulo, MARQUES \& TORRES (2005) mostram que ser pobre próximo do centro da cidade é diferente do que em área distante; morar em áreas mais ricas aumenta o acesso da população de baixa renda a, por exemplo, serviços públicos. Como exemplo, citam que homens pobres da periferia têm menos chances de concluir o ensino médio $(19,9 \%)$ do que mulheres pobres da mesma regiāo $(34,4 \%)$ e menos ainda do que as que habitam áreas mais ricas (42,4\%). Por outro lado, morar na favela Paraisópolis, situada em uma região com mais dinamismo econômico e estrutura assistencial, é mais vantajoso do que residir em um conjunto habitacional na cidade Tiradentes, no extremo da zona leste, longe das oportunidades de emprego e com menos assistência. Conclui-se que as políticas sociais têm que levar em conta os territórios onde residem as populações.

O estudo realizado por SICHIERI (2003) também constatou que escolaridade e renda foram as variáveis que mais explicaram o consumo alimentar, ainda assim a região de residência foi o terceiro maior componente explicativo. Neste estudo, verificou-se também que a variável local de residência, segundo as áreas homogêneas propostas por SPOSATI (1996), apresentou diferença estatisticamente significativa entre as médias dos escores dos padrões, ajustadas por sexo e idade.

Estudo realizado por YANG e colaboradores (2005) com imigrantes coreanos (Kas) residentes nos Estados Unidos, verifica as relaçōes entre os padrōes alimentares dessa população e características sócio-demográficas e 
concluiu que a análise de tais padrōes pode ser usada para entender comportamentos alimentares relacionados aos riscos à saúde de imigrantes, pois as preferências alimentares podem sofrer mudanças em decorrência da disponibilidade de alimentos e diferenças nas circunstâncias sociais.

6. 5 Padrões de alimentação da população de estudo associados aos fatores de risco para doenças cardiovasculares

Vários estudos já foram realizados identificando padrōes dietéticos, obtidos por meio de análise fatorial e posteriormente associando-os a fatores de risco comportamentais e biológicos para doenças cardiovasculares (APPEL e col. 1997; DE LORGERIL e col, 1999; HU e col. 2000; FUNG e col. 2001a, 2001b; BAZZANO e col. 2002; VAN DAM e col 2003; KERVER e col 2003).

FUNG e col. (2001a), em estudo comentado anteriormente, utilizando metodologia semelhante, identificaram entre as enfermeiras americanas, um padrão de dieta chamado de prudente e ocidental. Este último associou-se positivamente com as DCV.

Neste estudo, identificou-se que, em relação aos níveis pressóricos, os escores fatoriais do padrão "fast-food" associaram-se de modo significativo e positivamente com PAS e com PAD e os escores fatoriais do padrão 3 "moderno", de modo negativo com a pressão arterial.

No estudo de VAN DAM e col. (2003), já citado, os mais altos escores do padrão "cosmopolita" estavam, significativamente, associados com níveis pressóricos mais baixos e com mais altas concentrações de HDL-col, independentemente dos fatores relacionados ao estilo de vida e IMC. 
Quanto ao peso corporal, os escores fatoriais do padrão 3 "moderno" se associaram negativamente com este, no modelo ajustado com a relação cintura-quadril, ou seja, com a distribuição de gordura corporal.

Em relação ao sobrepeso/obesidade, os escores fatoriais dos padrōes 1 "cafeteria", 2 "tradicional" e 4 "aterogênico" associaram-se positivamente.

No estudo de SICHIERI e col. (2003), o IMC associou-se positivamente ao padrão alimentar misto (tubérculos, legumes, verduras, frutas, pães, bolos, macarrão, biscoitos, açúcar, leite e derivados, frango, carnes). O padrão de consumo tradicional (arroz e outros cereais, feijão, farinha mandioca, açúcar, macarrão) que no Brasil é em grande parte determinado pelas condiçōes sócioeconômicas, mostrou-se como fator de proteção para sobrepeso.

Verificou-se também que os escores fatoriais do padrão 1 "cafeteria" associaram-se de modo significativo com a RCQ.

Quanto à glicemia, os escores fatoriais dos padrões 2 "tradicional" e 4 "aterogênico" associaram-se positivamente e os escores fatoriais do Padrão 3 "moderno" associaram-se negativamente.

Sabe-se que o potencial de um alimento ou de uma dieta em influenciar no aumento do colesterol total e LDL-col está diretamente relacionado ao conteúdo de colesterol e sua quantidade de gordura saturada (WHO 2003). Como era esperado, verificou-se que, quanto ao colesterol total, os escores fatoriais do padrão 4 "aterogênico" associaram-se positivamente e o padrão 3 "moderno" associaram-se negativamente.

Em relação ao HDL-col - "bom colesterol", somente os escores fatoriais do padrão 1 "cafeteria" estavam associados e de forma negativa; enquanto que o LDL-col, o chamado "mau colesterol", somente os escores fatoriais do padrão 3 "moderno" estavam associados negativamente. 
VAN DAM e col. (2003) encontraram que os mais altos escores do padrão "cosmopolita" estavam, significativamente, associados com niveis pressóricos mais baixos e com mais altas concentrações de HDL-col, independentemente dos fatores relacionados ao estilo de vida e IMC. Os escores mais altos do padrão "tradicional" mostraram-se associados com os maiores niveis de pressão arterial e HDL-col, colesterol total e glicemia. Os escores do padrão "alimentos refinados" estavam associados com as mais altas concentrações de colesterol total e baixo consumo de micronutrientes.

Quanto aos triglicérides, os escores fatoriais do padrōes 2 "tradicional" e 4 "aterogênico" se associaram positivamente.

KERVER e col. (2003) em seu estudo, citado anteriormente, verificaram que o padrão alimentar denominado "ocidental" associou-se positivamente com níveis séricos de insulina, proteína-C, hemoglobina glicosilada e associação inversa com concentraçōes de folato em células vermelhas do sangue, no modelo ajustado com as variáveis de confusão. $O$ padrão chamado de "americano saudável" não se correlacionou com as variáveis examinadas. Concluiu-se que, além da identificação de padrões de consumo alimentar mostrar-se adequada para caracterizar grupos populacionais de alto risco para DCV.

As associaçōes observadas neste estudo, entre os escores dos padrões alimentares e os fatores de risco biológicos foram, de forma geral, os resultados esperados. Apenas a associação positiva entre os escores do padrão 2 "tradicional" com o sobrepeso/obesidade e glicemia causou surpresa, visto que, tal padrão é composto por alimentos tradicionais da alimentação do povo brasileiro. É bem provável que outros fatores relacionados aos hábitos comportamentais, principalmente a inatividade fisica, possam estar interferindo na relação entre a alimentação, o peso corporal e a glicemia. 
O conjunto dos resultados encontrados apontam para tendências desfavoráveis do padrão alimentar, sobretudo do ponto de vista do aumento do peso corporal, perfil lipídico alterado, principalmente aos padrões 1 e 4 ("fastfood" e aterogênico), padrōes com alta densidade energética, escassez de fibras, micronutrientes, excesso de gorduras em geral e de gorduras saturadas, bem como alimentos com alto índice glicêmico (WHO 2003).

Apenas o padrão alimentar 3 ("modemo") caracterizado por conter alimentos com baixos teores de gorduras e açúcares simples, frutas, peixes, entre outros, mostrou-se estar em concordância com as atuais recomendações sobre alimentação saudável e prevenção de doenças (WHO 2003; BARRETO 2005). Porém tal padrão alimentar está restrito a pessoas com nível de renda e educacional superior e áreas sócio-ambientais mais privilegiadas. 


\section{CONSIDERAÇÕES FINAIS}

O crescimento das DCNTs e, em especial, das DCVs constitui-se em importante problema de saúde pública deste século, por sua elevada morbimortalidade, por suas repercussōes na qualidade de vida (REGO e col 1990; LESSA 1995; BRASIL 2000). Entretanto, mudanças neste perfil têm sido possíveis por meio da melhoria nas condiçōes de vida e nível de informação da população, bem como medidas de intervenção em saúde por meio da redução da exposição a fatores de risco conhecidos que participam da gênese destes agravos, entre eles os fatores ligados a alimentação (WILLETT 1998).

São necessárias medidas para conscientizaçāo da população em relação à associação dieta/saúde, a importância de uma alimentação saudável no controle de doenças crônicas e uma melhor escolha e compra de alimentos. É sabido que os fatores culturais estão muito presentes na determinação da escolha da alimentação, tornando a informação insuficiente para promover mudanças (HAGDRUP e col. 1998; BRASIL 2000).

De acordo com a experiência de outros países, mudanças de hábitos e comportamento requerem esforço coletivo - políticas de saúde mais abrangentes objetivando uma reestruturação do comércio de alimentos e a valorização de padrões de consumo alimentares mais saudáveis, principalmente entre aqueles que estão nas camadas mais pobres e com menor nível de instrução.

Vários programas de prevenção e promoção de saúde já foram desenvolvidos no mundo todo, obtendo resultados positivos no controle de doenças crônicas (CDC 1989; PUSKA e col. 1985; OMS, 1990; US DHHSS, 1991; SUBAR e col. 1992, 1995; FONSECA 1996; TRUSWEL 1998; MEDINA 1998; SES 2002; PUSKA 2003). 
Experiências de sucesso de intervençōes de Saúde Pública com reversão e com mudanças positivas nas tendências de morbi-mortalidade por DCV, em diversos paises, mostram que alguns aspectos são cruciais para o desenvolvimento de estratégias efetivas de promoção da saúde na população geral. Mudanças positivas no estilo de vida - que são largamente determinados pelo ambiente fisico, socioeconômico e cultural - têm retorno direto sobre a saúde, em qualquer estágio da vida ou condição preexistente de saúde.

A proposta contida na Estratégia Global para Alimentação, Atividade Física e Saúde, da Organização Mundial da Saúde, conjunto de medidas de intervenção comunitária para mudanças no estilo de vida e adoção de padrōes mais saudáveis devem ser sustentáveis no longo prazo, necessitando da participação e parceria dos diversos setores e atores sociais e econômicos, locais e nacionais, responsáveis e comprometidos com a saúde e a qualidade de vida da população, devendo incluir todos os grupos sociais, especialmente aqueles com menores possibilidades de escolha em razão da pobreza e da exclusão social (WHO 2004; OPAS 2003; BARRETO e col. 2005). 


\section{8}

\section{CONCLUSÕES}

Os resultados do estudo "Padrões de consumo alimentar associado a outros fatores de risco predisponentes às doenças cardiovasculares em residentes da área urbana do municipio de São Paulo", realizado entre 2001-2, identificou que importante parcela dos entrevistados tem o hábito de fumar e de consumir bebidas alcoólicas regularmente, estão acima do peso desejável, tem níveis pressóricos elevados e perfil lipídico alterado.

Identificou quatro padrões alimentares que estão significativamente associados aos fatores sociodemográficos (sexo, grupo etário, escolaridade, renda e, principalmente, com o local de moradia), comportamentais (hábito de fumar e consumo de bebidas alcoólicas) e biológicos (peso corporal, pressão arterial, glicemia e perfil lipídico).

Três dos padrōes identificados ("fast-food", tradicional" e "aterogênico") associaram-se de modo significativo com fatores sociodemográficos, comportamentais e biológicos para DCV - aumento dos niveis pressóricos, do colesterol total e frações, da glicemia e aumento do peso corporal.

Apenas o padrão alimentar caracterizado por conter alimentos com baixos teores de gorduras e açúcares simples mostrou-se inversamente associado aos FR biológicos.

Observou-se baixo consumo de todos padrōes alimentares nas áreas homogêneas categorizadas como baixa e muito baixa.

O padrão alimentar "moderno" apresentou consumo mais elevado entre os indivíduos da área homogênea categorizada como alta e ocupação diferenciada (empregador). 
IV Diretrizes Brasileiras de Hipertensão Arterial. Arq Bras Cardiol 2004; 82; Supl IV. [on line]. Disponivel em URL <http://www.cardiol.br/dha/consenso>. [2005 set 15].

[ADA] - Report of the Expert Committee on the Diagnosis and Classification of Diabetes Mellitus. Diabetes Care 2003; 26:3160-7.

[AHA] American Heart Association. Dietary guidelines for healthy American adults. New York: American Heart Association; 1998.

Akerman M, Campanato P, Maia PB. Saúde e meio ambiente: análise de diferenciais intra-urbanos, municipio de São Paulo, Brasil. Rev Saude Pública 1996; 30(4): 372-82.

Appel LJ, Moore TJ, Obarzanek E, et al. A clinical trial of the effects of dietary patterns on blood pressure. DASH Collaborative Research Group. N Engl J Med 1997;336:1117-24.

Araújo $E$ AC. Diferenciais dos fatores de risco cardiovascular nas populações migrantes e não-migrantes de Minas Gerais. São Paulo; 2002. [Tese de Doutorado. Faculdade de Saúde Pública da USP].

Armitage P, Berry G - Statistical methods in medical research, 3rd. ed. Cambridge: 1994; University Press. 620p.

Aro A, Jauhiainen M, Partanen R, Salminen I, Mutanen M. Stearic acid, trans fatty acids, and dairy fat: effects on serum and lipoprotein lipids, apolipoproteins, lipoprotein(a), and lipid transfer proteins in healthy subjects. Am J Clin Nutr 1997; 65(5):1419-26. 
Astrup A, Grunwald GK, Melanson EL, Saris WH, Hill JO. The role of low-fat diets in body weigth control: a meta-analisys of ad libitum dietary intervention studies. Int J Obes Relat Met Dis 2000; 24: 1545-52.

Barreto SM, Pinheiro ARO, Sichieri R, Monteiro CA, Batista Filho, M, Shimidt M, et al. Análise da estratégia global para alimentação, atividade física e saúde da Organização Mundial da Saúde. Epidemiologia e Serviços de Saúde 2005; 14(1): 41-68.

Bazzano LA, He J, Ogden LG, et al. Fruit and vegetable intake and risk of cardiovascular disease in US adults: the first National Health and Nutrition Examination Survey Epidemiologic Follow-up Study. Am J Clin Nutr 2002; 76:93-9.

Beaghole R, Saracci R, Panico S. Cardiovascular diseases: causes, surveillance and prevention. Int J Epidemiol 2001; 30:S1-4.

Bertolami M, Faludi AA, Latorre MRDO, Zaidan FOT. Perfil lipídico de funcionários de indústria metalúrgica e sua relação com outros fatores de risco. Arq Bras Cardiol 1993; 60:293-9.

Bertrand E. Cardiovascular disease stoppable in developing countries? World Health Forum 1997; 18:163-8.

Bloch KV. Fatores de risco cardiovasculares e para o diabetes mellitus. In: Lessa I. $\mathbf{O}$ adulto brasileiro e as doenças da modernidade. Epidemiologia das doenças crônicas não-transmissíveis. São Paulo: Hucitec; 1998. p. 4372. 
Ministério da Saúde. Estatísticas de mortalidade - 1989. Brasília (DF); 1993.

Brasil. Conselho Nacional de Saúde. Regulamentação de pesquisas envolvendo seres humanos. Resolução no 196/96. Brasília (DF); 1996.

Brasil. Ministério da Saúde - Estudo multicêntrico sobre consumo alimentar. Cadernos de Debate (volume especial), 1997. Campinas, NEPAUnicamp. $62 p$.

Ministério da Saúde. Secretaria de Políticas de Saúde; Departamento de Formulação de Políticas de Saúde. Política Nacional de Alimentação e Nutrição. Brasília (DF); 2000.

Brasil. Ministério da Saúde. Fundação Nacional de Saúde. Vigilância Epidemiológica. Vigilância e monitoramento de doenças e agravos não transmissiveis.[on line]. Disponivel em URL<http://w.w.w.funasa.gov.br/epi/ntransmi/epi_ntransmi_00.htm $\left[\begin{array}{ll}2003 & \text { jul }\end{array}\right.$ 20].

Brasil. Ministério da Saúde. Secretaria de Vigilância em Saúde. Instituto Nacional do Câncer. Inquérito Domiciliar sobre Comportamentos de Risco e Morbidade Referida de Doenças e Agravos não Transmissíveis no Brasil - 15 capitais e Distrito Federal. Rio de Janeiro, 2004 [on line]. Disponivel em URL <http://w.w.w.inca. gov.br >. [2005 ago 10].

Bulliyya G, Reddy PC, Reddy KN, Reddanna P. Fatty acid profile and the atherogenic risk in fish consuming and non fish consuming people. Indian $\mathrm{J}$ Med Sci 1994; 48(11): 256-60. 
Buss PM Assistência hospitalar no Brasil (1984-1991): uma análise preliminar baseada no Sistema de Informação Hospitalar do SUS. Inf Epidemiol SUS 1993; 2 (1):5-44.

Callaway CW, Chumlea WC, Bouchard C, Himes JH, Lohman TG, Martin AD, Mitchell CD, Mueller WH, Roche AF, Seefeldt VD - Circumferences. In: Antropometric standardization reference manual. Lohman TG, Roche AF,

Cardoso MA, Kida AA, Tomita LY, Stocco, PR. Reproducibility and validity of a food frequency questionnaire among women of Japanese ancestry living in Brazil. Nutr Res 2001; 21 (5): 725-33.

Cardoso MA, Stocco PR. Desenvolvimento de um questionário quantitativo de freqüência alimentar em imigrantes japoneses e seus descendentes residentes em São Paulo, Brasil. Cad Saúde Pública, 2000; 16 (1): 107-14.

Cardoso SP, Martins C. Interaçōes droga-nutriente. Curitiba: Nutroclínica, 1998.

Carlini EA, Galduroz JCF, Noto AR, Nappo AS. I Levantamento domiciliar sobre o uso de drogas psicotrópicas no Brasil: estudo envolvendo as 107 maiores cidades do país. São Paulo:SENAC; 2002.

Carruthers SG. Cardiovascular risk factors in perspective. Can Fam Physician 1993; 39:309-14.

Carstairs V. Small area analysis and health service research. Community Medicine 1981; 3: 131-39.

CDAM-II, Second International Conference on Dietary Assessment Methods Dietary assessment methods. Am J Clin Nutr 1997; 65(Suppl):1097S-1368S. 
[CDC] Centers for Disease Control and Prevention. US chronic diseases reports: mortality trends US, 1979-1986. MWWR Morb Mortal Wkdy Rep 1989; 38:189-91.

Cervato AM, Mazzilli RN, Martins IS, Marucci MF. Dieta habitual e fatores de risco para doenças cardiovasculares. Rev Saúde Pública 1997; 31(3): 227-35.

Cordeiro AA. Padrão alimentar e consume domiciliary de produtos com redução de gorduras na área metropolitana de São Paulo. São Paulo; 2003 [Tese de Doutorado. Faculdade de Saúde Pública da USP].

Costa AA, Almeida Neto JS. Manual de diabetes: alimentação, medicamentos, exercicios. São Paulo: Sarvier, 1998.

Craig WJ. Phytochemicals: guardians of our health. J Am Diet Assoc 1997; 97: 10 (2):S199-204.

Cutler JA, Follmann D, Allender PS. Randomized trials of sodium reduction: an overview. Am J Clin Nutr 1997; 65:643-51.

De Angelis RC. Fome oculta, impacto para a população brasileira. São Paulo: Atheneu, 1999.

De Lorgeril M, Renauld S, Mamelle N, Salen P, Martin JL, Monjaud I, et al. Mediterranean alpha-linolenic acid-rich in secondary prevention of coronary heart disease. Lancet 1994; 343: 1454-9.

De Lorgeril M, Salen P, Martin JL, Monjaud I, Delaye J, Mamelle N. Mediterranean diet, traditional risk factors, and the rate of cardiovascular 
complications after myocardial infarction: final report of the Lyon Diet Heart Study. Circulation 1999;99:779-85.

Dietschy JM. Theoretical considerations of what regulates low-densitylipoprotein and high-density-lipoprotein cholesterol. Am J Clin Nutr 1997; 65 (5 Suppl):1581S-9S.

Diliberti N, Bordi PL, Conklin MT, Roe LS, Rolls BJ. Increased portion size leads to increased energy intake in a restaurant meal Obes Res 2004; 12:5628.

Duncan BB. Fatores de risco para doenças não transmissíveis em área metropolitana na região sul do Brasil. Prevalência e simultaneidade. Rev Saúde Pública 1993;27(1):143-8.

[NCEP] Expert Panel on Detection, Evaluation, And Treatment of High Blood Cholesterol in Adults. Executive summary of The Third Report of the National Cholesterol Education Program (NCEP) Expert Panel on Detection, Evaluation, And Treatment of High Blood Cholesterol in Adults (Adult Treatment Panel III). JAMA 2001;285:2486-97.

Everson SA, Goldeberg DE, Helmrich SP, Lakka TA Lynch JW, Kaplan GA, et al. Weight gain and the risk of developing insulin resistance syndrome. Care 1998; 21:1637-43.

[FIBGE] Fundação IBGE. Consumo alimentar; antropometria. Rio de Janeiro 1977; [Estudo Nacional de Despesa Familiar - ENDEF, v. 1: dados preliminares, Regiōes I, II, III, IV, V, t. 1]. 
[FIBGE] Fundação IBGE - Metodologia da Pesquisa Nacional por Amostra de Domicilios (PNAD) na década de 70. Rio de Janeiro: 1981.

[FIBGE] Fundação IBGE. Pesquisa de orçamentos familiares - POF 1987/88. Rio de Janeiro; 1991. v.1.

[FIBGE] Fundação IBGE. Pesquisa de orçamentos familiares - POF 1995/96: primeiro resultados. Rio de Janeiro; 1997.

[FIBGE] Fundação IBGE. Pesquisa de orçamentos familiares 1987 e 1996 [on line]. Disponível em URL <http://w.w.w.ibge.gov.br/sidra> [2000 nov 10].

[FIBGE] Fundação IBGE. Pesquisa de orçamentos familiares 2002/3: primeiros resultados [on line]. Disponivel em URL <http://w.w.w.ibge.gov.br/sidra> [2004 dez 29].

Fisberg RM, Slater B, Marchioni DML, Martini LA. Inquéritos alimentares: métodos e bases científicos. São Paulo: Manole; 2005.

Folsom AR, Prineas RJ, Jacobs DR, Luepker RV, Gillum RF - Measured differences between fourth and fifth phase diastolic blood pressure in 4885 adults: implications for blood pressure surveys. In: J Epidemiol 1984; 13:43641.

Fonseca MJM. Hábitos alimentares entre funcionários de banco estatal do Rio de Janeiro. Rio de Janeiro; 1996. [Dissertação de Mestrado_Escola Nacional de Saúde Pública - Fundação Oswaldo Cruz].

Fórnes NAS. Padrōes alimentares e suas relações com os lipídios séricos em população da área metropolitana de São Paulo. São Paulo; 1998. [Tese de Doutorado. Faculdade de Saúde Pública da USP]. 
Fórnes NAS, Martins IS, Velásquez-Meléndez G, Hernan M. Food frequency consumption and lipoproteins serum levels in the population of an urban area, Brazil. Rev Saúde Pública 2000; 34(4):380-7.

Fórnes NAS, Martins IS, Velásquez-Meléndez G, Latorre MRDO. Escores de consumo alimentar e niveis lipêmicos em população de São Paulo, Brasil._Rev Saúde Pública 2002; 36(1):12-8.

Fung TT, Rimm EB; Spiegemam D; Rifai N; Tofler GH; Willett W C; HU FB 2001a. Association between dietary patterns and plasma biomarkers of obesity and cardiovascular disease risk. Am J Clin Nutr 2001a; 73:61-67.

Fung TT, Willett WC, Stampfer MJ, Manson JE, Hu FB. Dietary patterns and the risk of coronary heart disease in women. Arch Intern Med 2001b;161:1857-62.

Fung TT, Schulze M, Manson JE, Willett WC, Hu FB. Dietary patterns, meat intake, and the risk of type 2 diabetes in women. Arch Intern Med. 2004 Nov $8 ; 164(20): 2235-40$.

Furberg CD, Hennekens CH, Hulley SB, Manolio T, Psaty BM, Whelton RK. A base conceitual para a interpretação dos fatores de risco. JACC 1997; 3(1):239.

Gibbs CR, Lip GY, Beevers DG. Salt and cardiovascular disease: clinical and epidemiological evidence. J Cardiovascular Risk 2000; 7: 9-13.

Gibson RS. Principles of nutritional assessment. New York: Oxford University Press; 1990. 
Gillman MW, Cupples LA, Posner B, Ellison RC, Castelli W, Wolf P. Protective effect of fruits and vegetables on development of stroke in men. JAMA 1995; 273:1113-7.

Gillman MW. Enjoy your fruits and vegetables: eating fruit and vegetables protects against the chronic diseases of adulthood. Br Med J 1996; 313: 765-6.

Grundy SM. Atherogenic dyslipidemia: lipoprotein abnormalities and implications for therapy. Am J Cardiol 1995; 75: 45B-52B.

Grundy SM. Grasa alimentaria. In: Ziegler EE, Filer Jr LJ. Conocimientos actuales sobre nutrición. $7^{a}$ ed. Washington (DC): ILSI Press; 1997. (OPSPublicación Científica número 565):49-63.

Haffner SM, Gingerich RL, Miettinen H, Stern MP - Leptin concentrations in relation to overall adiposity and regional bodyfat distribution in Mexican Americans. Int J Obes Relat Metab Disord 1996; 20:904-8.

Hagdrup MD, Simōes, EJ, Brownson RC. Fruit and vegetable consumption in Missouri: knowledge, barriers and benefits. Am J Health Behav 1998; 22 (2): 90-100.

Hair JFJr, Anderson RE, Tatham RL, Black WC. Multivariate data Analysis. Upper Saddle River, New Jersey, Prentice Hall, 1998; 87-138.

Halliwell B. Antioxidantes. In: Organización Panamericana de la Salud. Conocimientos actuales sobre nutrición. $7^{\mathrm{a}} \mathrm{ed}$. Washington (DC); 1997. p. 468-75. (OPS - Publicación Científica, 565).

Hankinson SE, Colditz GA, Manson JE, Speizer FE. Healthy Women, Healthy Lives: A Guide to Preventing Disease, From the Landmark Nurses' Health Study. New York: Simon \& Shuster Source; 2001. 
Havas A, Tucker KL, De Groot LC, Wilson P W, Van Staveren WA. Evaluation of dietary quality in relationship to nutritional and lifestyle factors in elderly people of the US Framingham Heart Study and the European SENECA study. Eur J Clin Nutr 2001; 55:870-880.

Helsing $E$, Becker W. Food and health data: their use in nutrition policy making. Copenhagen: World Health Organization; 1991. [WHO-Regional Publications, European Series; 34].

Hertog MGL, Feskens EJM, Hollman PCH, Katan MB, Kromhout D. Dietary antioxidant flavonoids and risk of coronary heart disease. Lancet 1993; 342:1007-11.

Hoffmann K, Schulze MB, Schienkiewitz A, Ute N, Boeing H. Application of a new statistical method to derive dietary patterns in nutritional epidemiology. Am J Epidemiol 2004; 159:935-44.

Hooper L, Summerbell CD, Higgins JPT, Thompson RL, Capps NE, Smith GE, Riemersma RA, Ebrahim S. Dietary fat intake and prevention of cardiovascular disease: systematic review. Br Med J 2001; 322: 757-63.

Hopkins PN, Williams RR. A survey of 246 suggested coronary risk factors. Atherosclerosis 1981; 40: 1-52.

Hu FB, Rimm E, Smith-Warner SA. Feskanich, D., Stampfer, M. J., Ascherio, A., Sampson, L. \& Willett, W. C. (1999) Reproducibility and validity of dietary patterns assessed with a food-frequency questionnaire. Am J Clin Nutr 1999a; 69:243-249. 
Hu FB, Stampfer MJ, Manson JE, Ascherio A, Colditz GA, Speizer FE. Dietary saturated fats and their food sources in relation to teh risk of coronary heart disease in women. Am J Clin Nutr 1999b; 70: 1001-8.

Hu FB, Rimm EB, Stampfer MJ, Ascherio A, Spiegelman D, Willett WC. Prospective study of major dietary patterns and risk of coronary heart disease in men. Am J Clin Nutr 2000;72:912-21.

Hubert HB. The importance of obesity in the development of coronary risk factors and disease: the epidemiologic evidence. Annual review of public health, 1983, 7:493-502.

[IARC]. Alcohol drinking. IARC Monographs on the evaluation carcinogenic risk in humans. Lyon: IARC Press; 1988.

Issa JS, Francisco YA. Obesidade e doenças cardiacas: aspectos epidemiológicos e preventivos. Rev Soc Cardiol Estado São Paulo 1996; 6:558-63.

Jackson R, Barham P, Bills J. Management of raised blood pressure in New Zealand: a discussion document. Br Med J 1993; 307:107-10.

JNC - The sixth report of the Joint National Committee on prevention, detection, evaluation, and treatment of high blood pressure. Arch Intern Med 1997; 157:2413-46.

Jorge MIE. Padrões de dieta, estresse psicossocial e suas repercussões sobre a obesidade e a pressão arterial em mulheres residents em Cotia/SP. São Paulo; 2005. [Tese de Doutorado. Faculdade de Saúde Pública da USP]. 
Kannel WB. Una perspective sobre los factores de riesgo de las enfermedades cardivasculares. In: Buck C, Llopis A, Najera E, Terris m. EI desafio de la epidemiolgia. Problemas y lecturas selecionadas. Publicación científica 505. Washington DC: Opas, 1988.

Kannel WB. The Framingham experience. In: Coronary heart disease epidemiology: from aetiology to public health. Marmot M, Elliot P. E.U.A.: Oxford Med Publ, 1992.

Kant AK, Schatzkin A, Graubard BI, Schairer C. A prospective study of diet quality and mortality in women. JAMA 2000; 283: 2109-15.

Kerver JM, Yang EJ, Bianchi L, Song WO. Dietary patterns associated with risk factors for cardiovascular disease in healthy US adults. Am J Clin Nutr 2003; 78: 1103-10.

Keys A, Anderson JT, Grande F. Serum cholesterol response to changes in the diet. II. The effect of cholesterol in the diet. Metabolism 1965; 14:759-65.

Keys A. Coronary heart disease in seven countries. Circulation 1970; 41(4 suppl 1):I1-I211.

Keys A, Menotti A, Aravanis C, Blackburn H, Djordeirc BS, Buzina R et al. The seven countries study: 2289 deaths in 15 years. Prev Med 1984; 13:141-54.

Keys A. Mediterranean diet and public health: personal reflections. Am J Clin Nutr 1995; 1321S:3S.

Kim KK, Yu ES, Chen H, Cross N, Kim J. Nuritional status of Korean Americans: implications for cancer risk. Oncol Nurs Forum 2000; 27:1573-83. 
Khani BR Ye W, Terry P, Wolk A. Reproducibility and validity of major dietary patterns among Swedish women assessed with a food-frequency questionnaire. J Nutr 2004; 134(6): 1541-5.

Kleinbaum DG, Kupper LL, Muller KE. Variable reduction and factor analysis. Applied Regression Analysis and Other Multivariable Methods. . Boston: PWS-Kent Publishing Company; 1988:595-640

Krinksy N I. Action of carotenoids in biological systems. Annu Rev Nutr 1993; 13:561-87.

Kushi LH, Lenart EB, Willet W. Health implications of mediterranean diets in light of contemporary knowledge. 2. Meat, wine, fats and oils. Am J Clin Nutr 1995; 61 suppl:1416S-27S.

Laustiola KE. Atherothrombotic mechanims in smoking. J Intern Med 1991; 230:469-70.

Law MR, Morris JK. By how much does fruit and vegetable cosumption reduce the risk of ischaemic heart disease? Eur J Clin Nutr 1998; 52:549-56.

Law MR, Morris JK. By how much does fruit and vegetable cosumption reduce the risk of ischaemic heart disease: Response to commentary. Eur J Clin Nutr 1999; 53: 903-4.

Law MR, Morris JK. By how much does fruit and vegetable consumption reduce the risk of ischaemic heart disease: Response to commentary. Eur J Clin Nutr 1999; 53: 903-4. 
Lébart L, Dreyfus JF. Comment limiter de façon non arbitraire le nombre de facteurs dans une analyse en compasantes principales. Rev Rech Fond Barth 1972; 2:7-9.

Ledikwe JH, Smiciklas-Wright H, Mitchell DC, Miller CK, Jensen GL. Dietary patterns of rural older adults are associated with weigt and nutritional status. $J$ Am Geratr Soc 2004; 52(4): 589-95.

Leon A. Contributions of regular moderate-intensity physical activity to reduce risk of coronary heart disease. In: Leon A. Physical activity and cardiovascular health: a National Consensus. Human Kinetics; 1997. p. 5766.

Leone A. Cigarette smoking and health of the heart. J Roy Soc Health 1995; 3: 354-5.

Lerner DJ, Kannel WB. Patterns of coronary heart disease morbidity and mortality in the sexes: a 26 years follow-up of Framingham population. Am Heart J 1986; 111:383-90.

Leser W. Relacionamento de certas características populacionais com a mortalidade infantil no municipio de São Paulo de 1950 a 1970 . Prob Bras 1972; 10: 17-33.

Lessa I. Estudos brasileiros sobre epidemiologia da hipertensão arterial: análise crítica dos estudos de prevalência. Inf Epid SUS. Brasília: CENEPI 1993.

Lessa I, Mendonça GAS, Teixeira MTB. Doenças crônicas não transmissiveis no Brasil: dos fatores de risco ao impacto social. Bol Oficina Sanit Panam $1996 ; 120: 389-413$. 
Lessa I. Doenças crônicas não transmissíveis. In: Lessa I. O adulto brasileiro e as doenças da modernidade. Epidemiologia das doenças crônicas não-transmissiveis. São Paulo: Hucitec; 1998.

Levy-Costa RB, Sichieri R, Pontes NS, Monteiro CA. Disponibilidade domiciliar de alimentos no Brasil: distribuição e evolução (1974-2003). Rev Saúde Pública 2005; 39(4):530-40.

Lolio CA. Epidemiologia da hipertensão arterial. Rev Saúde Pública 1993; 27(5): 257-62.

Lorenzo C, Ikoloise M, Williams K, Stern MP, Haffner SM. The metabolic syndrome as predictor of type 2: the San Antonio heart study. Care 2003; 26:3153-9.

Lotufo PA, Lolio CA. Tendências de evolução da mortalidade por doenças cardiovasculares: o caso do Estado de São Paulo. In: Monteiro CA. Velhos e novos males da saúde no Brasil. A evolução do país e de suas doenças. $2^{\mathrm{a}}$ ed. São Paulo: Hucitec; 2000. p. 279-87.

Ludwig DS, Peterson KE, Gortmaker SL. Relation between consumption of sugar-sweetened drinks and childhood obesity: a prospective, observational analysis. Lancet 2001; 357: 505-508.

Mahan LK, Arlin MT. Krause: alimentos, nutrição e dietoterapia. $10^{\mathrm{a}}$ ed. São Paulo: Roca; 2000. 
Marchioni DML. Fatores dietéticos e câncer oral: um estudo caso controle na região metropolitana de São Paulo. São Paulo; 2003. [Tese de Doutorado_Faculdade de Saúde Pública da USP]

Marchioni DML, Latorre MRDO, Eluf-Neto J, Wünch JE, Fisberg RM. Identificação de padrōes de alimentação usando análise fatorial em um estudo epidemiológico em São Paulo. São Paulo Med J 2005: 123(3): $124-7$.

Marcopito LF, Goldfeder AJ, Medina MC, Shirassu MM, Rodrigues SSR, Neumann AICP et al. Doenças e Agravos não Transmissiveis (DANT): Monitorização da Exposição aos Fatores de Risco para um Subgrupo de Doenças no Município de São Paulo. Boletim Epidemiológico Paulista 2004; 9. São Paulo, 2004 [on line]. Disponivel em URL http://www.cve.saude.sp.gov.br/agencia/bepa_menu.htm. [2005 ago 10].

Marcopito LF, Rodrigues SSR, Pacheco MA, Shirassu MM, Goldfeder AJ, Moraes MA. Prevalência de alguns fatores de risco para doenças crônicas na cidade de São Paulo. Rev Saúde Pública 2005: 39(5): 738-45.

Marmot M, Elliot P. Coronary heart disease epidemiology: from aetiology to public health. Oxford: Oxford Medical Publication; 1992.

Marques RM, Berquó E - Seleção da unidade de informação em estudos de tipo "survey": um método para a construção das tabelas de sorteio. Rev Saúde Publica 1976: 37:81-92.

Marques E, Torres H. São Paulo: segregação, pobreza e desigualdades sociais. São Paulo: Senac; 2005. 
Martinez ME, Marshall JR, Sechrest L. Invited commentary: factor analysis and the search for objectivity. Am J Epidemiol 1998;148:17-9.

Martins IS, Coelho LT, Matos IMS, Mazzilli RN, Trigo M, Wilson LD. Dislipidemias e alguns fatores de risco associados em uma população periférica da região metropolitana de São Paulo, SP-Brasil: um estudo piloto. Rev Saúde Pública 1989; 23:236-43.

Matsudo V. Physical activity: passport for health. World Health Rep 1997; 50 (3): 16-7.

McNamara DJ. Cardiovascular disease. In: Shils M E, Olson JA, Shike M. Modern nutrition in health and disease. 8th ed. Philadelphia: Lea \& Febiger; 1994. p. $1533-44$.

Medina MCG. Prevenção de doenças não transmissíveis: estratégias para implantação de um programa, São Paulo: Centro de Vigilância Epidemiológica/Secretaria de Estado da Saúde de São Paulo; 1998.

Menezes EW, Lajolo FM. Utilização do amido de leguminosas. Arch Latinoam Nutr 1995; 45 Sppl 1:270-2.

Midgley JP, Matthew AG, Greenwood CM, Logan AG. Effect of reduced dietary sodium on blood pressure, a meta-analysis of randomized controlled trials. JAMA 1996; $275 ; 1590-7$.

Millen BE, Quadromoni PA, Gagnon DR, Cupples LA, Franz MM, D'Agostino R B. Dietary patterns of men and women suggest targets for health promotion: The Framingham Nutrition Studies. Am J Health Promotion 1996; 11:42-53. 
Mondini L, Monteiro CA. Mudanças no padrão de alimentação da população urbana brasileira (1962-1988). Rev Saúde Pública 1994; 28: 433-9.

Mondini L, Monteiro CA. Mudanças no padrão de alimentação. In: Monteiro CA. Velhos e novos males da saúde no Brasil. A evolução do país e de suas doenças. $2^{\mathrm{a}}$ ed. São Paulo: Hucitec; 2000.

Monteiro CA, Conde WL. A tendência secular da obesidade segundo estratos sociais: Nordeste e sudeste do Brasil. Arq Bras End Met 1999; 43:186-94.

Monteiro CA, Mondini L, Costa RBL. Mudanças na composição e adequação nutricional da dieta familiar nas áreas metropolitanas do Brasil. Rev Saúde Pública 2000; 34:251-8.

Monteiro CA. Velhos e novos males da saúde no Brasil. A evolução do país e de suas doenças. $2^{a}$ ed. São Paulo: Hucitec; 2000.

Murray CJL, Lopez AD. Progress and directions in refining the Global Burden of disease approach. Geneva, 1999. (WHO - Global Programme on Evidence for Health Policy Discussion Paper $n^{\circ} 1$ )

NCEP - Summary of the second report of the National Cholesterol Education Program (NCEP) Expert Panel on Detection, Evaluation, and Treatment of High Blood Cholesterol in Adults (Adult Treatment Panel II). JAMA 1993; 269:301523.

Ness AR, Powles JW . Fruit and vegetables and cardiovascular disease: a review. Int J Epidemiol 1997; 26:1-13. 
Neumann AICP, Shirassu MM, Fisberg RM. Consumo de alimentos de risco e proteção para doenças cardiovasculares entre funcionários públicos estaduais do município de São Paulo. Rev Nutrição 2005a (no prelo).

Neumann AICP. Consumo de frutas, verduras e legumes entre residentes da área urbana do municipio de São Paulo. [Resultados parciais da pesquisa Fatores de risco para doenças crônicas não-transmissiveis: inquérito domiciliar no município de São Paulo, 2001-2001,apresentado Seminário Nacional de Vigilância em Doenças e Agravos não Transmissiveis e Promoção da Saúde, 2005 out 20; Brasília, Brasil].

Okonek DV, Berben PH, Martelli G. Precious metal catalysis for fats and oils applications. In: Anais do Seminário da Sociedade Brasileira de Óleos e Gorduras, 1996. Gorduras modificadas com baixos teores de ácidos graxos trans: aspectos nutricionais e tecnológicos. São Paulo: Instituto Adolfo Lutz; 1996. p.39-46.

Oomen CM, Ocké MC, Feskens EJM, van Erp-Baart MAJ, Kok FJ, Kromhout D. Association between trans fatty acid intake and 10-year risk of coronary heart disease in the Zutphen Elderly Study: a prospective population based study. Lancet 2001;347:746-51.

[OMS] Organización Mundial de la Salud. Dieta, nutrición y prevención de enfermedades crónicas. Ginebra; 1990. (OMS - Serie de Informes Técnicos, 797).

[OMS] Organización Mundial de la Salud. Factores de riesgo de enfermedades cardiovasculares: nuevas esferas de investigación. Ginebra; 1994.(OMS - Serie de Informes Técnicos, 841). 
[OMS] Organización Mundial de la Salud. El estado físico: uso e interpretación de la antropometria. Ginebra; 1995. (OMS - Serie de Informes Técnicos, 854).

[OMS] Organização Mundial da Saúde. Classificação Estatística Internacional de Doenças e Problemas relacionados à Saúde, $10^{\mathrm{a}}$ versão. São Paulo: EDUSP; 1996.v.1; p. 471-515.

[OMS] Organização Mundial da Saúde. Organização Panamericana da Saúde. $130^{\text {a }}$ Sessão do Comitê Executivo. Resposta da Saúde Pública às Doenças Crônicas. Washington; 24-28 de junho de 2002.

[OPAS] Organização Pan-Americana da Saúde. Doenças crônicodegenerativas e obesidade: estratégia mundial sobre alimentação saudável, atividade física e saúde. Brasilia, 2003.

Paffenbarger R, Hyde R Wing A, Lee I, Jung D, Kampter J. The association of changes in physical-activity level and other lifestyle characteristics with mortality among men. N Engl J Med 1993; 328: 538-45.

Pereira JCR. Análise de dados qualitativos: Estratégias Metodológicas para as Ciências da Saúde, Humanas e Sociais. São Paulo: $3^{a}$ ed. EDUSP, 2001.

Pols MA, Peeters PH, Ocké MC, Slimani N, Bueno-de-Mesquita HB, Collette HJ. Estimation of reproducibility and relative validity of the questions included in the EPIC Physical Activity Questionnaire. Int J Epidemiol 1997; 26 (suppl 1):S181-9.

[PMSP] Prefeitura do Municipio de São Paulo. Imigração. [on line].Disponível em URL < http://milpovos.prefeitura.sp.gov.brl [2004 dez 15]. 
[PMSP] Prefeitura do Município de São Paulo. Saúde. [on line].Disponível em URL < http://prefeitura.sp.gov.br/saude/mortalidade [2005 out 5].

Prentice AM, Jebb SA. Fast foods, energy density and obesity: a possible mechanistic link. Obes Rev 2003; 4: 187-94.

Puska P. The community-based strategy to prevent coronary heart disease: conclusions from the tem years of North Karelia Project. Ann Rev Public Health 1985; 6: 147-93.

Puska P. Community change and the role of public health. Geneva: WHO; 2003 [on line]. Disponivel em URL $<$ http:I/w.w.w.ncbi.nlm.nih.gov/entrez/query.fcgi

Quatromoni PA, Copenhafer DL, Demissie S, D'agostinho RB, O'Horo CE, Nam $\mathrm{BH}$, Millen BE. The internal validity of a dietary pattern analysis. The Framingham Nutrition Studies. J Epid Comm Health 2002; 56:381-8.

Rabelo LM. Fatores de risco para doença aterosclerótica em estudantes de uma universidade privada de São Paulo. São Paulo; 1998. [Dissertação de Mestrado. Universidade Federal de São Paulo].

Rego RA, Berardo FA, Rodrigues SS, Oliveira ZM, Oliveira MB, Vasconcellos C, Aventurato LV, Moncau JE, Ramos LR - Fatores de risco para doenças crônicas não-transmissíveis: inquérito domiciliar no município de São Paulo. Rev Saúde Pública 1990; 24:277-85.

Ribeiro AB, Cardoso MA. Construção de um questionário de freqüência alimentar como subsídio para programas de prevenção de doenças crônicas não transmissíveis. Rev Nutr 2002; 15(2):239-45. 
Rimm EB, Ascherio A, Giovannucci E, Spiegelman D, Stampfer MJ, Willet W. Vegetable, fruit and cereal fiber intake and risk of coronary heart disease among men. J Am Med Acad 1996; 275:447-51.

Rimm EB, Giovannucci EL, Stampfer MJ, Colditz GA, Litin LB, Willett WC. Reproducibility and validity of an expanded self-administered semiquantitative food frequency questionnaire among male health professionals. Am $\mathbf{J}$ Epidemiol 1992;135:1114-26.

Rolls BJ, Ello-Martin JA, Tohill BC. What can intervention studies tell us about the relationship between fruit and vegetable consumption and weight management? Nutr Rev 2004; 62:1-17.

Rose G - Standardisation of observers in blood pressure measurement. Lancet 1965; i: 673-4.

Rosenberg J. Sobre a Lei Antitabágica. Pulmão 1996; 5:167.

Rosenberg J. Tabagismo. São Paulo: Imprensa Oficial do Estado, 2003.

Rosner B - Power and sample-size estimation for stratified categorical data. In: Rosner B - Fundamentals of biostatistics, 4th ed. Belmont (CA): 1995; Duxbury Press. pp.417-9.

Santos TM. Lipídeos. In: Dutra de Oliveira JE, Marchini JS. Ciências nutricionais. São Paulo: Sarvier, 1998. p. 87-98. 
[SBC] Sociedade Brasileira de Cardiologia. $2^{\circ}$ Consenso Brasileiro sobre Dislipidemias - Avaliação-Detecção-Tratamento. Arq Bras Cardiol 1996; 67:109-29.

[SBC] II Diretrizes Brasileiras Sobre Dislipidemias e Diretriz de Prevenção da Aterosclerose do Departamento de Aterosclerose da Sociedade Brasileira de Cardiologia. Arq Bras Cardiol 2001: 77; Supl III.

[SBD] Sociedade Brasileira de Diabetes. Diagnóstico e classificação do diabetes melito e tratamento do diabetes melito do tipo 2. In: Consenso Brasileiro sobre Diabetes. Rio de Janeiro: Diagraphic, 2003.

[SES] Secretaria de Estado da Saúde, Centro de Vigilância Epidemiológica "Professor Alexandre Vranjac", Divisão de Doenças Crônicas Não Transmissiveis - DDCNT. Indicadores utilizados na vigilância de doenças crônicas não transmissiveis. São Paulo; 1997.

[SES] Secretaria de Estado da Saúde, Grupo Técnico de Informações de Saúde. Mortalidade do municipio de São Paulo. São Paulo, 2000 [on line]. Disponível em URL <http://w.w.w.saude.sp. gov.br >. [2000 nov 10].

[SES] Secretaria de Estado da Saúde, Centro de Vigilância Epidemiológica "Professor Alexandre Vranjac", Divisão de Doenças Crônicas Não Transmissiveis - DDCNT. Programa Alimentação Saudável na Prevenção de Doenças Crônicas Não Transmissiveis. São Paulo, 2002. [on line]. Disponivel em URL <http://uww.cve.saude.sp.gov.br/htm/cronicas/dent_docman.htm >. [2004 nov 10].

Shimidt MI, Duncan BB. Diabesity: an inflammatory metabolic condition. Clin Chem Lab Med 2003; 41:1120-30. 
Singh RB, Dubnov G, Niaz MA, Ghosh S, Singh R, Rastogi SS, et al. Effect of an Indo-Mediterranean diet on progression of coronary artery disease in high risk patients (Indo-Mediterranean Dit Herart Study): a randomized single-blind trial. Lancet 2002; 360: 1455-61.

Sichieri R, Castro JFG, Moura AS. Fatores associados ao padrão de consumo alimentar da população brasileira urbana. Cad Saúde Pública 2003; 19 (Sup 1): S47-S53.

Silva MR, Silva MAAP. Aspectos nutricionais de fitatos e taninos. Rev Nutr Campinas 1999; 12:21-32.

Slattery ML, Boucher KM, Caan BJ, Potter JD, Ma KN. Eating patterns and risk of colon cancer. Am J Epidemiol 1998;148:4-16.

Sposati A (coordenadora) - Mapa da inclusãolexclusão social da cidade de São Paulo. São Paulo: 1996; Editora da PUC-SP. 124p.

[SPSS] Statistical Package for the Social Sciences. Base 10,0. User's guide. Chicago: SPSS, 1999.

Stern MP, Haffner SM - Body fat distribution and hyperinsulinemia as risk factors for diabetes and cardiovascular disease. Arteriosclerosis 1986: 6:12330.

Subar AF, Heimendinger J, Patterson BH, Krebs-Smith SM, Pivonka E, Kessler R. Five a Day for Better Health: baselines study of American finit and vegetables consumption. Rockville, MD: National Cancer Institute, National Institute of Health 1992. 
Subar AF, Heimendinger J, Patterson BH, Krebs-Smith SM, Pivonka E, Kessler R. Fruit and vegetable intake in the United States: the baseline survey of the Five a Day for Better Health Program. Am J Health Promot 1995; 9: 352-60.

Sweeting H, Anderson A, West P. Socio-demographic correlates of dietary habits in mild to late adolescence. Eur J Clin Nutr 1994; 48: 736-48.

Thrichopoulos D, Lagiou P. Dietary patterns and mortality. Br J Nutr 2001; 85:133-4.

Truswell AS. Practical and realistic approaches to healthier diet modifications. Am J Clin Nutr 1998; 67(suppl):583S-90S.

[USDHHS] US Department of Health and Human Services. Healthy people 2000. national health promotion and disease prevention objectives. Washington (DC), 1991. (DHSS Publication PHS 91-50213).

Valenzuela A, King J, Nieto S. Trans fatty acid from hydrogenated fats: The controversy about health implications. Grasas y Aceites 1995; 46(6): 369-75.

van Dam RM, Rimm EB, Willett WC, Stampfer MJ, Hu FB. Dietary patterns and risk for type 2 diabetes mellitus in U.S. men. Ann Intern Med 2002; 136:201-9.

Vartiainen E, Puska P, Pekkanen J,Tuomilehto J, Jousilahti P - Changes in risk factors explain changes in mortality from ischaemic heart disease in Finland. $\mathrm{Br}$ Med J 1991; 309:23-7.

Venn BJ, Mann JI. Cereal grains, legumes and diabetes. Eur J Clin Nutr 2004; 58: $1443-61$. 
[WCRF] World Cancer Research Found. American Institute for Cancer Research. Food, nutrition and prevention of cancer: a global perspective. Washington DC, 1997.

Whelton PK, He J, Cutler JA. Effects of oral potassium on blood pressure: meta-analysis of randomized controlled clinical trials. J Am Med Assoc 1997; 227:1624-32.

Willett WC. Validity of food-frequency questionnaries; Nutritional Epidemiology. Nova York: Oxford University Press; 1990, p. 92-126.

Willett WC. Diet and health: what should we eat ? Science 1994; 264:532-7.

Willett WC, Sacks F, Tricopoulou a et al. Mediterranean diet pyramid: a cultural model for healthy eating. Am J Clin Nutr 1995; 61 (suppl):1402S-6S.

Willett WC, Stampfer MJ. Implications of total energy intake for epidemiological analysis. In: Willett WC, ed. Nutritional epidemiology. 2nd ed. New York: Oxford University Press, 1998:273-301.

Willett WC. Nutritional Epidemiology. $2^{\text {nd }}$ ed. New York: Oxford University Press; 1998.

Willett WC. Nutritional epidemiology issues in chronic disease at the turn of the century. Epidemiol Rev 2000: 22(1),82-6.

Willett WC, Leibel RL. Dietary fat is not a major determinant of body fat. Am J Med 2002; 113: 47S-59S. 
[WHO] World Health Organization. Diet, nutrition and prevention of chronic diseases. Geneva; 1990. (WHO Technical Report Series, 797).

[WHO] World Health Organization. Physical status: the use and interpretation of anthropometry. Geneva; 1995.(WHO- Report series, 854).

[WHO] World Health Organization. Obesity: preventing and managing the global epidemy. Report of WHO consultation on obesity. Geneva: WHO; 1997.

[WHO] World Health Organization.. Report of a Joint FAONWO Consultation. Preparation and use of food-based dietary guidelines. Geneva: WHO; 1998.

[WHO] World Health Organization. Obesity: preventing and managing the global epidemic. Geneva; 2000.(WHO- Report series, 894).

[WHO] World Health Organization. The world health report 2002: reducing risks, promoting healthy life. Geneva; 2002.

[WHO] World Health Organization. Diet, nutrition and prevention of chronic diseases. Geneva; 2003. (WHO Technical Report Series, 916).

[WHO] World Health Organization. Fifty-seven World Health Assembly. Global Strategy on Diet, Physical Activity and Health. Geneva; 2004 [on line]. Disponivel em URL http://w.w.w.who.int/hpr/NPH/docs/gs global strategy general.pdf. [2004 set10].

Yang EJ Kerver JM, Song WO. Dietary patterns of Korean American described by factor analysis. J Am Coll Nutr 2005; 24(2):115-21. 
ANEXO 1.

a antiga e a nova distribuição espacial dos distritos do município de são paulo

ANEXO 2.

questionário geral

ANEXO 3.

formulário suplementar

ANEXO 4.

carta enviada aos entrevistados contendo os resultados dos exames realizados

ANEXO 5.

pareceres dos conselhos de ética em pesquisa da UNIFESP e da USP

ANEXO 6.

matriz de correlação anti-imagem

ANEXO 7.

fatores definidos pela análise fatorial 
Anexo 1.

A antiga e a nova distribuições espaciais dos distritos do municipio de São Paulo. 
Figura - Antiga (A) e nova (B) distribuições espaciais dos distritos do municipio de São Paulo em estudo.

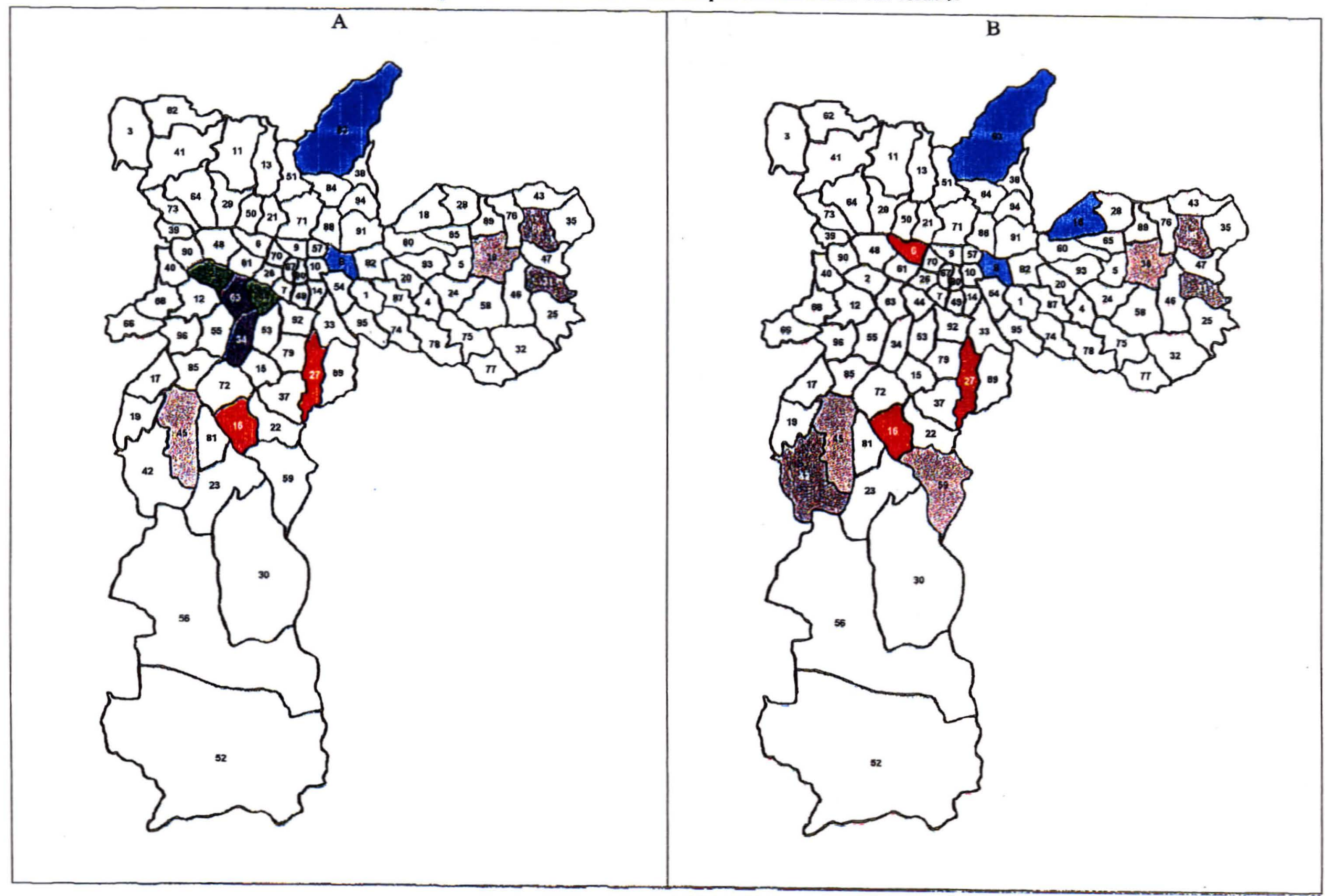


Município de São Paulo: áreas sócio-ambientais-homogêneas

propostas por Sposati (1996).

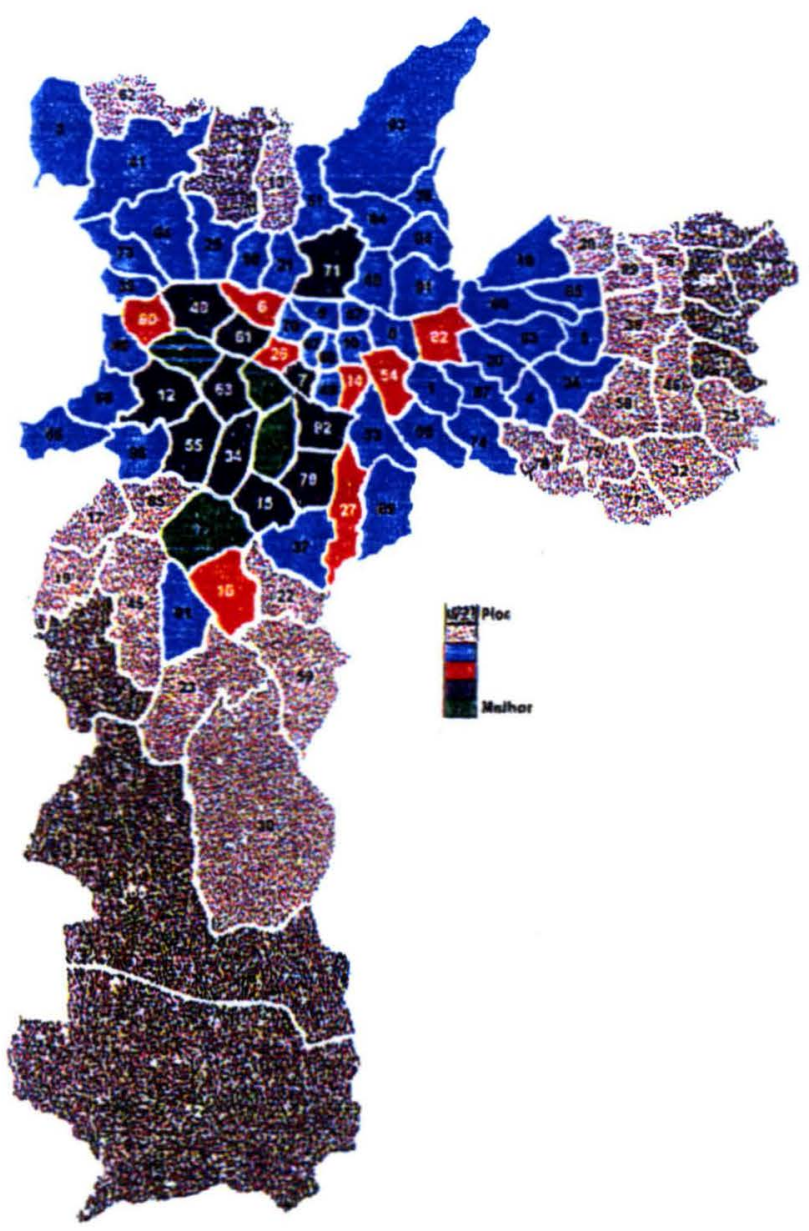

\begin{tabular}{|c|c|}
\hline Número & Distrito \\
\hline$\frac{z}{4}$ & $\begin{array}{l}\text { Moema } \\
\text { Afto de Pinlreiros } \\
\text { Jardim Paulista } \\
\text { Santo Amaro } \\
\end{array}$ \\
\hline $\begin{array}{l}15 \\
92\end{array}$ & $\begin{array}{l}\text { Campo Belo } \\
\text { Vila Mariaua }\end{array}$ \\
\hline 61. & Perdizes \\
\hline 34 & Ilaim Bibi \\
\hline 12 & Butantã \\
\hline 71 & Santana \\
\hline 79 & Saúde \\
\hline 63 & Pinheiros \\
\hline 48 & Lapa \\
\hline $\begin{array}{r}55 \\
7\end{array}$ & Morumbi \\
\hline 26 & Consolação \\
\hline 54 & Moóca \\
\hline 27 & Cursino \\
\hline 82 & Tatuapé \\
\hline 6. & Barra Funda \\
\hline 16 & Campo Grande \\
\hline 90 & Vila Leopoldina \\
\hline 14 & Cambuci \\
\hline 96 & Vila Sônia \\
\hline
\end{tabular}

\begin{tabular}{|c|c|}
\hline Núnero & Distrito \\
\hline 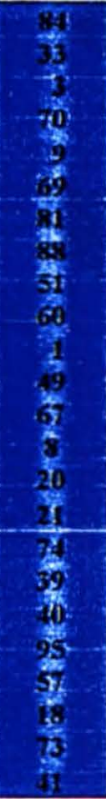 & \begin{tabular}{|l} 
Tucunıvi \\
Ipiranga \\
Aunhangitera \\
Santa Cecilia \\
Bom Retiro \\
Saconã \\
Socono \\
Vila Guilhermina \\
Mandaqui \\
Penhh \\
Águia Rasa \\
Liberdade \\
República \\
Belém \\
Carrão \\
Casa Verde \\
São Lucas \\
Jaguarn \\
Jaguaré \\
Vila Prudente \\
Puri \\
Cangaiba \\
São Donningos \\
Jaraguá \\
\end{tabular} \\
\hline
\end{tabular}

\begin{tabular}{|c|c|}
\hline Número & Distrito \\
\hline 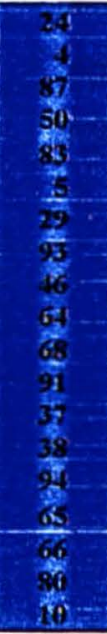 & \begin{tabular}{|l|} 
Cidnde Lider \\
Aricanduva \\
Vila Formosa \\
Limũo \\
Tremembé \\
Artur Alvim \\
Freguesia do Ó \\
Vila Matilde \\
José Bonifficio \\
Pirituba \\
Rio Pequeno \\
Vila Maria \\
Jabaquara \\
Jaçanã \\
Vila Medeiros \\
Ponte Rasa \\
Raposo Tavares \\
Sé \\
Brús \\
\end{tabular} \\
\hline $\begin{array}{l}85 \\
28 \\
77 \\
75 \\
78\end{array}$ & $\begin{array}{l}\text { Vila Andrade } \\
\text { Ermelino Matarazzo } \\
\text { São Rafael } \\
\text { São Mateus } \\
\text { Sapopembn }\end{array}$ \\
\hline
\end{tabular}

\begin{tabular}{|c|c|}
\hline Número & Distrito \\
\hline $\begin{array}{l}17 \\
36 \\
89 \\
23 \\
58 \\
59 \\
32 \\
22 \\
45 \\
25 \\
76 \\
62 \\
13 \\
30 \\
19\end{array}$ & $\begin{array}{l}\text { Cannpo Limpo } \\
\text { Itaquera } \\
\text { Vila Jacui } \\
\text { Cidade Dutra } \\
\text { Parcaue do Carmo } \\
\text { Pedreira } \\
\text { Iguatemi } \\
\text { Cidade Ademar } \\
\text { Jardim Sĩo Luís } \\
\text { Cidade Tiradenles } \\
\text { São Miguel } \\
\text { Perus } \\
\text { Cachoeirinha } \\
\text { Grajau } \\
\text { Capão Redondo }\end{array}$ \\
\hline 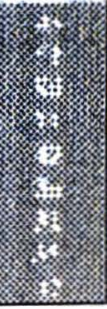 & $\begin{array}{l}\text { Jardim Helena } \\
\text { Marsilac } \\
\text { Vila Curnçá } \\
\text { Brasilândia } \\
\text { Jardim Ângela } \\
\text { Partlheiros } \\
\text { Guaianases } \\
\text { Itaim Paulista } \\
\text { Lajendo }\end{array}$ \\
\hline
\end{tabular}




\section{MAPA DE EXCLUSÃO DA CIDADE DE SÃO PAULO.}

Coordenação: Aldaíza Sposati.

Entidades responsáveis: PUC-SP/INPE/Instituto Polis.

Este Mapa foi elaborado para ser um instrumento de análise do processo de exclusăo/inclusăo social em Săo Paulo, expresso por meio das desigualdades sociais, económicas, políticas e culturais da populaçâo da cidade em seus 96 distritos. Mostra o distanciamento das condiçőes de vida entre os distritos, comparando indices e estabelecendo notas de exclusão/inclusão social a partir de padrőes básicos de cidadania.

o Mapa torna visivel a existência de ilhas de inclusăo social convivendo com territórios marcados pela pobreza, discriminaçăo, subalternidade, ausência de equidade e representaçăo pública na mesma cidade

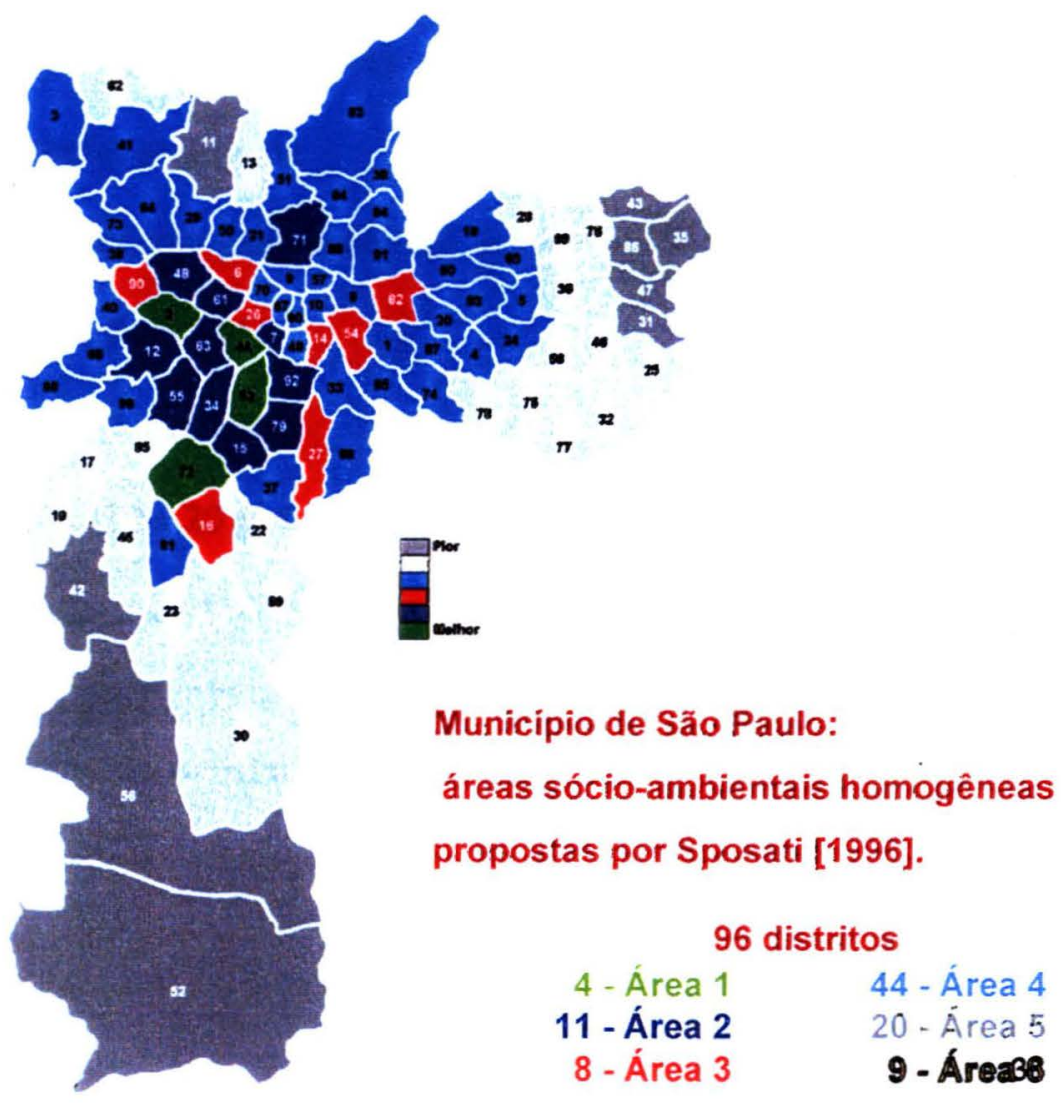


Composição do índice de inclusão/exclusão social autonomia (iexa)

\begin{tabular}{|c|c|}
\hline Campo & Indicadores \\
\hline $\begin{array}{l}\text { Autonomia } \\
\text { Iexa }\end{array}$ & $\begin{array}{l}\text { Iex chefes de família abaixo da linha da pobreza } \\
\text { (sem rendimento) } \\
\text { Iex chefe de família na linha da pobreza } \\
\quad \text { (com ganho até } 2 \mathrm{SM} \text { ) } \\
\text { Iex chefes sem renda } \\
\text { Iex chefes com ganhos de + de } 1,5 \mathrm{SM} \text { e } 3 \mathrm{SM} \\
\text { Iex + de } 3 \text { a } 5 \mathrm{SM} \\
\text { Iex + de } 5 \text { a } 10 \mathrm{SM} \\
\text { Iex + de } 10 \text { a } 20 \mathrm{SM} \\
\text { Iex + de } 20 \mathrm{SM}\end{array}$ \\
\hline
\end{tabular}

Fonte: Mapa da exclusão/inclusão social da cidade de São Paulo. Sposati, 1996. 
Composição do índice de inclusão/exclusão social desenvolvimento humano (iexdh).

\begin{tabular}{|c|c|}
\hline Campo & Indicadores \\
\hline $\begin{array}{c}\text { Desenvolvimento } \\
\text { humano } \\
\text { Iexdh }\end{array}$ & $\begin{array}{l}\text { Iex de chefes de família não alfabetizados } \\
\text { Iex chefes de família com alfabetização precária } \\
\text { (até } 1 \text { ano de estudo) } \\
\text { Iex chefes de família não alfabetizados } \\
\text { Iex chefes de família com } 1 \text { a } 3 \text { anos de estudos } \\
\text { Iex chefes de família com } 4 \text { a } 7 \text { anos de estudo } \\
\text { Iex chefes de família com } 8 \text { a } 14 \text { anos de estudo } \\
\text { Iex chefes de família com + de } 15 \text { anos de estudo } \\
\text { Iex alfabetização precoce (aos } 5 \text { anos de idade) } \\
\text { Iex alfabetização tardia (10 a } 14 \text { anos de idade) } \\
\text { Iex concentração da longevidade da população } \\
\text { Iex mortalidade na infância } \\
\text { Iex mortalidade juvenil } \\
\text { Iex anos potenciais de vida perdidos } \\
\text { Iex casos de furto } \\
\text { Iex casos de roubo }\end{array}$ \\
\hline
\end{tabular}

Fonte: Mapa da exclusão/inclusão social da cidade de São Paulo. Sposati, 1996. 
Composição do índice de inclusão/exclusão social qualidade de vida (iexqv)

\begin{tabular}{|c|c|}
\hline Campo & Indicadores \\
\hline $\begin{array}{l}\text { Qualidade de } \\
\text { vida } \\
\text { Iexqv }\end{array}$ & $\begin{array}{l}\text { Iex domicílios precariamente servidos por água } \\
\text { Iex domicílios precariamente servidos por esgoto } \\
\text { Iex domicílios precariamente servidos por coleta de } \\
\quad \text { lixo } \\
\text { Iex densidade habitacional } \\
\text { Iex oferta banheiro/domicílio } \\
\text { Iex densidade pessoa/banheiro } \\
\text { Iex oferta dormitório/domicílio } \\
\text { Iex densidade pessoa/dormitório } \\
\text { Iex concentração de moradias precárias } \\
\quad \text { (favela, cortiço e improvisados) } \\
\text { Iex concentração de população moradora em habitação } \\
\text { precária (favela, cortiço e improvisados) } \\
\text { Iex garantia de moradia } \\
\text { Iex potencial de atração de investimento público } \\
\text { Iex uso do tempo útil } \\
\text { Iex potencial de acesso à saúde básica } \\
\text { Iex cobertura pública de matrículas }\end{array}$ \\
\hline
\end{tabular}

Fonte: Mapa da exclusão/inclusão social da cidade de São Paulo.

Sposati, 1996. 
Composição do índice de inclusão/exclusão social eqüidade (iexeq)

\begin{tabular}{|c|l|}
\hline Campo & \multicolumn{1}{c|}{ Indicadores } \\
\hline $\begin{array}{c}\text { Eqũidade } \\
\text { Iexeq }\end{array}$ & $\begin{array}{c}\text { Iex concentração de mulheres chefes de familia } \\
\text { Iex concentração de mulheres chefes de familia } \\
\text { não alfabetizadas }\end{array}$ \\
\hline
\end{tabular}

Fonte: Mapa da exclusão/inclusão social da cidade de São Paulo. Sposati, 1996. 
Distribuição dos distritos de São Paulo, segundo índice global de inclusão/exclusão social - Iex

DISTRITO

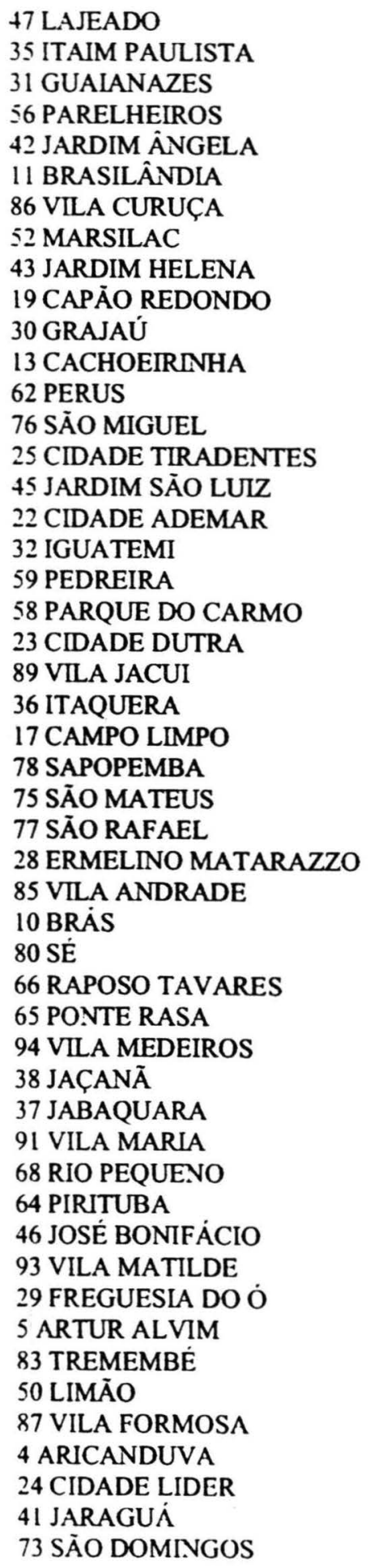

IEX

$-1,00$

$-0,95$

$-0,87$

$-0,87$

$-0,83$

$-0,83$

$-0,80$

$-0,79$

$-0,78$

$-0,74$

$-0,73$

$-0,73$

$-0,72$

$-0,71$

$-0,70$

$-0,69$

$-0,68$

$-0,68$

$-0,64$

$-0,63$

$-0,61$

$-0,60$

$-0,59$

$-0,58$

$-0,55$

$-0,53$

$-0,52$

$-0,52$

$-0,51$

$-0,49$

$-0,45$

$-0,43$

$-0,42$

$-0,41$

$-0,41$

$-0,40$

$-0,40$

$-0,39$

$-0,39$

$-0,37$

$-0,36$

$-0,35$

$-0,33$

$-0,32$

$-0,32$

$-0,31$

$-0,29$

$-(0,27$

$-0,27$

$-0,27$
DISTRITO

IEX

18 CANGAIBA

$-0,25$

57 PARI

$-0,24$

95 VILA PRUDENTE $\quad-0,22$

40 JAGUARÉ $\quad-0,20$

39 JAGUARÁ $\quad-0,19$

74 SÃO LUCAS $\quad-0,18$

21 CASA VERDE $\quad-0,18$

20 CARRÃO $-0,15$

8 BELÉM $-0,15$

67 REPÚBLICA $-0,14$

49 LIBERDADE $\quad-0,13$

1 ÁGUA RASA $\quad-0,10$

60 PENHA $\quad-0,10$

51 MANDAQUI $\quad-0,08$

88 VILA GUILHERME $\quad-0,08$

81 SOCORRO $\quad-0,08$

69 SACOMÃ $\quad-0,08$

9 BOM RETIRO $\quad-0,05$

70 SANTA CECILLA $\quad-0,05$

3 ANHANGUERA $\quad-0,04$

33 IPIRANGA $\quad-0,02$

84 TUCURUVI $\quad-0,02$

96 VILA SONIA $\quad-0,01$

14 CAMBUCI $\quad 0,04$

90 VILA LEOPOLDINA $\quad 0,04$

16 CAMPO GRANDE $\quad 0,09$

6 BARRA FUNDA 0,16

82 TATUAPÉ $\quad 0,17$

27 CURSINO $\quad 0,17$

54 MOOCA 0,20

26 CONSOLAÇÃO $\quad 0,20$

7 BELA VISTA $\quad 0,26$

55 MORUMBI $\quad 0,27$

48 LAPA $\quad 0,29$

63 PINHEIROS $\quad 0,30$

79 SAÚDE $\quad 0,36$

71 SANTANA $\quad 0,37$

12 BUTANTÃ $\quad 0,38$

34 ITAIM BIBI $\quad 0,38$

61 PERDIZES $\quad 0,41$

92 VILA MARIANA $\quad 0,48$

15 CAMPO BELO $\quad 0,48$

72 SANTO AMARO 0,51

44 JARDIM PAULISTA $\quad 0,54$

2 ALTO DE PINHEIROS $\quad 0,83$

53 MOEMA $\quad 1,00$ 
Anexo 2.

Questionário geral. 

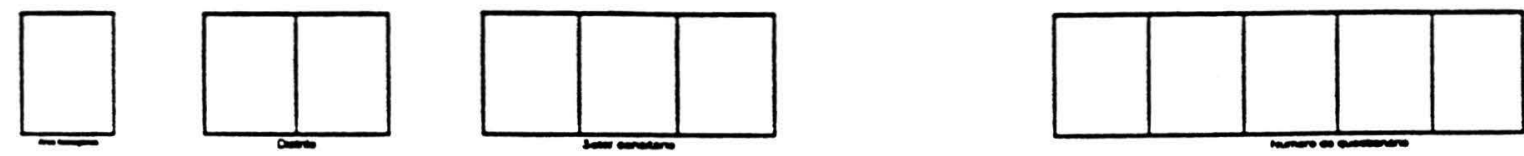

FATORES DE RISCO PARA DOENÇAS CRÓNICAS NĀO-TRANSMISSIVEIS: INQUÉRITO DOMICILIAR NO MUNICÍPIO DE SÃO PAULO

\section{QUESTIONÁRIO GERAL}

SÓ COMEÇAR POR ESTE QUESTIONÁRIO SE A PESSOA A SER ENTREVISTADA NÃO ESTIVER EM JEJUM PARA COLETA DE SANGUE.

DIVISÃO DE DOENÇAS CRÓNICAS NĀO-TRANSMISSIVEIS

CENTRO DE VIGILÂNCIA EPIDEMIOLÓGICA

SECRETARIA DE ESTADO DA SAÚDE DE SÃO PAULO

Versão 09/01/2001

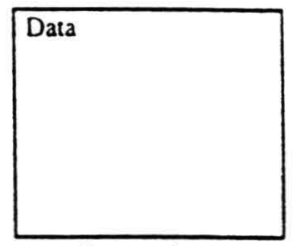

Supervisor

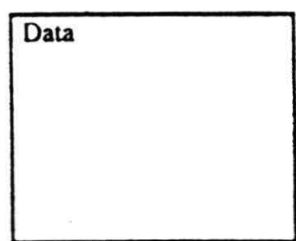

Codificador

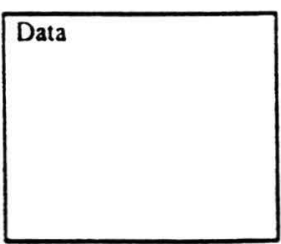

Digitador 1

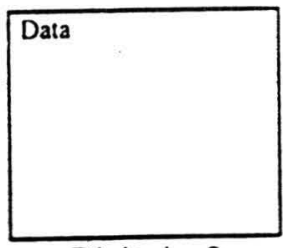

Digitador 2 
NÃO ESCREVER

NESTE ESPAÇO A01

A01 NÚMERO DO QUESTIONÁRIO

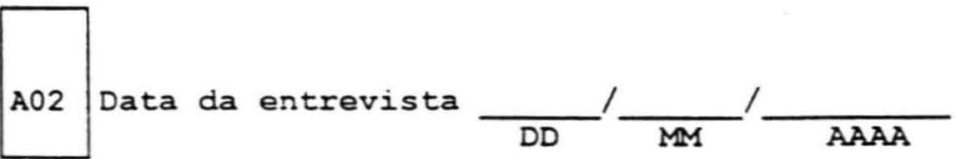

201

Entrevistador (a) :

201

\section{BLOCO A - IDENTIFICAÇÃO DO DOMICÍLIO}

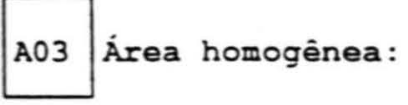

A04 Distrito:

A05 Setor censitário:

A06 Ponderação:

LISTAGEM DE TODOS OS MORADORES ADULTOS DO DOMICILIO COM IDADE ENTRE 15 E 59 ANOS.

(Listar todos os homens em ordem decrescente de idade e. em seguida. todas as mulheres. tambèm em ordem decrescente de idade.)

\begin{tabular}{|l|l|l|l|}
\hline $\begin{array}{c}\text { So pretercerer comat } \\
\text { o oretan ao finat }\end{array}$ & NOME & SEXO & IDADE \\
\hline & & & \\
\hline & & & \\
\hline & & & \\
\hline & & & \\
\hline & & & \\
\hline & & & \\
\hline & & & \\
\hline & & & \\
\hline & & & \\
\hline
\end{tabular}

\section{QUADRO DE SORTEIO}

Verificar o número de azultos moraocres. Assinalar este número na linha superior co quadro adaixo. 0 entrevistado deverá ser 0 morador com. o número de ordem na :Istagem igual ao número situado exatamente abaixo do número de moradores.

\begin{tabular}{|c|l|l|l|l|l|l|l|l|l|l|}
\hline Número de moradores & 1 & 2 & 3 & 4 & 5 & 6 & 7 & 8 & 9 & 10 \\
\hline Pessoa sorteada & & & & & & & & & & \\
\hline
\end{tabular}


BLOCO B - IDENTIFICAÇÃO DEMOGRÁFICA B01 Nome

NĀO ESCREVER

NESTE ESPAÇO

B01 $---$

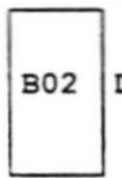

Data de nascimento
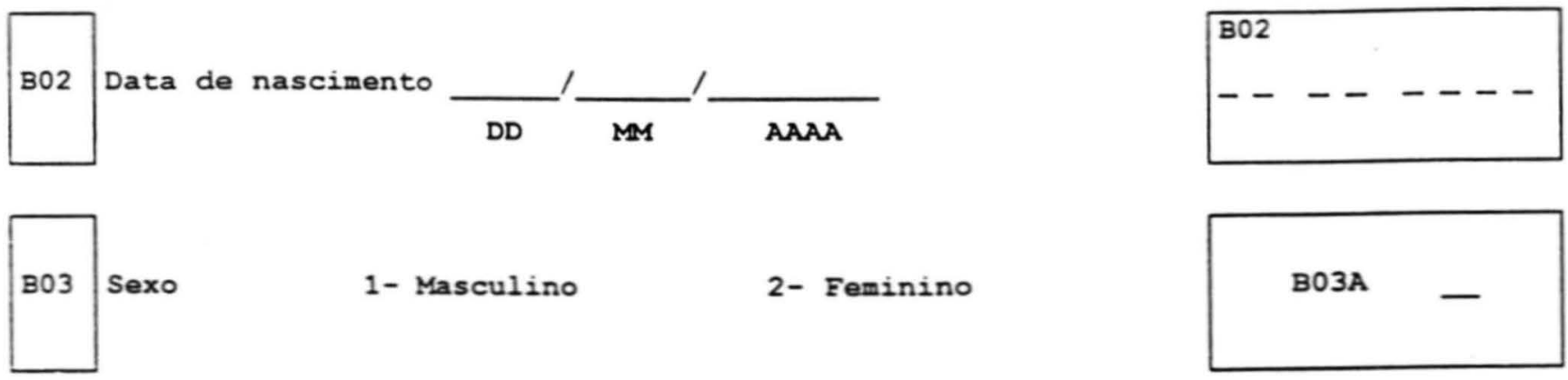

1- Masculino

2- Feminino

BO3A

B04 Qual o local do seu nascimento?

[A] Pais [B] UF

[C] Municipio

B05 Desde quando reside no municipio de São Paulo?

B05

B06 Cor / raça

[A] Cor que predomina na aparência :

1 - Branca

2- Mulata (parda)

3- Preta (negra)

4- Amarela (oriental)

5- Outra:

[B] Cor auto-declarada pelo(a) entrevistado(a):

\section{1- Branca}

2- Mulata (parda)

3- Preta (negra)

4- Amarela (oriental)

5- Outra:

9- NS/NQR

stado civil/conjugal atual

1 - Casado (a)

5- Divorciado(a)

2- Amigado (a)

6- Solteiro(a)

3- Viúvo(a)

7- Outro:

4- Separado (a) 

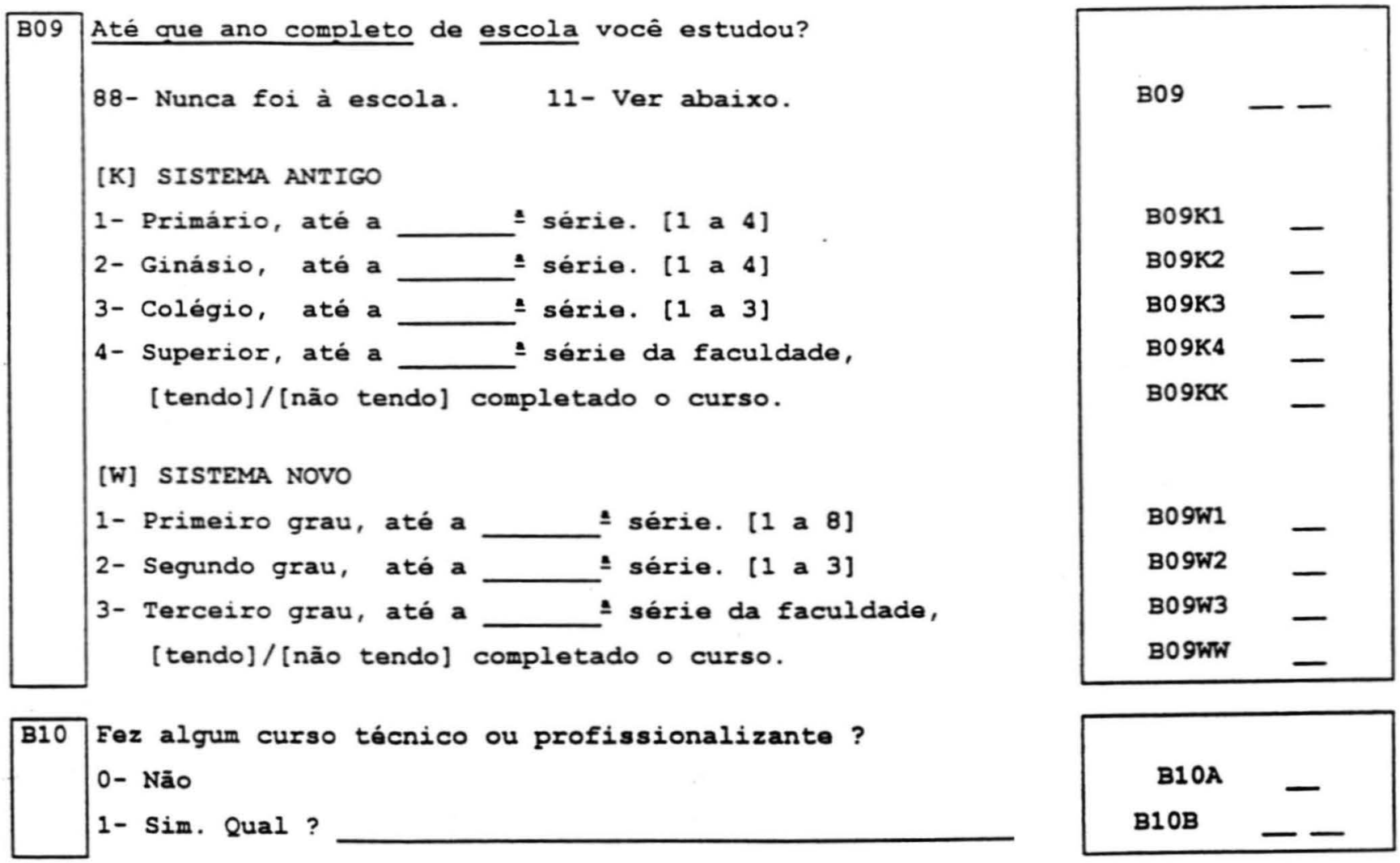

\section{BLOCO C - IDENTIFICAÇÃO SÓCIO-ECONÔMICA}

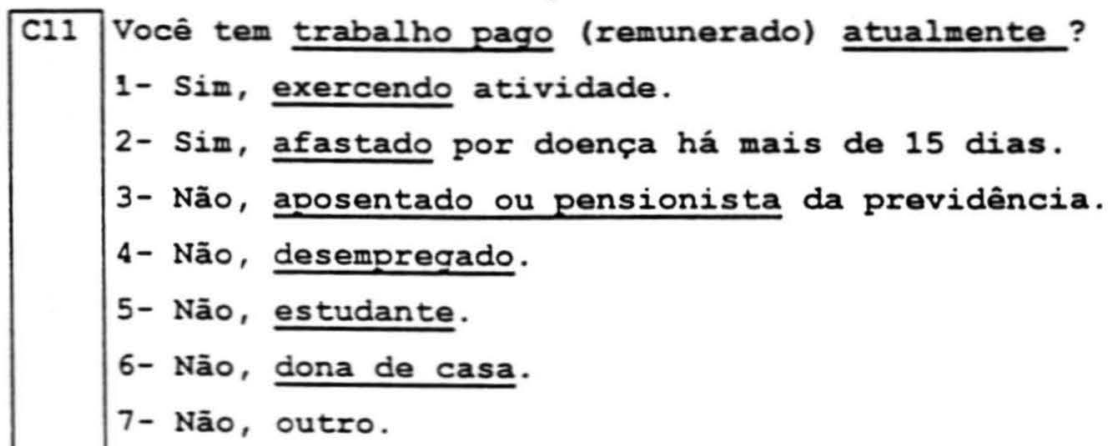

B- Em que ocupação você trabalhou a maior parte da sua vida profissional ? 
No seu trabalho remunerado principal vocé é:

1 - empregado assalariado.

2 - empregado que só recebe por comissão, produçã de serviço, peças, tarefas.

3- empregado que presta serviço militar obrigatório, assistencial ou religioso com alguma remuneração.

4- empregador. Número de funcionários:

5- profissional liberal autônomo.

6- conta-própria ou autônomo que trabalha para a população geral.

7- conta-própria ou autônomo que trabalka exclusivamente para firmas ou empresas.

8- Não se aplica.

Quanto você ganhou com esse trabalho no mês passado?

] Ganho liquido RS

[ ] Não se aplica.

C14
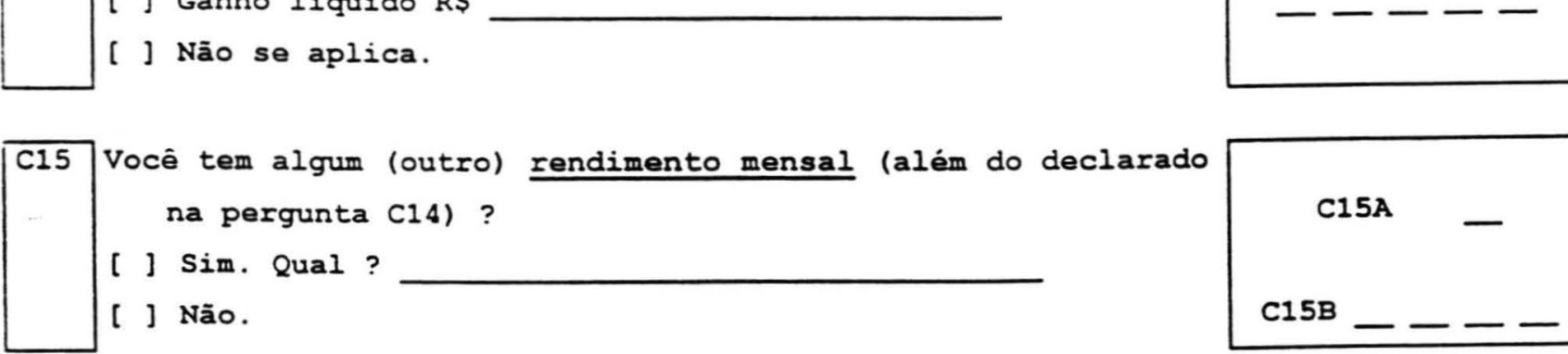

Você tem algum (outro) rendimento mensal (além do declarado na pergunta (14) ?

[ ] Sim. Qual?

[ ] Não.

Quanto você ganhou com estes rendimentos no mês passado?

[ ] Renda líquida R\$

[ ] Não se aplica.

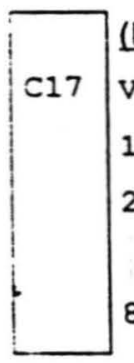

\section{(ESTA PERGUNTA É SÓ PARA APOSENTADOS)}

Você está aposentado por qual motivo?

1- Tempo de serviço.

2- Doença ou invalidez.

Qual foi a causa?

8- Não se aplica.

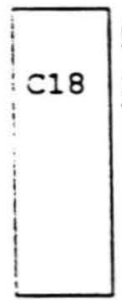

(ESTA PERGUNTA É SÓ PARA DESEMPREGADOS)

Há guantos meses você está desempregado?

[ ] meses.

[ ] Não se aplica.

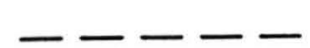

C17B

C15A

C15B

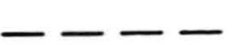

\section{C16}

C17A

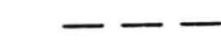




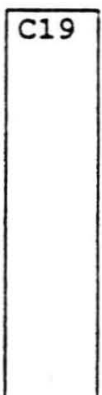

[A] Qual foi a renda familiar total no último mês?

[ ] Renda líquida RS

[B] Contando com você, quantas pessoas no total moram neste domicílio ? pessoas

C19B

C19A

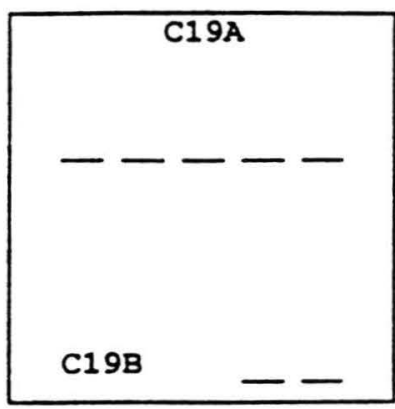

[A] A residência em que você vive é

1- Própria, quitada.

2- Própria, não-quitada.

3- Alugada.

4 - Cedida.

5- Outro:

[B] Há despesa mensal de condominio ?

1- Sim

o- Não

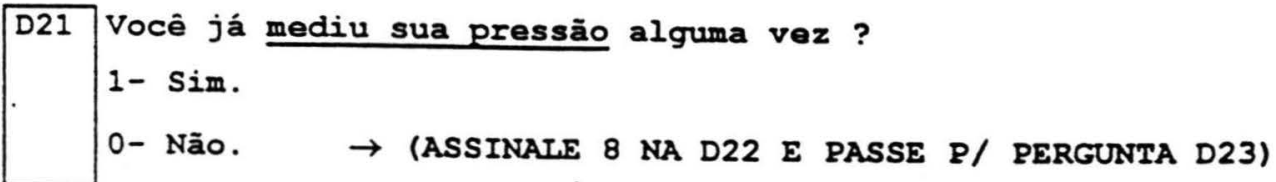

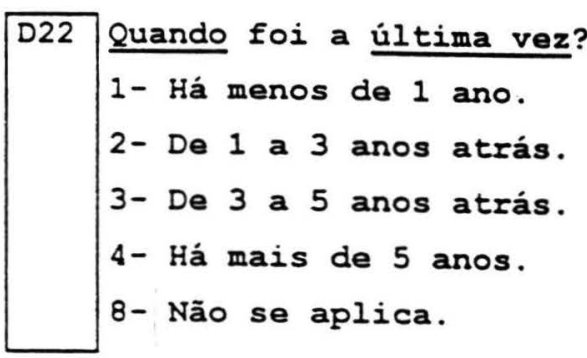

D23 Algum médico, alguma vez, lhe disse que você tem pressão alta?

1-Sim.

0- Não. $\rightarrow$ (ASSINALE 8 NAS PERGUNTAS D24 A D28

$\rightarrow$ E PASSE P/ PERGUNTA D29)
C20B

NÃO ESCRSVER

NESTE ESPAÇO

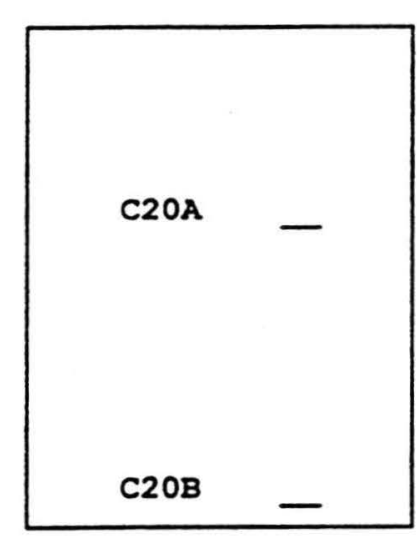

D21

D22

D23 

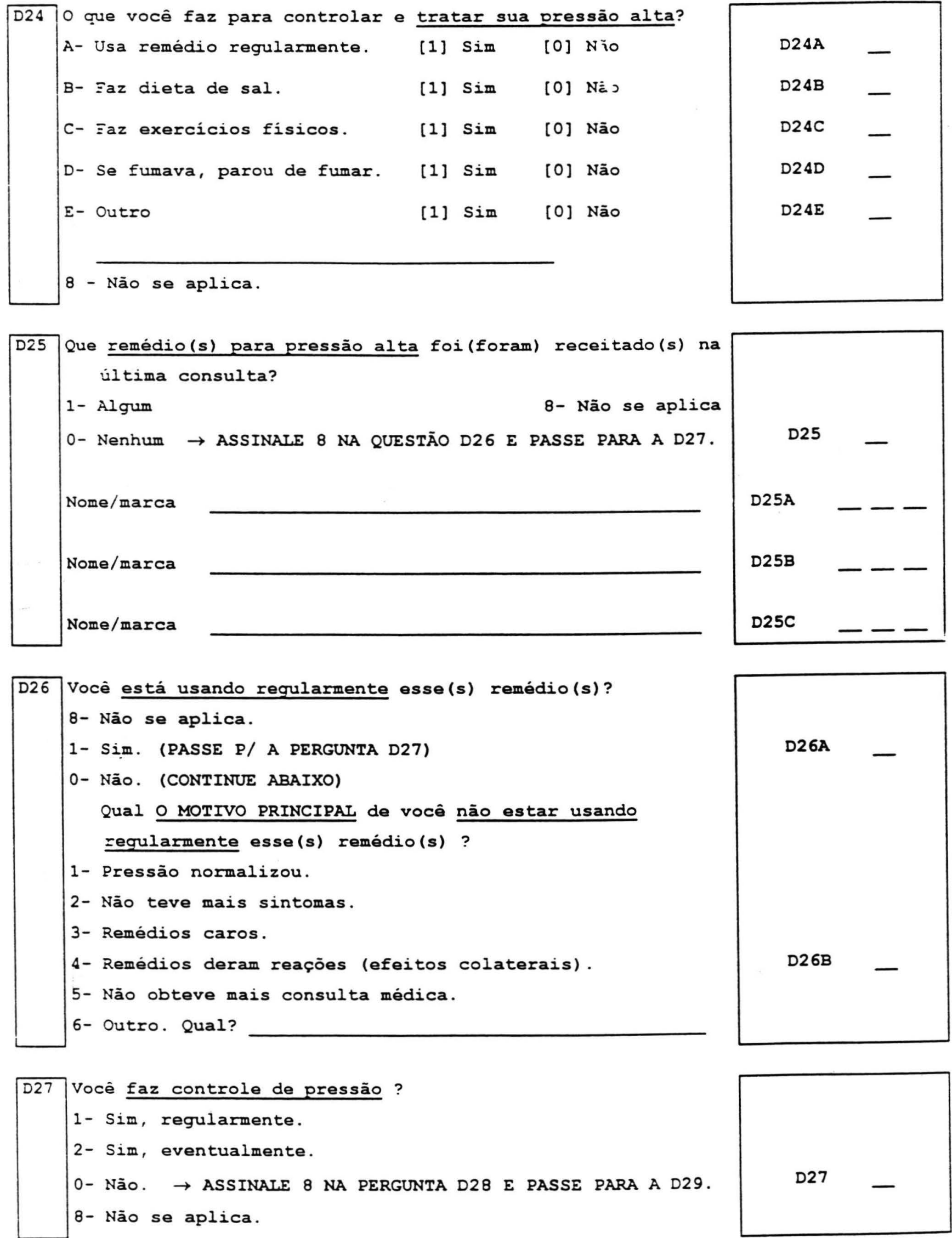

\begin{tabular}{ll|l|} 
Vocé faz controle de pressão ? \\
1- Sim, regularmente. \\
2- Sim, eventualmente. \\
0- Não. $\rightarrow$ ASSINALE 8 NA PERGUNTA D28 E PASSE PARA A D29. \\
8- Não se aplica.
\end{tabular}




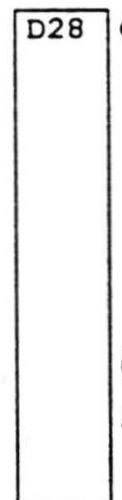

Que tipo de serviço de saúde você utiliza, na maioria das vezes, para fazer o controle da pressão alta?

(ANOTAR O NOME OU TIPO DE SERVIÇO E, SE NECESSÁRIO, ENDEREÇO - MESMO QUE APROXIMADO, NO CASO DE O ENTREVISTADO NĀO SABER PRECISAR O TIPO DE SERVIÇO).

8- Não se aplica.

\begin{tabular}{|l|r|r|} 
D29 Você tem algum parente consangüineo (de sangue) que tenha & \\
ou teve pressão alta? & 9- NS/NQR & \\
1- Sim. & D29 \\
O- Não. & & \\
(SE SIM, ESPECIFIQUE O GRAU DE PARENTESCO DE TODOS OS & \\
FAMILIARES CITADOS): & D29A & - \\
& D29B & - \\
& D29C & - \\
\end{tabular}

BLOCO E - METABOLISMO

NÃO ESCREVER NESTE ESPAÇO
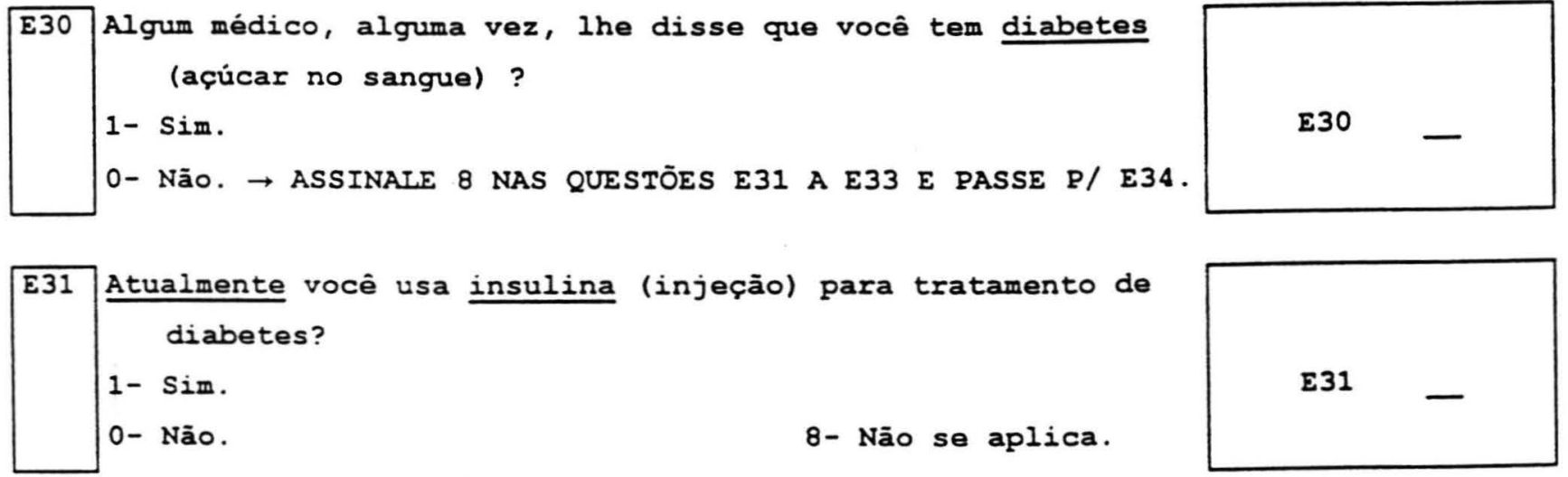
E32 Atualmente você toma algum tipo de comprimido para tratamento de diabetes?
1- Sim.
0 - Não.
8- Não se aplica.



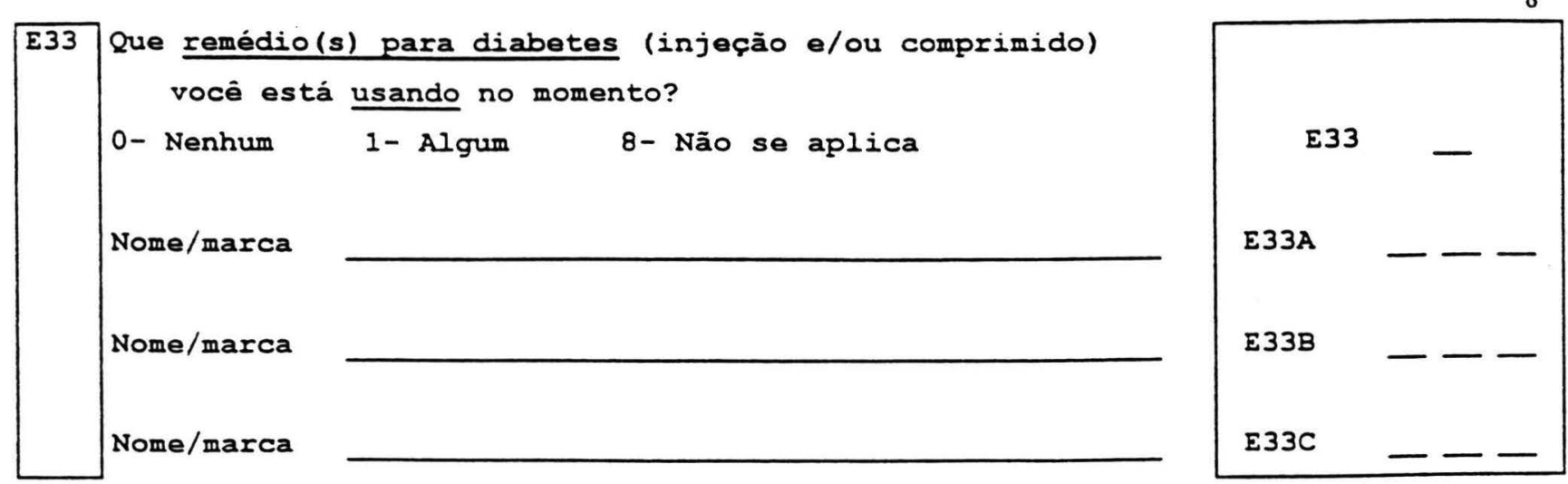

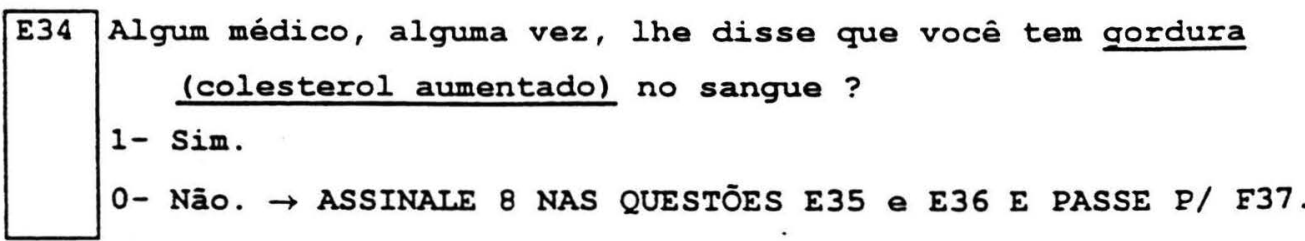
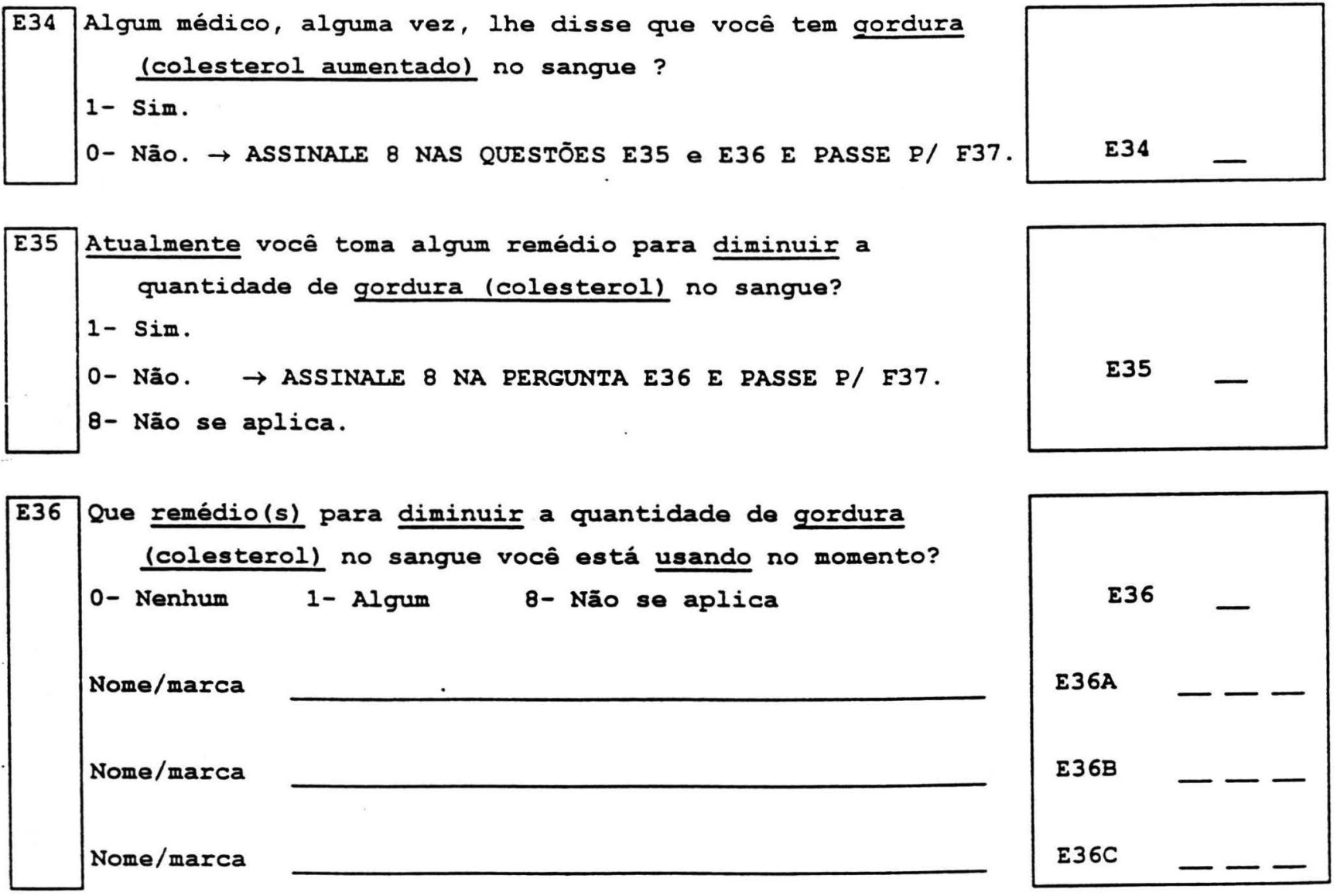

\section{BLOCO F - ANABOLIZANTES}

NÃO ESCREVER

NESTE ESPAÇO
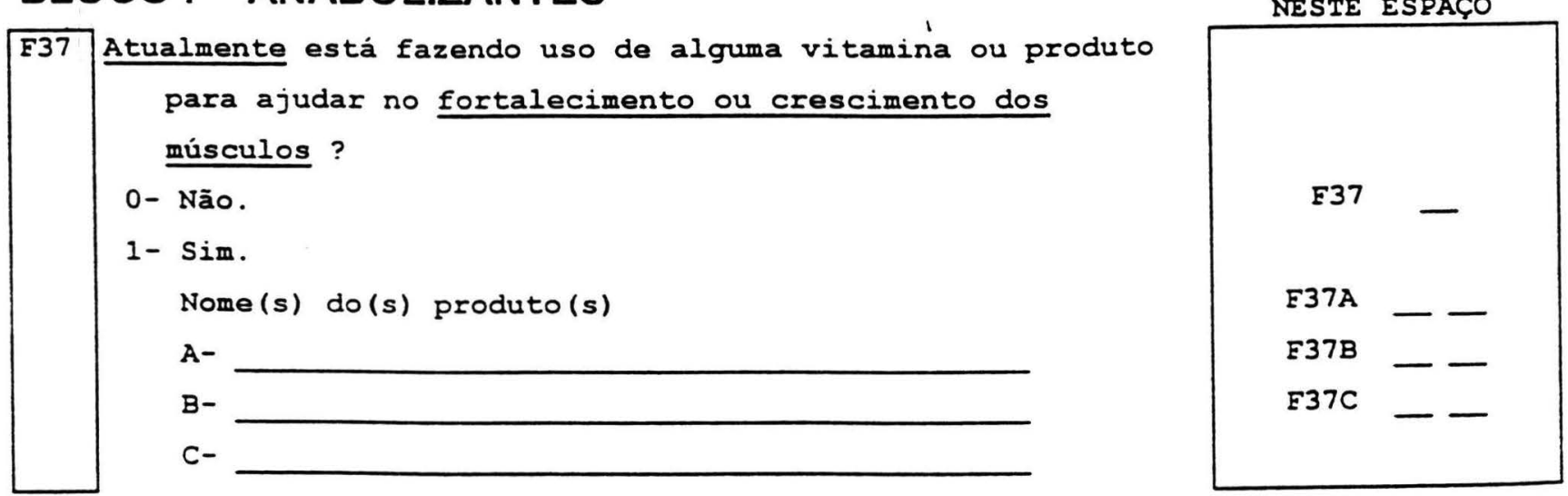
BLOCO G - APENAS PARA O SEXO FEMININO
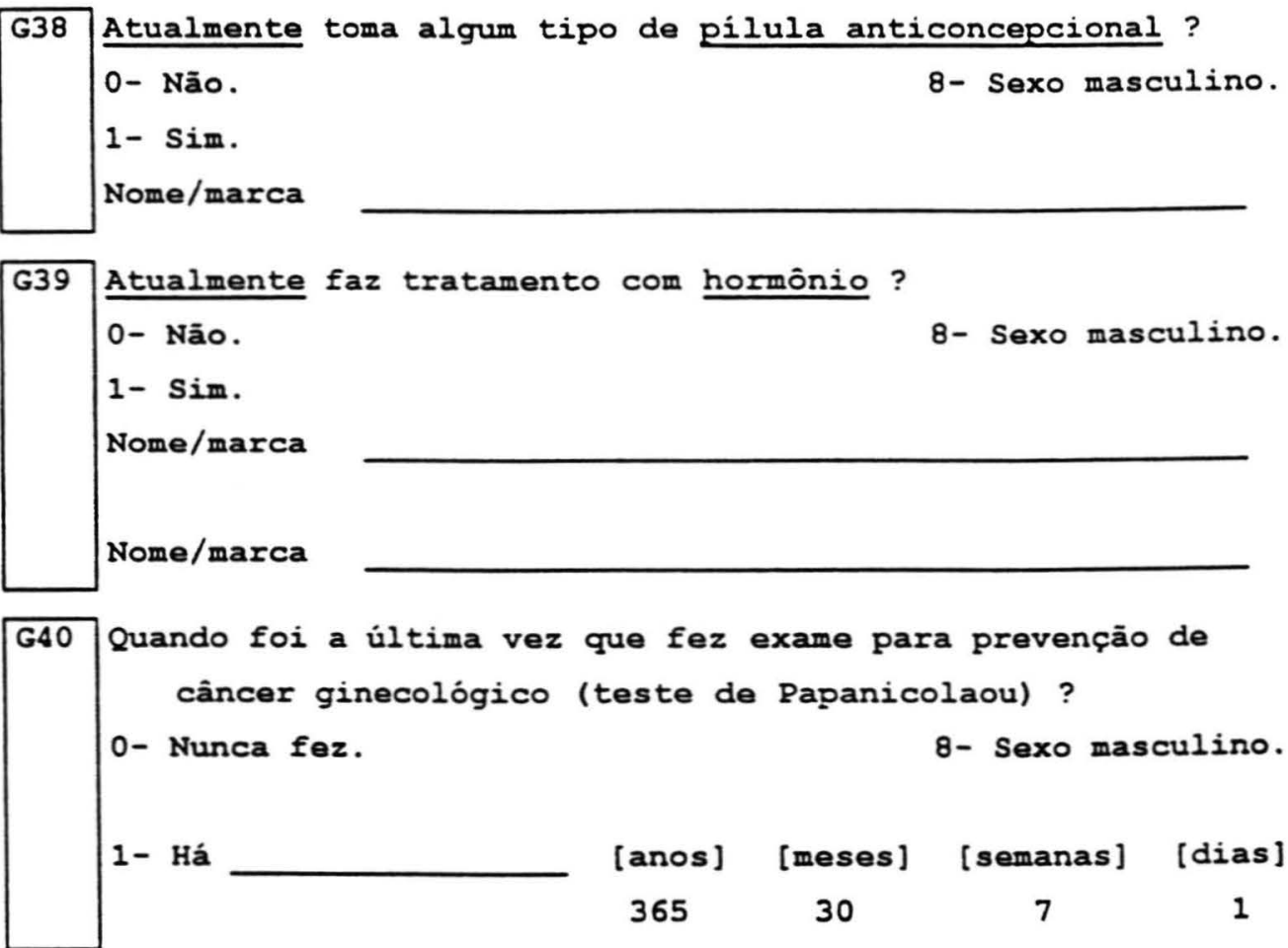

G41 Quando foi a última vez que fez auto-exame para prevenção de caroço (ou câncer) do seio (ou de mama) ?

0- Nunca fez.

8- Sexo masculino.

1- Há

$\begin{array}{cccc}\text { [anos] } & \text { [meses] } & \text { [semanas] } & \text { [dias] } \\ 365 & 30 & 7 & 1\end{array}$

G42 Quando foi a última vez que um médico fez exame para prevenção de caroço (ou câncer) do seio (ou de mama) ? 0- Nunca fez. 8- Sexo masculino.

1- Há [anos] [meses] [semanas] [dias] 365 30 7 1

G43 Quando foi sua última regra ou menstruação ou incômodo ? 0 - Nunca teve.

8- Sexo masculino.

1- Há [anos

[meses]

30 NESTE ESPAÇO
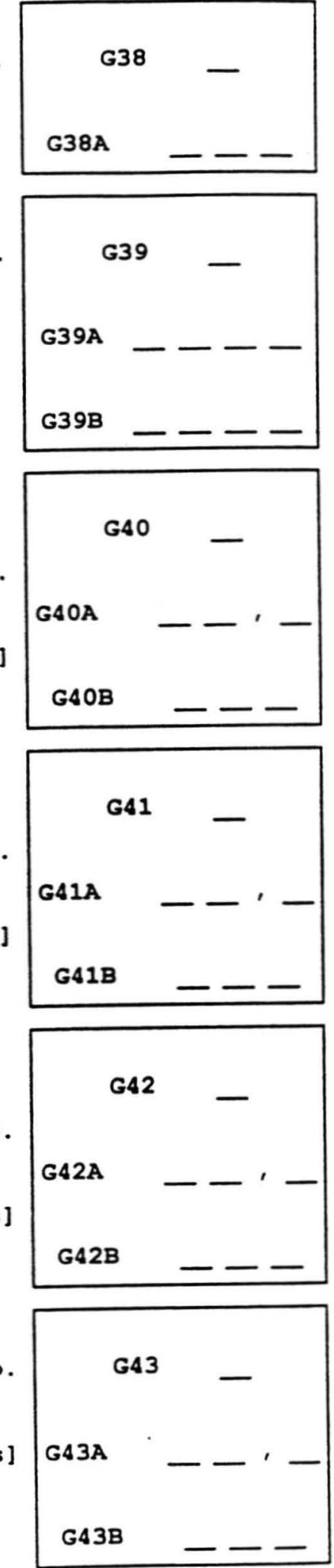

G44 Já chegou sua menopausa ?
0 - Não.
1 - Sim.

8- Sexo masculino.

9- NS/NQR 


\section{ATENÇÃO !}

INTERROMPER O INTERROGATÓRIO AQUI, PARA A PRIMEIRA MEDIDA DE PULSO E PRESSÃO ARTERIAL.

MARCAR OS RESULTADO DAS MEDIDAS NO LOCAL APROPRIADO, À PÁGINA 23 DESTE FORMULÁRIO.

RETOMAR O INTERROGATÓRIO EM SEGUIDA, REINICIANDO DA PÁGINA 11. 
H52 Você costuma fumar cigarros fracos, isto é, de baixo teor? $1-\operatorname{sim}$.

0- Não.

8- Não se aplica.

H52 $-$

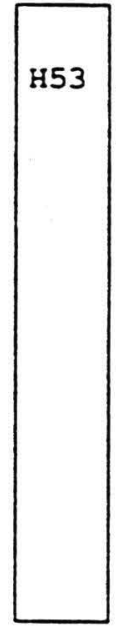

A- Quantos cigarros você fuma por dia?

B- Que outra forma de tabaco e em que quantidade vocè fuma por dia? $\rightarrow$ ASSINALE TANTAS QUANTAS SE APLICAREM.

[ ] Cigarrilha

por dia.

[ ] Charuto

por dia.

[ ] Cachimbada

por dia.

[ ] Cigarro de palha por dia.

[ ] Outra (especificar abaixo) por dia.

H53A

888 - Não se aplica.
H54 Você já tentou seriamente parar de fumar?
1- Sim.
0- Não. $\rightarrow$ ASSINALE 8 NA PERGUNTA H55 E PASSE P/ H56.
8- Não se aplica.

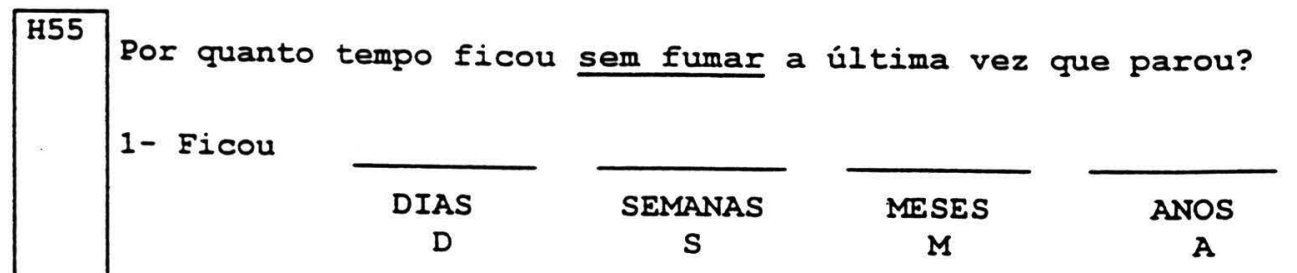

8- Não se aplica.

H56 Daqui a 5 anos você acha que seu modo de fumar terá mudado? 1- Sim.

0 - Não. $\rightarrow$ ASSINALE 8 NA PERGUNTA H57 E PASSE P/ H58. 8- Não se aplica.

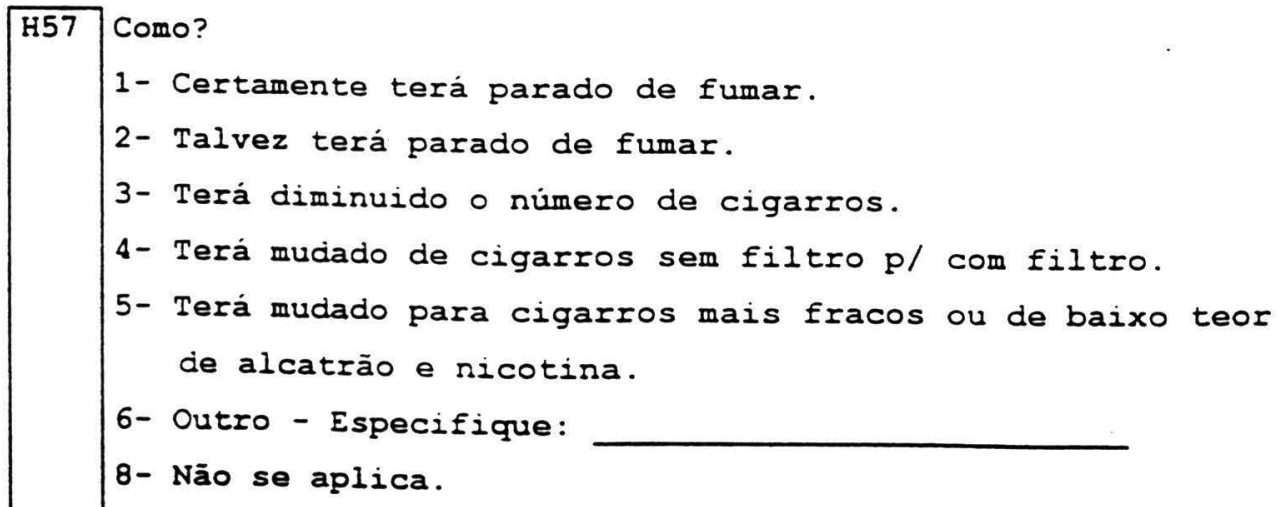




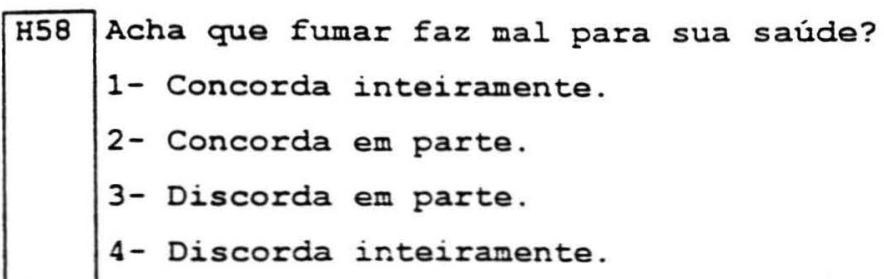

Que tipo de problema(s) o habito de funar pode causar para sua saúde?

A

B

C

9000 - Nenhum.

\section{BLOCO I - ÁLCOOL}

I60 Quando foi a última vez que você tomou bebida alcoolica, qualquer que seja ?

Foi em
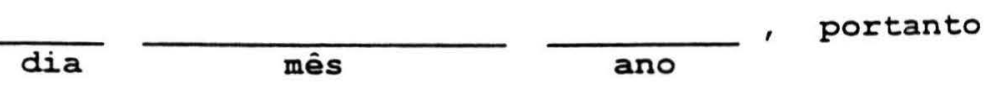

2- há menos de 1 ano. $\rightarrow$ CONTINUE COM A QUESTÃo I61.

1- faz mais de um ano. $\rightarrow$ ASSINALE "Não se aplica" ATÉ A QUESTÃO I66 E PASSE PARA O BLOCO J, QUESTÃO J67.

0- Nunca tomou. $\rightarrow$ ASSINALE "Não se aplica" AtÉ A QUESTÃo I66 E PASSE PARA O BLOCO J, QUESTÃO J67.

Com que freqüência você toma bebida alcoólica (de qualquer tipo, incluindo cerveja, vinho, pinga, uisque, etc.) ?

2- Diariamente.

$1-$ vez(es) por [ ] semana

[ ] mês

[ ] ano

8- Não se aplica.
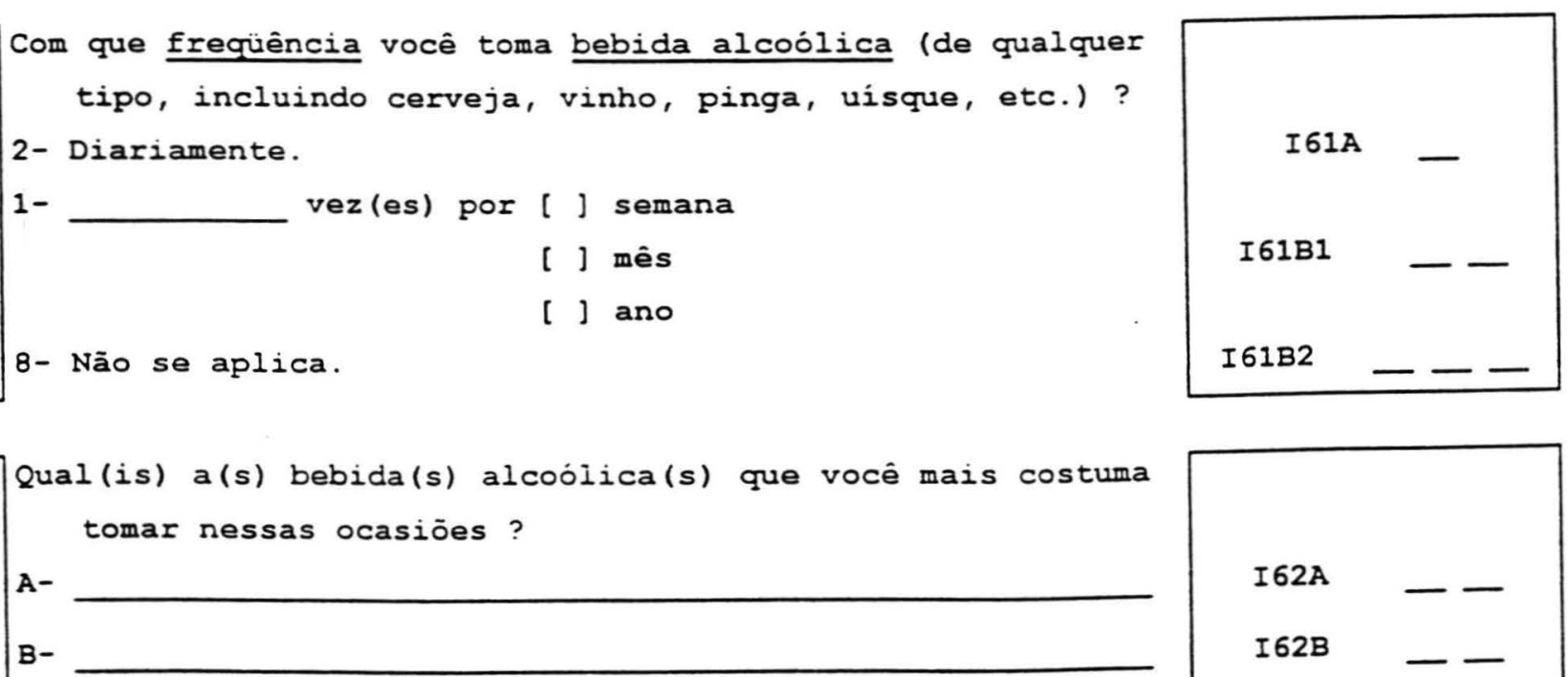

NĀO ESCREVER

NESTE ESPAÇO
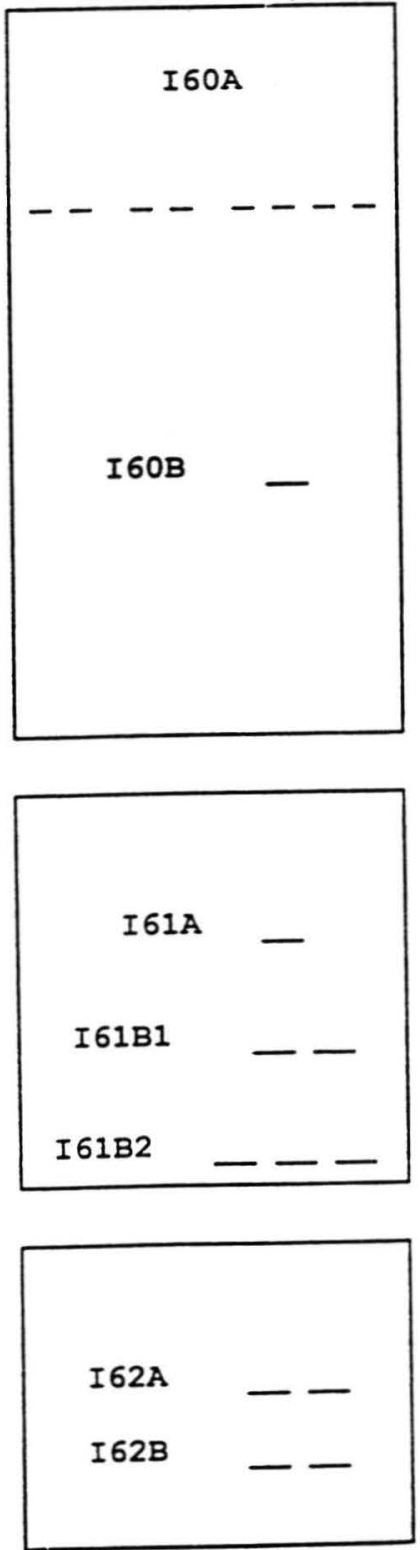

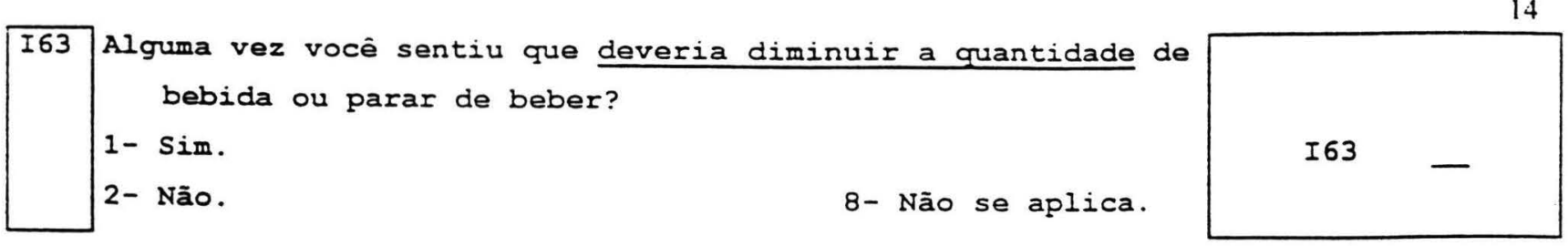

\begin{tabular}{|c|c|c|}
\hline I64 & $\begin{array}{l}\text { As pessoas o(a) aborrecem porque criticam o seu modo de } \\
\text { beber? } \\
\begin{array}{ll}\text { 1- Sim. } & \text { - Não se aplica. } \\
\text { 2- Não. } & \text { - }\end{array}\end{array}$ & I64 \\
\hline
\end{tabular}

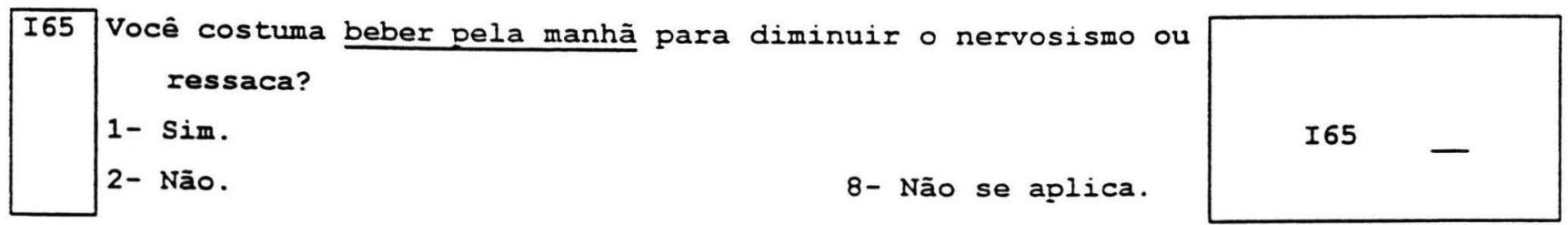

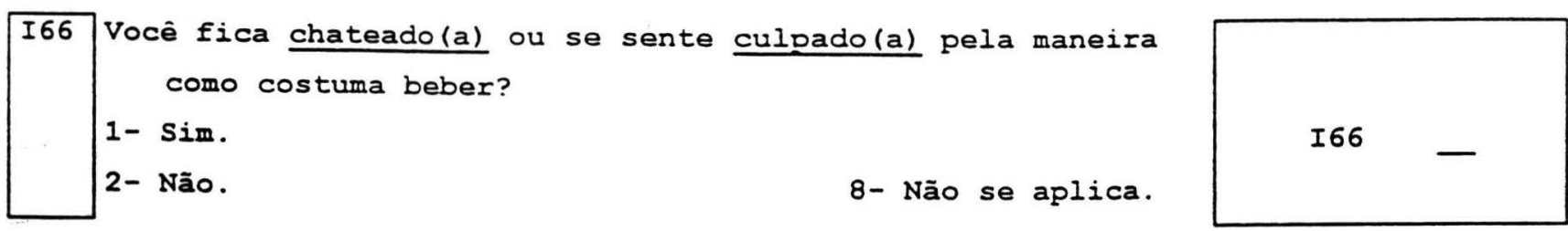

\section{BLOCO J - ATIVIDADE FISICA}

NÃO ESCREVER

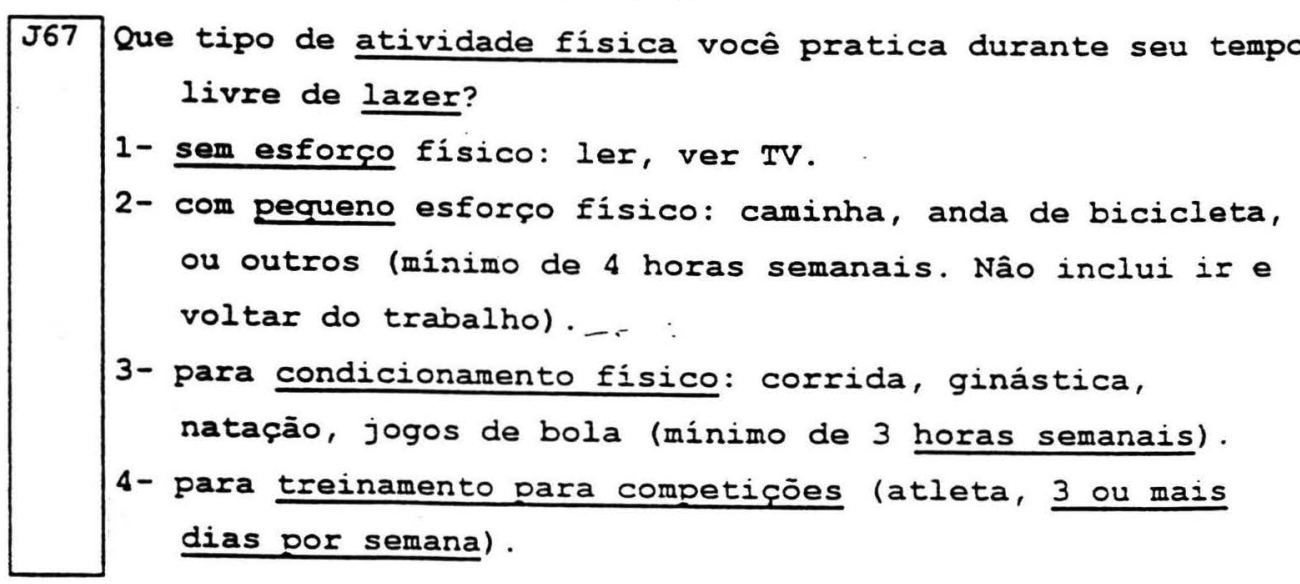
J68 Atividades leves ou moderados são aquelas que fazem você suar pouco ou aumentam leve ou moderadamente sua respiração ou batimentos do coração. Quantas vezes por semana você realiza essas atividades por pelo menos 10 minutos?
[ ] Freqüência: vez(es) por semana, ou 00- Nunca. 88- Incapaz de fazer esse tipo de atividade.


Atividades vigorosas são aquelas que fazem você suar bastante ou aumentam muito sua respiração ou batimentos do ccração. Quantas vezes por semana você realiza essas atividades por pelo menos 10 minutos ?

[ ] Frequência: vez(es) por semana, ou 00 - nunca.

88- Incapaz de fazer esse tipo de atividade.

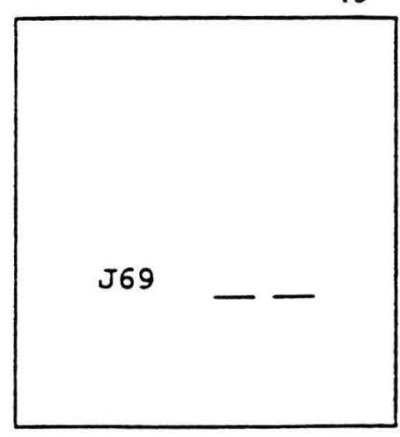

J70 Quantos minutos gasta caminhando, andando de bicicleta ou fazenco outro tipo de atividade fisica ro caminho de seu serviço e/ou escola por dia ?

1 - Menos de 15 minutos.

2- De 15 a 29 minutos.

3- De 30 a 59 minutos.

4- 60 minutos ou mais.

8- Não se aplica.

J71 Assinale qual destas frases bate com o que você pensa em relação ao exercício hoje:

[ ] Agora eu não quero me dedicar ao exercicio regular.

[ ] Eu não tenho necessidade de fazer exercício regular.

[ ] Eu não penso em me dedicar a fazer exercicio.

[ ] Ás vezes eu me preocupo com a falta de exercicio regular.

[ ] Às vezes eu penso que deveria me dedicar ao exercicio regular.

[ ] Eu penso em me dedicar a fazer exercicio regularmente mas nunca consigo.

[ ] Eu estou seriamente pensando como me dedicar a fazer exercicio regularmente em un futuro próximo.

[ ] Eu gostaria de me dedicar a fazer exercicio regular mas não tenho certeza como começar.

[ ] Eu fiz exercicio regular no passado e gostaria de voltar a fazer isso logo.

[ ] Eu já faço exercicio e quero manter.

[ ] Eu já faço exercicio e quezo aumentar.

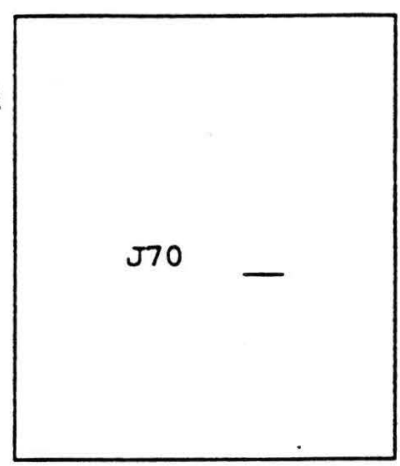

\begin{tabular}{|ll|}
\hline J71A & - \\
J71B & - \\
J71C & - \\
J71D & - \\
J71E & - \\
J71E & - \\
J71G & - \\
J71H & - \\
J71I & - \\
J71K & \\
\hline
\end{tabular}


INSTRUÇÕES PARA A QUESTÃO NO.J72, QUE VEM A SEGUIR

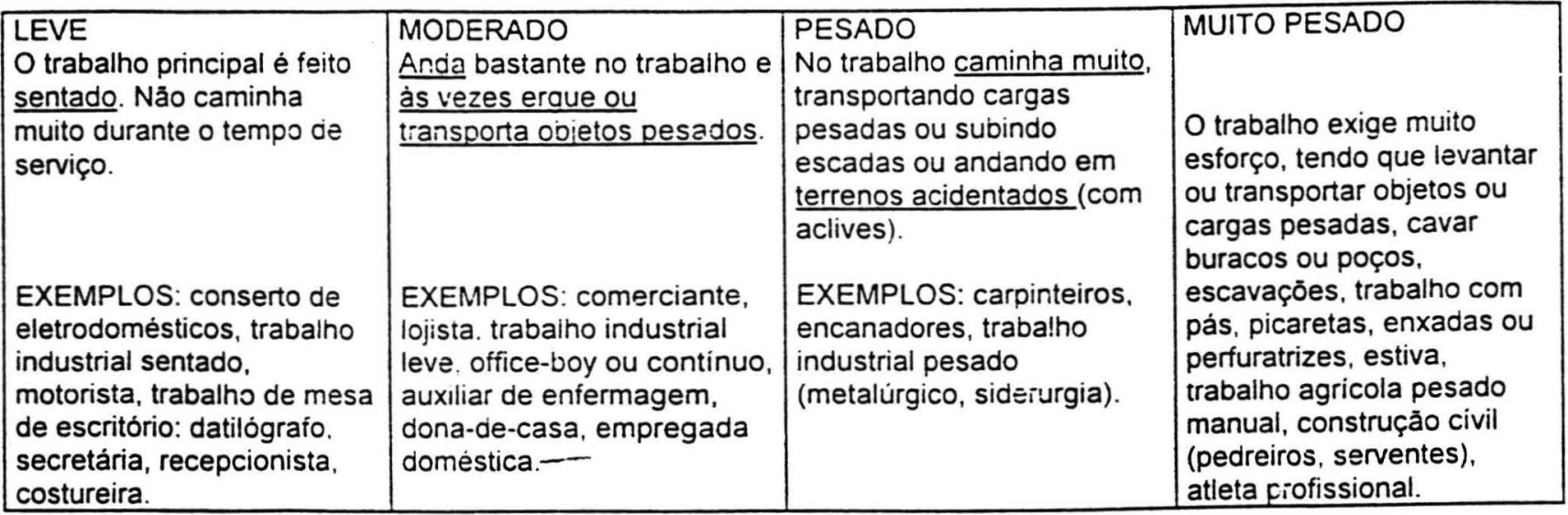

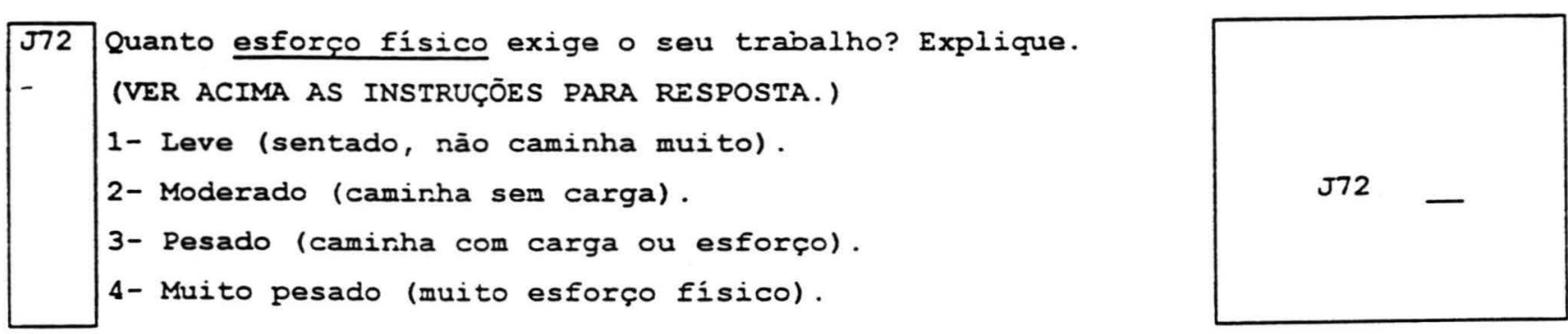

\section{BLOCO K - ESTRESSE}

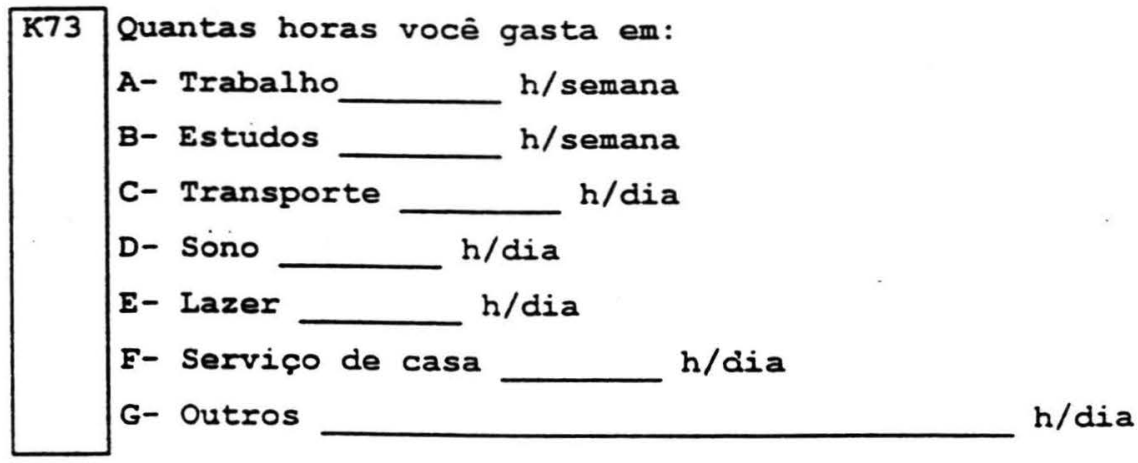

NÃO ESCREVER NESTE ESPAÇO

$\mathrm{K} 72 \mathrm{~A}--$
$\mathrm{K} 72 \mathrm{~B}--$
$\mathrm{K} 72 \mathrm{C}-$
$\mathrm{K} 72 \mathrm{D}--$
$\mathrm{K} 72 \mathrm{E}--$
$\mathrm{K} 72 \mathrm{E}--$
$\mathrm{K} 72 \mathrm{G}--$
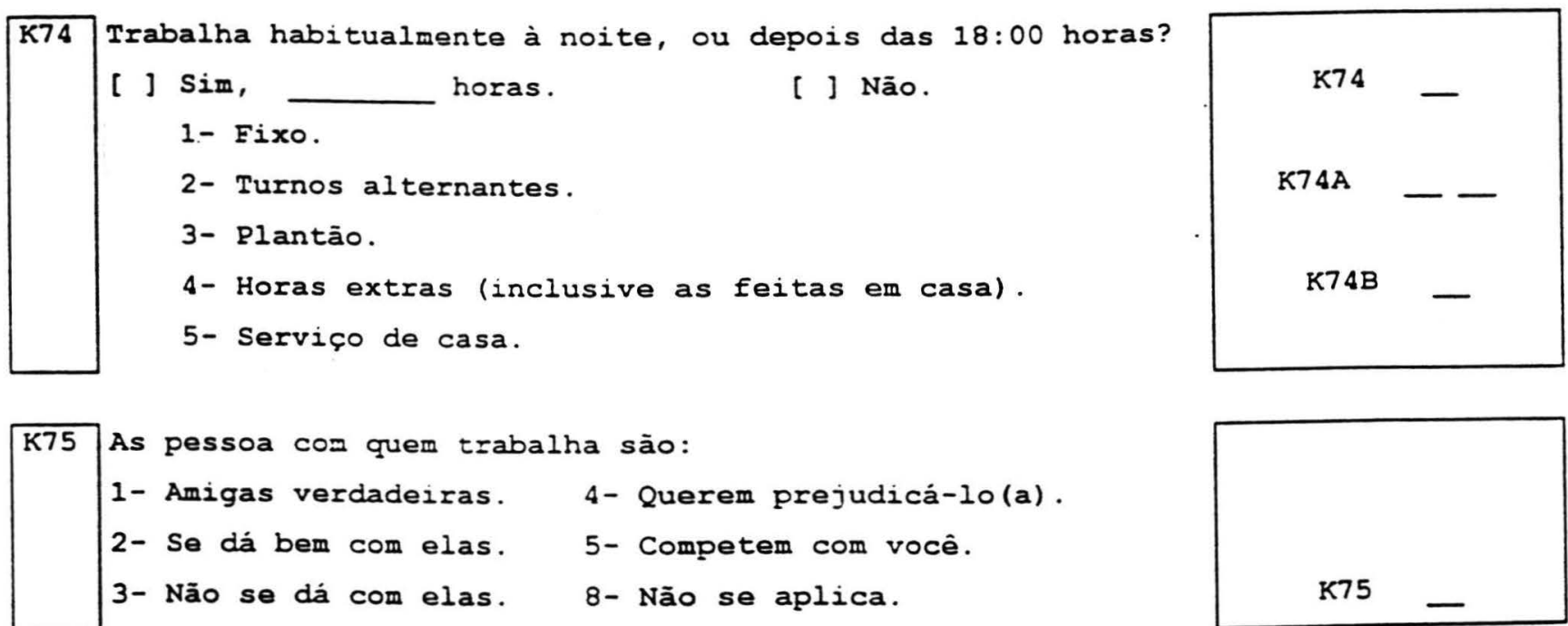


\begin{tabular}{|c|c|c|c|c|} 
K76 uma escala de 0 a 3 , sendo: \\
3= muito; 2= mais ou menos; $1=$ pouco; e $0=$ nada, \\
qual o seu nivel de satisfação em relação a:
\end{tabular}

\begin{tabular}{|c|c|c|c|c|c|c|c|}
\hline \multirow{2}{*}{\multicolumn{2}{|c|}{ K77 }} & corre $r$ & em que & da? & & \multirow[b]{3}{*}{ K77A } & \multirow[b]{3}{*}{ - } \\
\hline & & 3-Alto & 2-Médio & 1-Baixo & 0-Nenhum & & \\
\hline & Acidente & & & & & & \\
\hline & Assalto & & & & & $\mathrm{K} 77 \mathrm{~B}$ & \\
\hline & Violência & & & & & K77C & \\
\hline & Desemprego & & & & & K77D & \\
\hline & Adoecer & & & & & K77E & \\
\hline & Outros & & & & & K77F & - \\
\hline
\end{tabular}

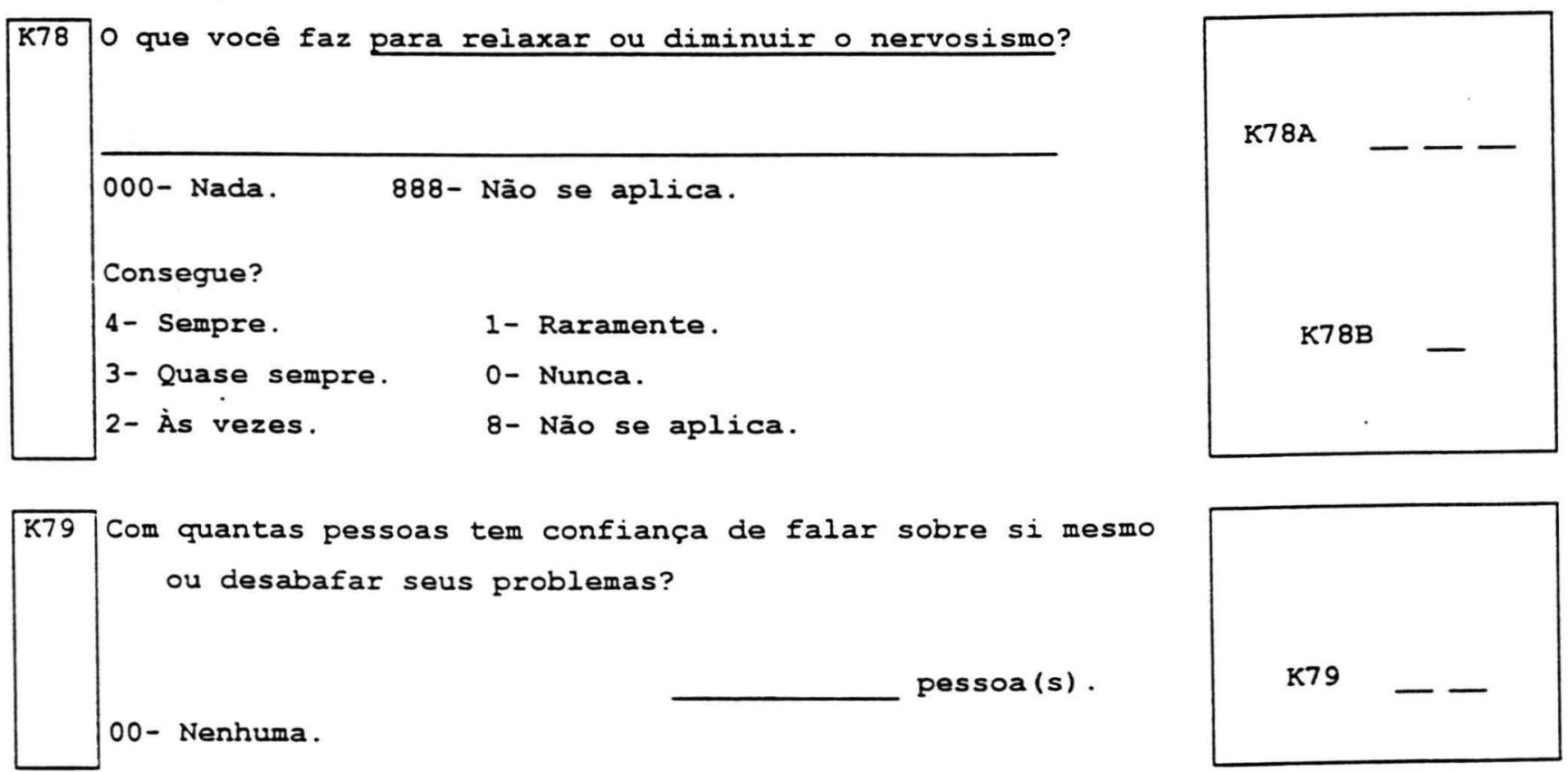


Você participa atualmente de atividades comunitárias? 1- Sim. Quais? o- Não.

\begin{tabular}{|lll} 
K80 & - & \\
& K80A & - \\
K80B & - \\
K80C & - \\
K8OD & - \\
K80E & - \\
K80F & - \\
K8OG & - \\
\hline
\end{tabular}

Com que freqüência, NO ÚLTIMO MÊS, você diria que

\begin{tabular}{|c|c|c|c|c|c|}
\hline & & Nhng & De vez & Muitas & \\
\hline K81 & $\begin{array}{l}\text { teve batidas rápidas no } \\
\text { coração }\end{array}$ & 1 & 2 & 3 & K81 \\
\hline K82 & $\begin{array}{l}\text { se sentiu atrapalhado(a) ao } \\
\text { ter que fazer algum trabalho } \\
\text { depressa }\end{array}$ & 1 & 2 & 3 & К82 \\
\hline K83 & teve tremor nas mãos & 1 & 2 & 3 & K83 \\
\hline K84 & se sentiu agitado e nervoso & 1 & 2 & 3 & K84 \\
\hline K85 & $\begin{array}{l}\text { teve pensamentos ruins que } \\
\text { não saiam da cabeça }\end{array}$ & 1 & 2 & 3 & K85 \\
\hline K86 & $\begin{array}{l}\text { teve muito cansaço ou excesso } \\
\text { de trabalho }\end{array}$ & 1 & 2 & 3 & K86 \\
\hline K87 & $\begin{array}{l}\text { teve mal-estar com batidas } \\
\text { fora do ritmo do coração }\end{array}$ & 1 & 2 & 3 & K87 \\
\hline K88 & teve tonturas & 1 & 2 & 3 & K88 \\
\hline K89 & teve pesadelos & 1 & 2 & 3 & K89 \\
\hline K90 & teve depressão ou tristeza & 1 & 2 & 3 & K90 \\
\hline к91 & teve insônia ou falta de sono & 1 & 2 & 3 & K91 \\
\hline K92 & teve dores de cabeça & 1 & 2 & 3 & $\mathrm{~K} 92$ \\
\hline K93 & teve mãos úmidas & 1 & 2 & 3 & K93 \\
\hline K94 & $\begin{array}{l}\text { teve problema digestivo como } \\
\text { digestão dificil, queimação } \\
\text { ou falta de apetite }\end{array}$ & 1 & 2 & 3 & K94 \\
\hline
\end{tabular}


BLOCO L - "SF-36"

NÃO ESCREVER

GH01 Em geral você diria que sua saúde é

\begin{tabular}{|c|c|c|c|c|}
\hline Excelente & Muito boa & Boa & Ruim & Muito ruim \\
\hline 1 & 2 & 3 & 4 & 5 \\
\hline
\end{tabular}

\begin{tabular}{|c|c|c|c|c|c|c|}
\hline \multirow[t]{2}{*}{ HTO2 } & $\frac{\text { Comparada }}{\text { saude gera. }}$ & $\begin{array}{l}\text { um ano atrás } \\
\text { agora? }\end{array}$ & , como você & classifica & sua & \multirow{3}{*}{ нт02 } \\
\hline & Muito melhor & Um pouco melhor & Quase a mesma & Um pouco pior & Muito pior & \\
\hline & 1 & 2 & 3 & 4 & 5 & \\
\hline
\end{tabular}

OS SEGUINTES ITENS SÃO SOBRE ATIVIDADES QUE VOCÊ ATUALMENTE PODERIA FAZER DURANTE UM DIA COMUM.

DEVIDO À SUA SAÚDE, VOCÊ TERIA DIFICULDADE PARA FAZER ESSAS

\section{ATIVIDADES?}

NESTE CASO, QUANTO?

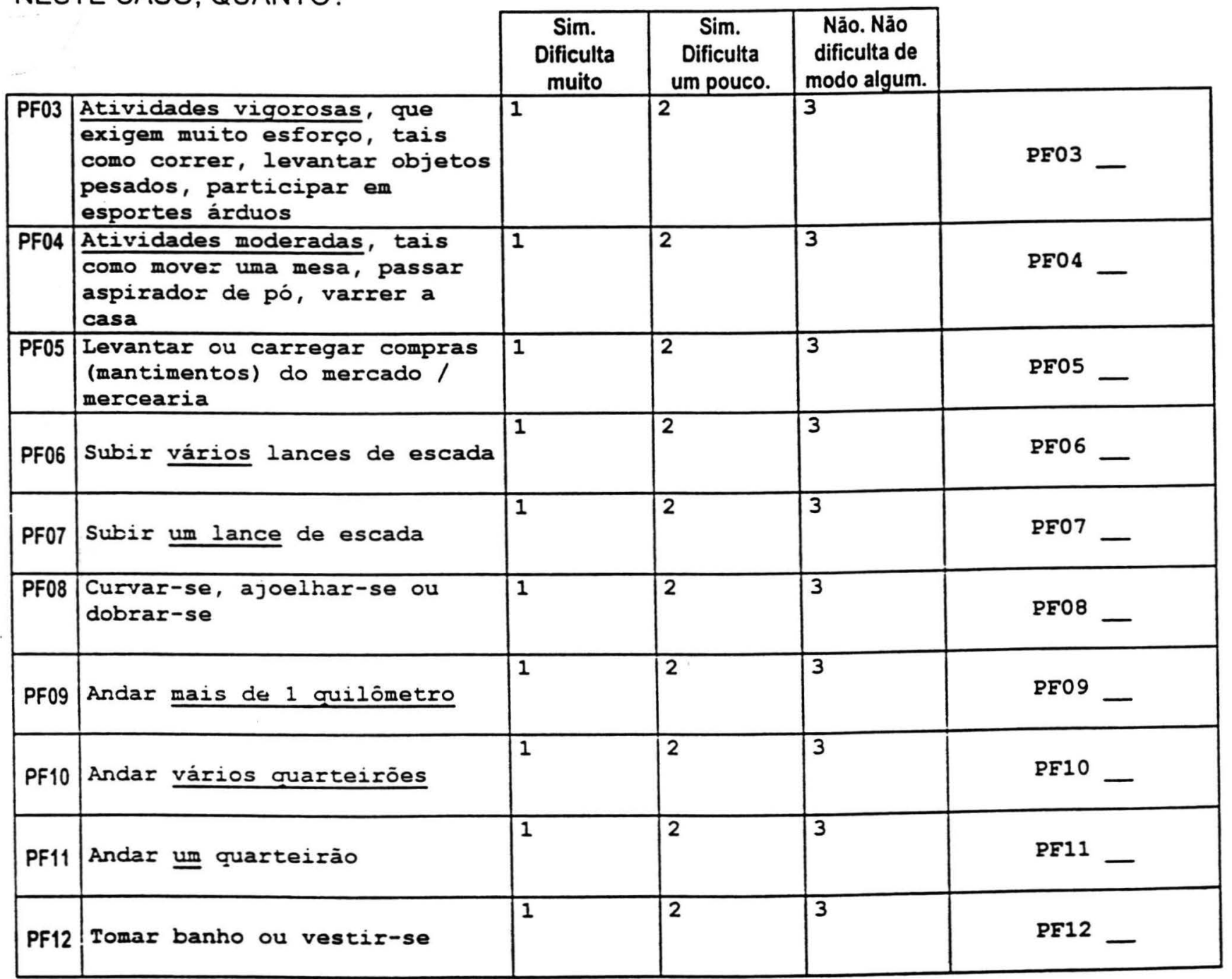


DURANTE AS ÚLTIMAS 4 SEMANAS, VOCÊ TEVE ALGUM DOS SEGUINTES PROBLEMAS COM O SEU TRABALHO OU COM ALGUMA ATIVIDADE DIÁRIA REGULAR, COMO CONSEQÜENNCIA DE SUA SAÚDE FISICA?

\begin{tabular}{|l|l|l|l|l|}
\cline { 3 - 4 } \multicolumn{2}{l|}{} & Sim & Năo & \\
\hline RP13 & $\begin{array}{l}\text { Jocê diminuiu a guantidade de tempo que } \\
\text { dedicava ao seu trabalho ou a outras } \\
\text { atividades? }\end{array}$ & 1 & 2 & RP13 \\
\hline RP14 & $\begin{array}{l}\text { Realizou menos tarefas do que você } \\
\text { gostaria? }\end{array}$ & 1 & RP14 \\
\hline RP15 & $\begin{array}{l}\text { Esteve limitado no seu tipo de trabalho } \\
\text { ou em outras atividades? }\end{array}$ & 1 & 2 & RP15 \\
\hline RP16 & $\begin{array}{l}\text { Teve dificuldade de fazer seu trabalho } \\
\text { ou outras atividades (p.ex. necessitou } \\
\text { de um esforço extra)? }\end{array}$ & 1 & 2 & RP16 - \\
\hline
\end{tabular}

DURANTE AS ÚLTIMAS 4 SEMANAS, VOCÊ TEVE ALGUM DOS SEGUINTES PROBLEMAS COM O SEU TRABALHO OU OUTRA ATIVIDADE REGULAR DIÁRIA, COMO CONSEQÜENNCIA DE ALGUM PROBLEMA EMOCIONAL (COMO SENTIR-SE DEPRIMIDO OU ANSIOSO)?

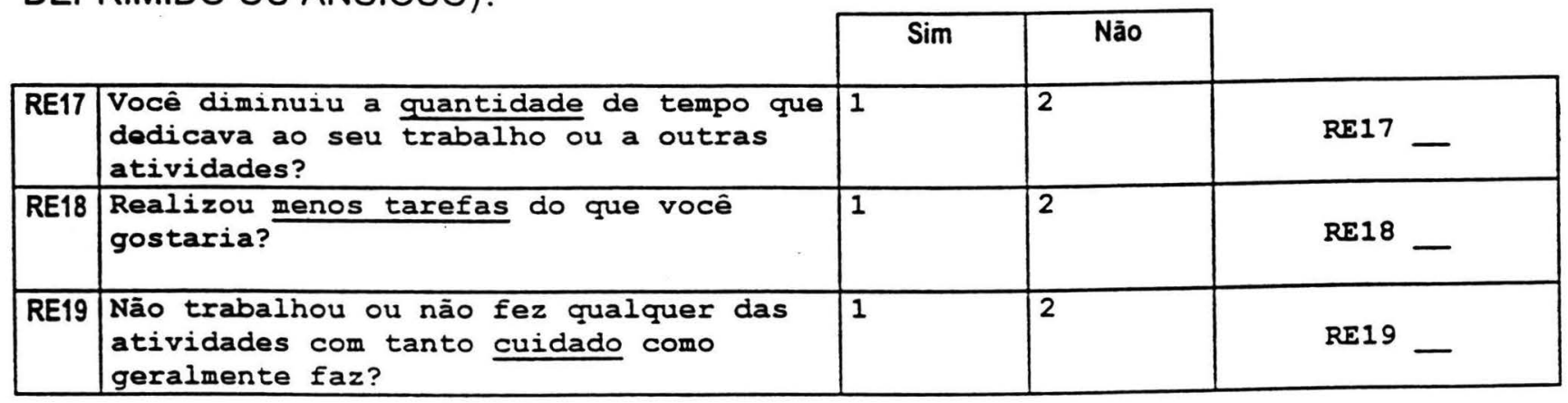

\begin{tabular}{|c|l|c|c|c|}
\hline SF20 & $\begin{array}{l}\text { Durante as últimas } 4 \text { semanas, de que maneira sua saúde } \\
\text { fisica ou problemas emocionais interferiram nas suas } \\
\text { atividades sociais normais, em relação a familia, vizinhos } \\
\text { ou em grupo? }\end{array}$ \\
\hline $\begin{array}{c}\text { Deforma } \\
\text { nenhuma }\end{array}$ & Ligeiramente & Moderadamente & Bastante & Extremamente \\
\hline 1 & 2 & 3 & 4 & 5 \\
\hline
\end{tabular}

\begin{tabular}{|c|c|c|c|c|c|c|}
\hline BP21 & \multicolumn{6}{|c|}{ Quanta dor no coroo vocè teve durante as últimas 4 senanas? } \\
\cline { 2 - 7 } & Nenhuma & Muito leve & Leve & Moderada & Grave & Muito grave \\
\hline 1 & 2 & 3 & 4 & 5 & 6 & BP21 \\
\hline
\end{tabular}




\begin{tabular}{|c|c|c|c|c|}
\hline BP22 & $\begin{array}{l}\text { Durante as últimas } 4 \text { semanas, quanto a dor interferiu com } 0 \\
\text { seu trabalho normal (incluindo tanto o trabalho fora de } \\
\text { casa e dentro de casa)? }\end{array}$ \\
\begin{tabular}{|c|c|c|c|c|c|} 
De forma \\
alguma
\end{tabular} & Um pouco & Moderadamente & Bastante & Extremamente \\
\hline 1 & 2 & 3 & 4 & 5 \\
\hline
\end{tabular}

ESTAS QUESTÕES SÃO SOBRE COMO VOCÊ SE SENTE E COMO TUDO TEM ACONTECIDO COM VOCE DURANTE AS ÚLTIMAS 4 SEMANAS.

PARA CADA QUESTĀO, POR FAVOR DÊ UMA RESPOSTA QUE MAIS SE APROXIME DA MANEIRA COMO VOCÊ SE SENTE. EM RELAÇÃO ÀS ÚLTIMAS 4 SEMANAS:

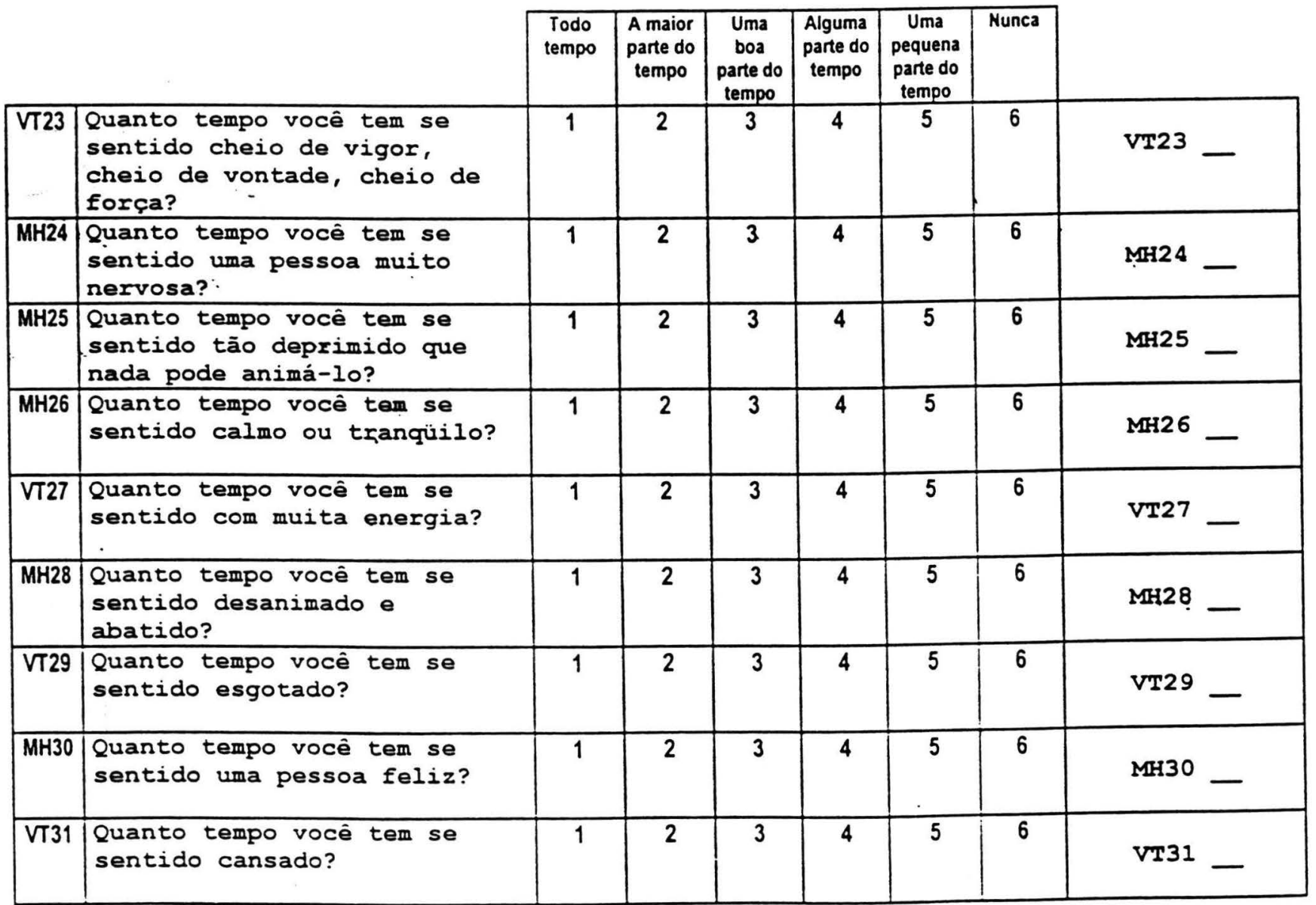




\begin{tabular}{|c|c|c|c|c|c|c|}
\hline SF32 & $\begin{array}{l}\text { Durante as } \\
\text { saúde fisic } \\
\text { suas ativic } \\
\text { etc.)? }\end{array}$ & $\frac{\text { timas } 4 \text { se }}{\text { ou problen }}$ & $\frac{\text { ras, quan }}{\text { emociona }}$ & $\begin{array}{l}\text { do seu tem } \\
\text { interferir } \\
\text { amigos, }\end{array}$ & $\begin{array}{l}\text { a sua } \\
\text { com as } \\
\text { centes. }\end{array}$ & \\
\hline & Todo o tempo & $\begin{array}{c}\text { A maior parte } \\
\text { do tempo }\end{array}$ & $\begin{array}{c}\text { Alguma parte } \\
\text { do tempo }\end{array}$ & $\begin{array}{l}\text { Uma pequena } \\
\text { parte do tempo }\end{array}$ & $\begin{array}{c}\text { Nenhuma parte } \\
\text { do tempo }\end{array}$ & SE32 \\
\hline & 1. & 2 & 3 & 4 & 5 & \\
\hline
\end{tabular}

O QUANTO VERDADEIRO OU FALSO É CADA UMA DAS AFIRMAÇÕES PARA VOCÊ?

\begin{tabular}{|c|c|c|c|c|c|c|c|}
\hline & & $\begin{array}{c}\begin{array}{c}\text { Definitiva- } \\
\text { mente } \\
\text { verdadeiro }\end{array} \\
\end{array}$ & $\begin{array}{l}\text { A maioria } \\
\text { das vezes } \\
\text { verdadeiro } \\
\end{array}$ & Não sei & $\begin{array}{l}\text { A maioria } \\
\text { das fezes } \\
\text { falso }\end{array}$ & $\begin{array}{c}\text { Definitiva- } \\
\text { mente } \\
\text { falso } \\
\end{array}$ & \\
\hline GH33 & $\begin{array}{l}\text { Eu costumo adoecer um pouco } \\
\text { mais facilmente que as } \\
\text { outras pessoas }\end{array}$ & 1 & 2 & 3 & 4 & 5. & GH33 \\
\hline $\mathrm{GH} 34$ & $\begin{array}{l}\text { Eu sou tão saudável quanto } \\
\text { qualquer pessoa que eu } \\
\text { conheço }\end{array}$ & 1 & 2 & 3 & 4 & 5 & GH34 \\
\hline GH35 & $\begin{array}{l}\text { Eu acho que a minha saúde } \\
\text { vai piorar }\end{array}$ & 1 & 2 & 3 & 4 & 5 & GH35 \\
\hline GH36 & Minha saúde é excelente & 1 & 2 & 3 & 4 & 5 & GH36 \\
\hline
\end{tabular}

\section{BLOCO L - MORBIDADE REFERIDA}

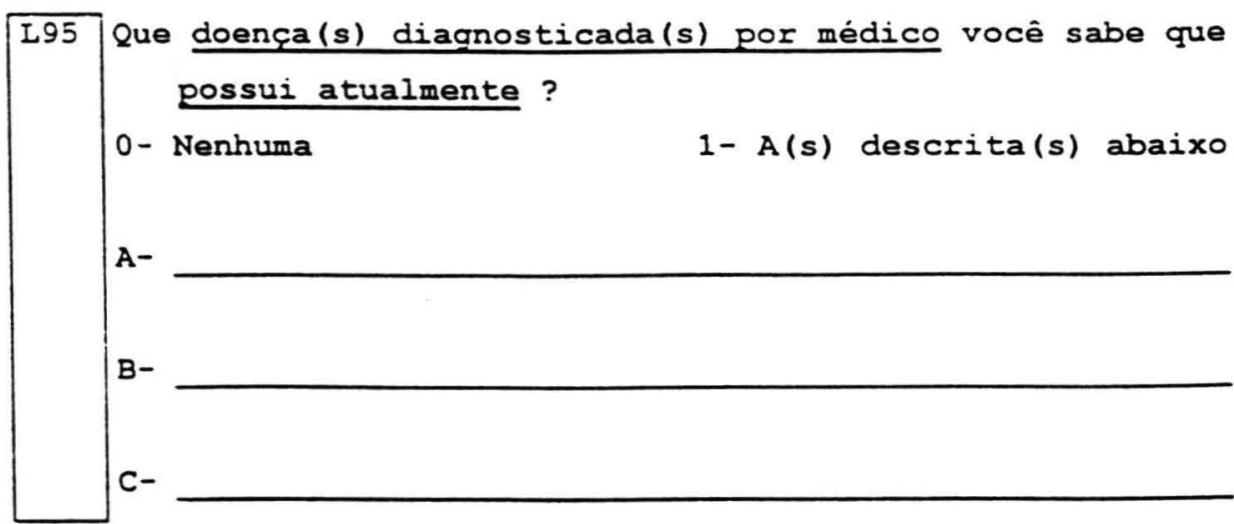

NÃO ESCREVER NESTE ESPAÇO

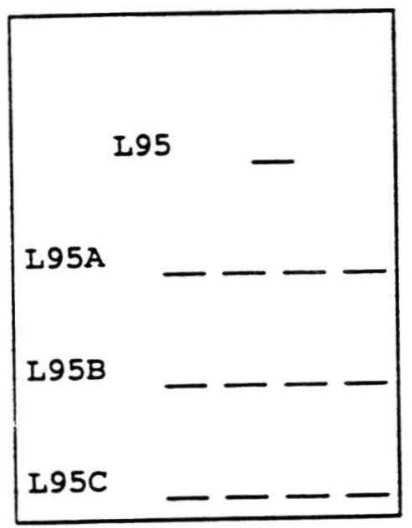


BLOCO N - PULSO, PRESSÃO ARTERIAL E ANTROPOMETRIA

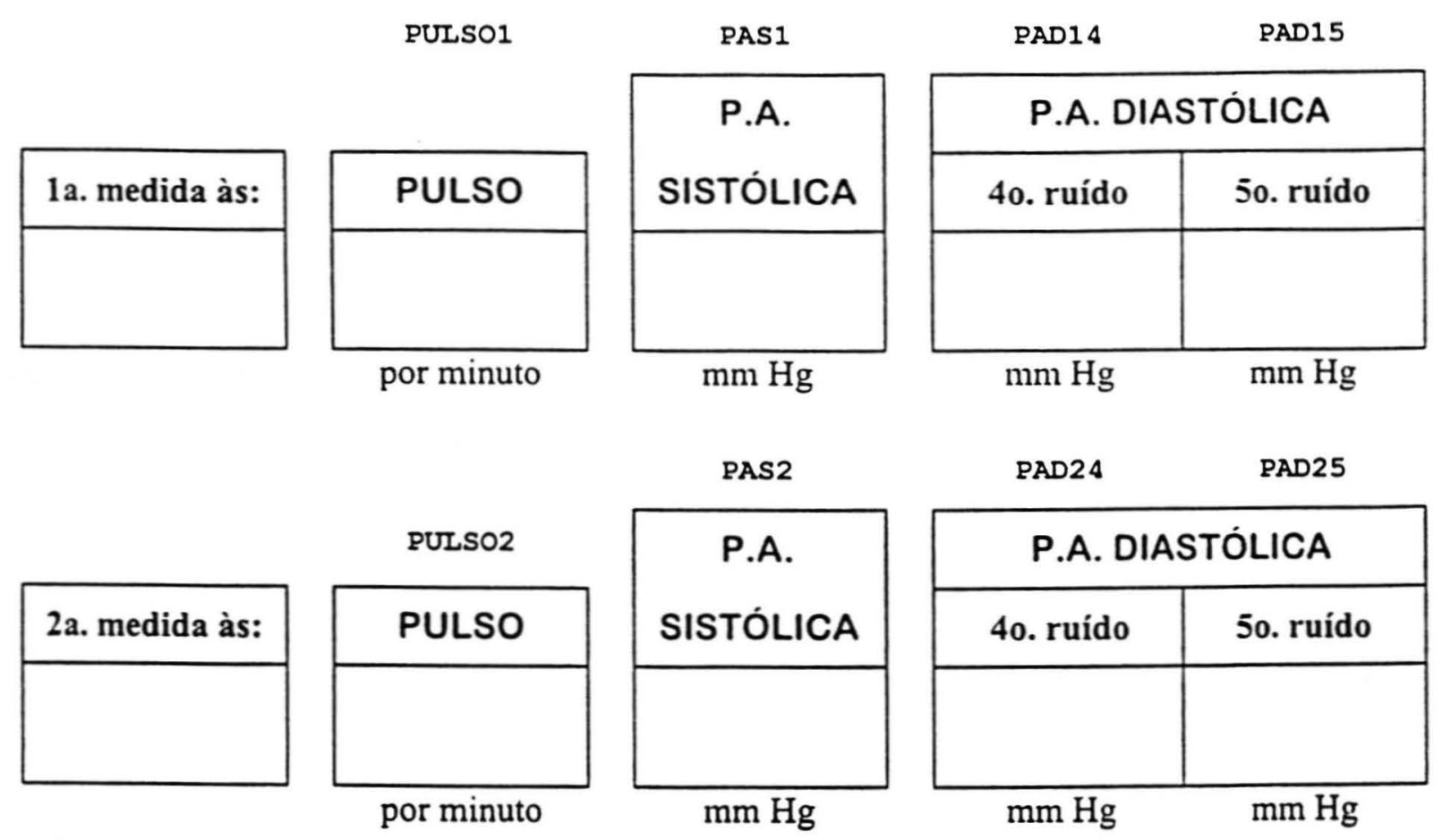

\begin{tabular}{|c|c|}
\hline PESO1 & PESO2 \\
\hline \multicolumn{2}{|c|}{ PESO (kg) } \\
\hline 1a. medida & 2a. medida \\
\hline$--\ldots$ &,--- \\
\hline
\end{tabular}

\begin{tabular}{|c|c|}
\multicolumn{1}{c}{ ESTAT1 } & \multicolumn{1}{c|}{ ESTAT2 } \\
\hline \multicolumn{2}{|c|}{ ESTATURA $(\mathrm{m})$} \\
\hline 1a. medida & 2a. medida \\
\hline & \\
,--- & - \\
\hline
\end{tabular}

ANTROPO

METRIA

\begin{tabular}{|c|c|}
\multicolumn{1}{c}{ CINT1 } & \multicolumn{1}{c|}{ CINT2 } \\
\hline \multicolumn{2}{|c|}{ CINTURA (cm) } \\
\hline 1a. medida & 2a. medida \\
\hline & \\
,---- &,--- \\
\hline
\end{tabular}

\begin{tabular}{|c|c|}
\hline QUAD1 & QUAD2 \\
\hline \multicolumn{2}{|c|}{ QUADRIL (cm) } \\
\hline 1a. medida & 2a. medida \\
\hline$-\ldots$ & $--\ldots$ \\
\hline
\end{tabular}


NÃO ESCREVER

NESTE ESPAÇO

z03 Hora do término da entrevista:

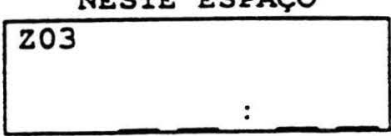

COMENTÁRIOS 
Anexo 3.

Formulário suplementar. 

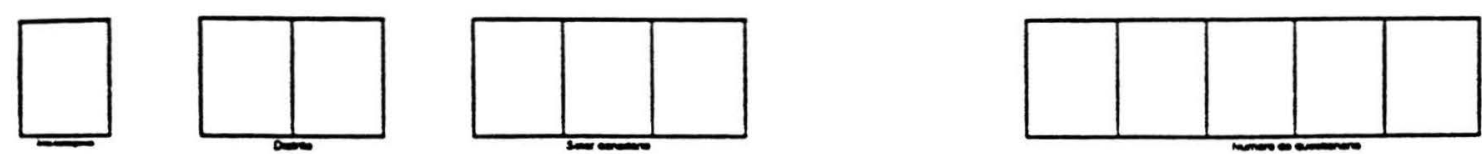

FATORES DE RISCO PARA DOENÇAS CRÓNICAS NÃO-TRANSMISSIVEIS: INQUÉRITO DOMICILIAR NO MUNICIPIO DE SÃO PAULO

\section{$====$ FORMULÁRIO ESPECIAL ==== EXAMES E QUESTIONÁRIO ALIMENTAR}

(1) COMEÇAR PELOS EXAMES SE A PESSOA A SER ENTREVISTADA ESTIVER EM JEJUM PARA COLETA DE SANGUE.

(2) TERMINADOS OS EXAMES, INICIAR ENTREVISTA PELO QUESTIONÁRIO GERAL

DIVISÃO DE DOENÇAS CRÓNICAS NÃO-TRANSMISSIVEIS

CENTRO DE VIGILÂNCIA EPIDEMIOLÓGICA

SECRETARIA DE ESTADO DA SAÚDE DE SÃO PAULO

Versão 09/01/2001

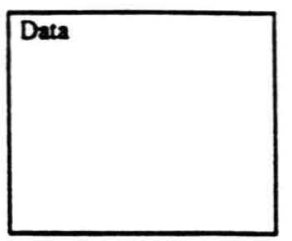

Supervisor

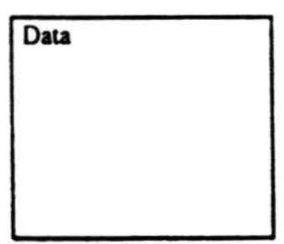

Codificador

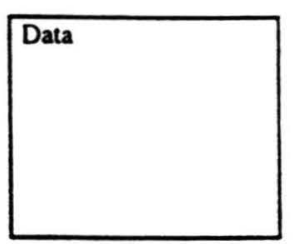

Digitador 1

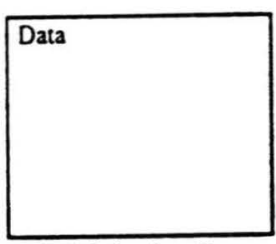

Digitador 2 

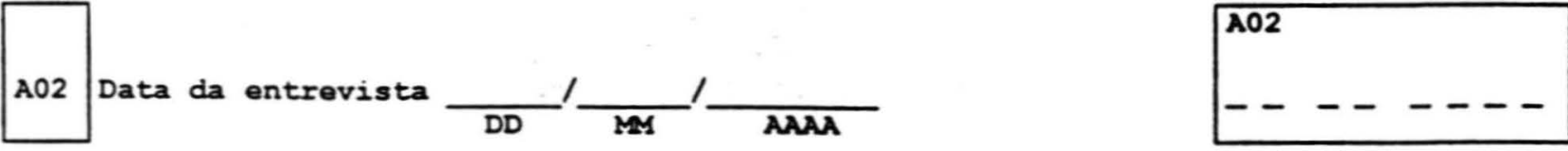

201

Entrevistador (a) :

\section{BLOCO 1 - EXAME DE SANGUE}

Última refeição: horas do dia

horas do dia de 200

[ ] Luvas

[ ] Lanceta descartável

[ ] Aparelho preparado

[ ] Papel absorvente

[ ] Algodão com álcool

GLICOSE

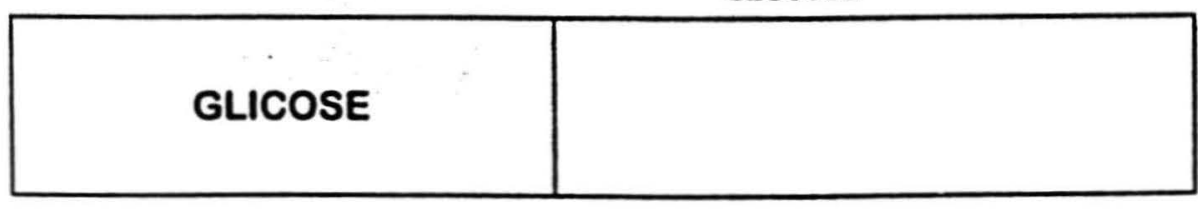

COLTOT

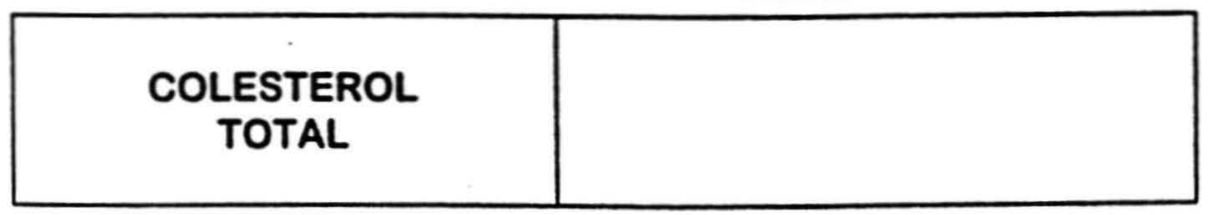

TRIGLIC

TRIGLICÉRIDES 
BLOCO 2 - HÁBITOS ALIMENTARES

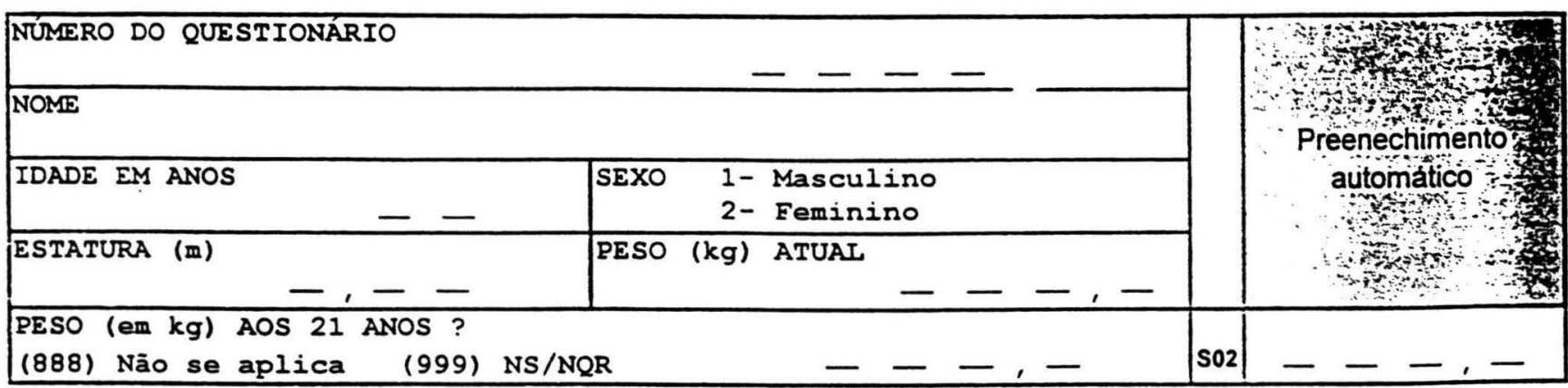

Nos últimos DOZE MESES você mudou seus hábitos alimentares ou estả fazendo dieta?

(0) Não

(1) Sim, (A) para perda de peso

(B) sob orientaçāo médica

(C) dieta vegetariana

(D) redução de sal

(E) redução de colesterol/triglicérides

(F) para ganho de peso

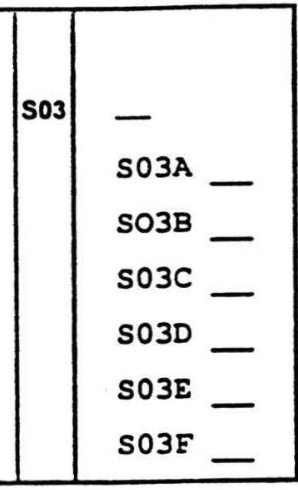

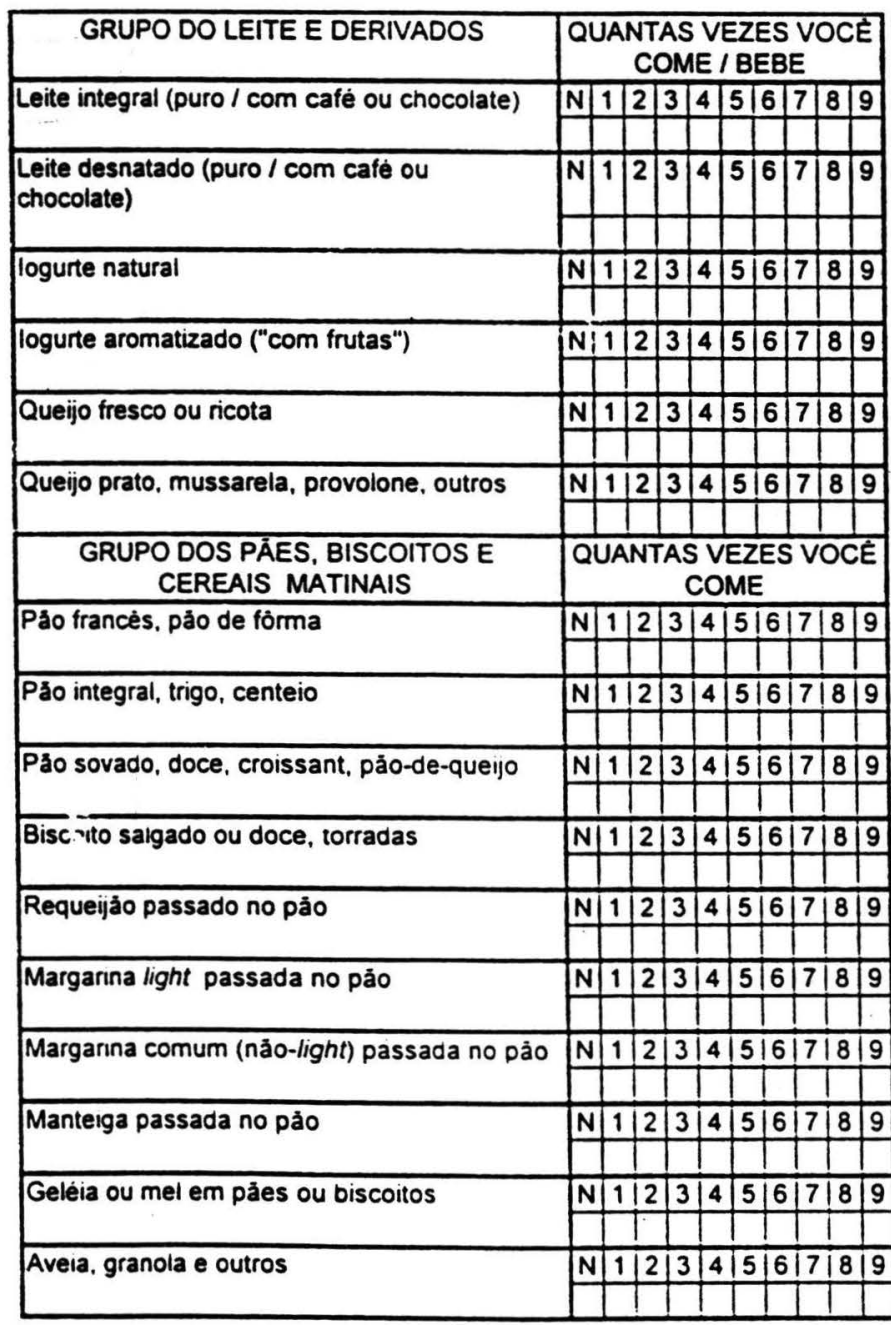

\begin{tabular}{|c|c|c|c|}
\hline \multicolumn{2}{|c|}{ UNIDADE } & $\begin{array}{l}\text { PORÇÁO MEDIA } \\
\text { (M) }\end{array}$ & \begin{tabular}{|c|} 
SUA \\
PORCCAO \\
\end{tabular} \\
\hline \multirow[t]{2}{*}{015} & \multirow[t]{2}{*}{ S|M|A } & \multirow{2}{*}{$\begin{array}{l}1 \text { copo pequeno } \\
(150 \mathrm{ml})\end{array}$} & \begin{tabular}{|l|l|l|} 
PIMIG \\
\end{tabular} \\
\hline & & & \\
\hline \multirow[t]{2}{*}{ DS } & S|M|A & \multirow{2}{*}{$\begin{array}{c}1 \text { copo pequeno } \\
(150 \mathrm{ml})\end{array}$} & $\bar{P} \mid \mathrm{M} / \mathrm{G}$ \\
\hline & & & \\
\hline DS & \begin{tabular}{l|l|l}
$S$ & $M$ & $A$ \\
\end{tabular} & $\begin{array}{l}1 \text { copo americano } \\
(200 \mathrm{ml})\end{array}$ & PIMIG \\
\hline \multirow[t]{2}{*}{ D.S } & \begin{tabular}{l|l|l|} 
& \\
\end{tabular} & \multirow{2}{*}{$\begin{array}{c}1 \text { copo americano } \\
(200 \mathrm{ml})\end{array}$} & $P|M| G$ \\
\hline & & & \\
\hline \multirow[t]{2}{*}{ DS } & $\sin A$ & \multirow{2}{*}{$\begin{array}{l}1 \text { fatia } \\
(30 \mathrm{~g})\end{array}$} & PIMIG \\
\hline & & & \\
\hline \multirow[t]{2}{*}{ Dis } & S|M|A & \multirow{2}{*}{$\begin{array}{l}1 \text { fatia } \\
(20 \mathrm{~g})\end{array}$} & PIMIG \\
\hline & & & 11 \\
\hline \multicolumn{2}{|c|}{ UNIDADE } & $\begin{array}{l}\text { PORÇĀO ME } \\
\text { (M) }\end{array}$ & \begin{tabular}{|l|} 
SUA \\
PORÇAOO
\end{tabular} \\
\hline \multirow[t]{2}{*}{$0 \mathrm{~s}$} & $S|M| A$ & \multirow{2}{*}{$\begin{array}{l}1 \text { unidade / } 2 \text { fatias } \\
(50 \mathrm{~g})\end{array}$} & $P|M| G$ \\
\hline & & & \\
\hline \multirow[t]{2}{*}{$\overline{0} \bar{s}$} & $S|M| A$ & \multirow{2}{*}{$\begin{array}{l}2 \text { fatias } \\
(50 \mathrm{~g})\end{array}$} & $P|M| G$ \\
\hline & & & $i 1$ \\
\hline \multirow[t]{2}{*}{ Dis } & SIMIA & \multirow{2}{*}{$\begin{array}{c}2 \text { unidades pequenas } \\
(40 \mathrm{~g})\end{array}$} & \multirow{2}{*}{\begin{tabular}{|l|l|}
$\mathrm{P} ! \mathrm{MIG}$ \\
$! \quad !$ \\
\end{tabular}} \\
\hline & & & \\
\hline \multirow[t]{2}{*}{ D } & $\operatorname{SiM|A}$ & 3 unidades & PIMIG \\
\hline & & & $1 i$ \\
\hline DS & S|M|A & $1 \mathrm{c}$ & $P ! M ! G$ \\
\hline & & & 11 \\
\hline 01 & SIMIA & 1 & $\mathrm{PIMIG}$ \\
\hline & & & 11 \\
\hline 0 & SIMIA & faca & $P|M| G$ \\
\hline & & & 11 \\
\hline D: & $S|M| A$ & 2 pontas & $\mathrm{P} \mid \mathrm{M}: \mathrm{C}$ \\
\hline & & & \\
\hline D: & $S|M| A$ & 1 colner de sopa & $P|M| G$ \\
\hline & & & 11 \\
\hline D) & $\operatorname{SIM} \mid A$ & 3 colneres de sopa & $P|M| G$ \\
\hline & 7 & & 11 \\
\hline
\end{tabular}

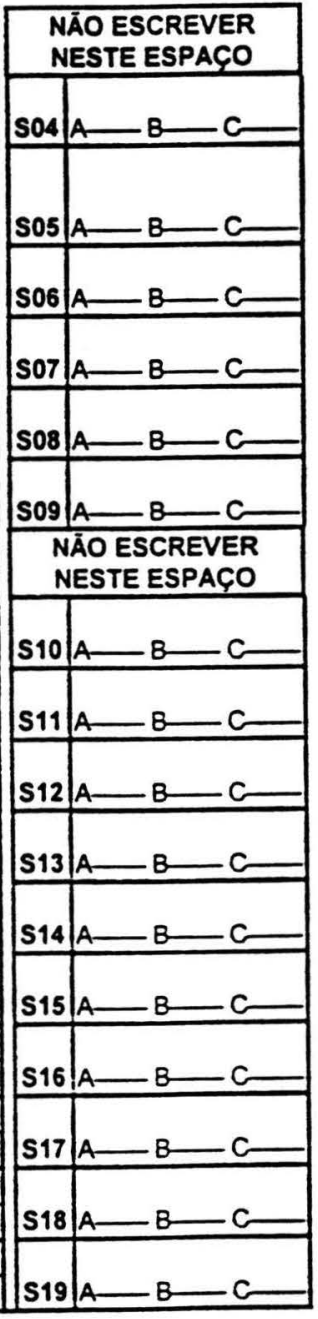




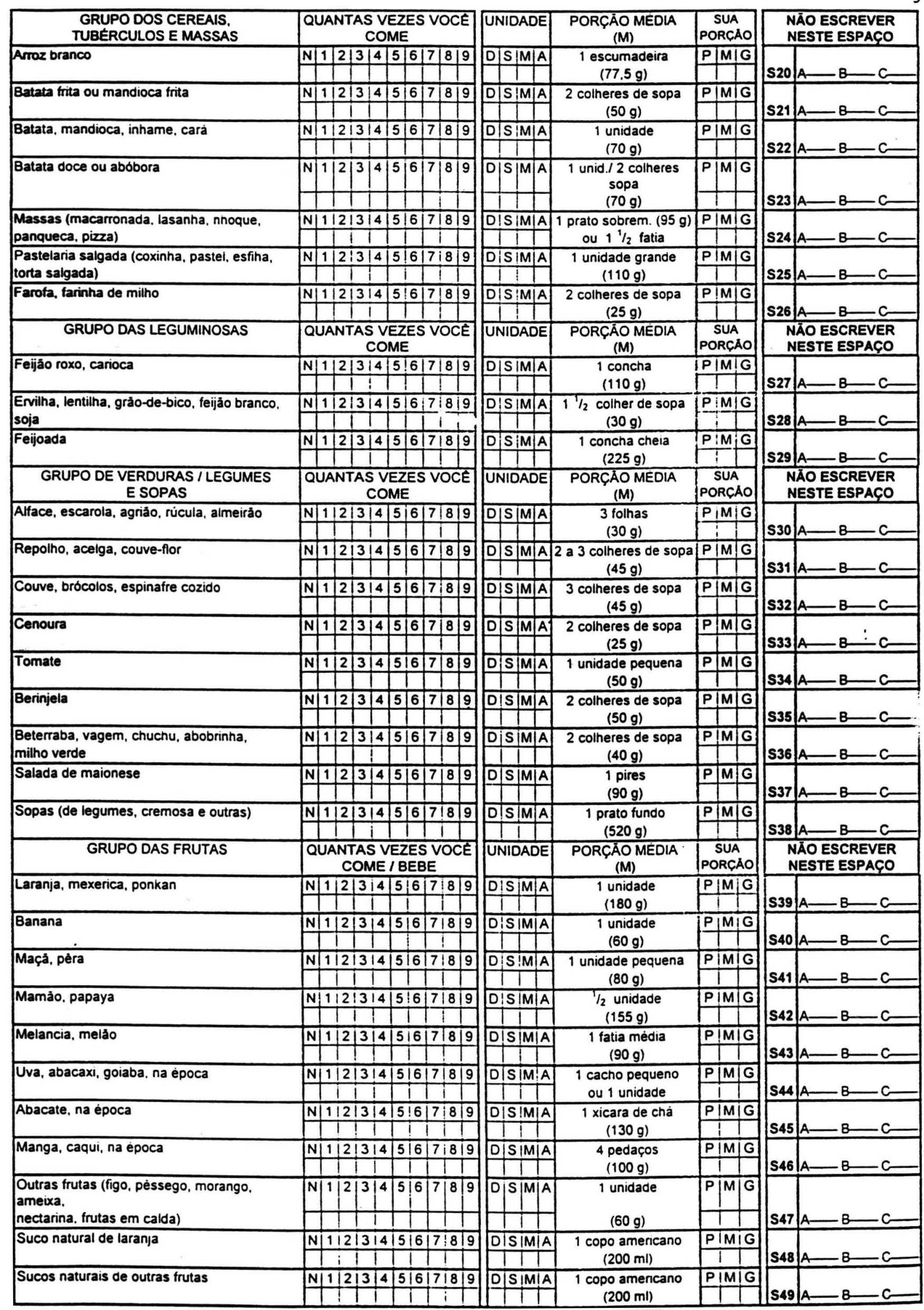




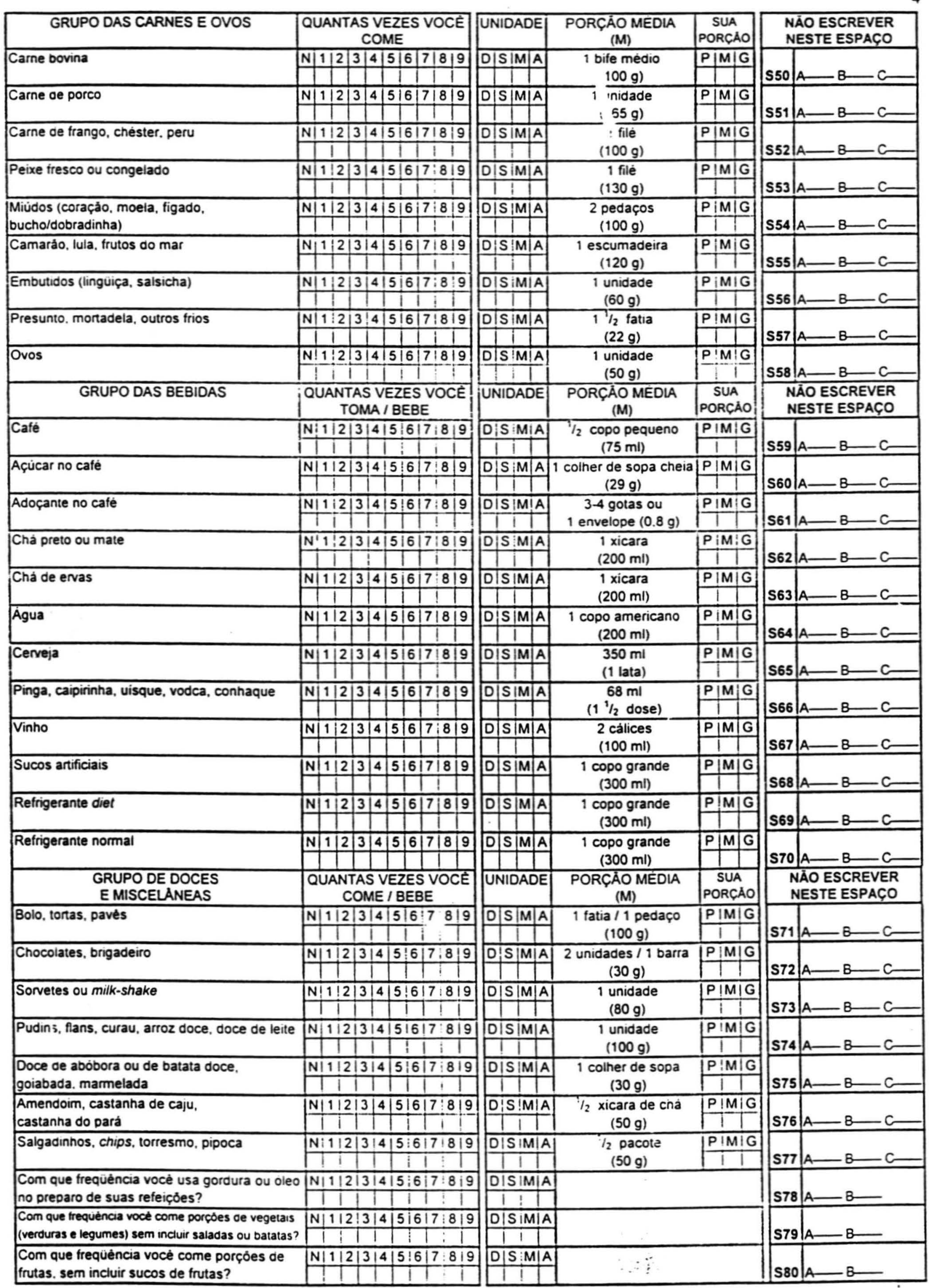


Outro(s) alimento(s) ou preparação(ões) que você COSTUMA comer ou beber PELO MENOS UMA VEZ POR SEMANA, que não foi(ram) citado(s) no questionário:

\begin{tabular}{|l|l|}
\hline Alimento & Freqüencia por semana: \\
\hline Alimento & Freqüència por semana: \\
\hline
\end{tabular}

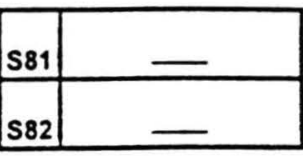

\begin{tabular}{|l|}
\hline Quantas refeiçōes você faz por dia? \\
\hline Quantas refeições você faz fora de casa, por semana? \\
\hline
\end{tabular}

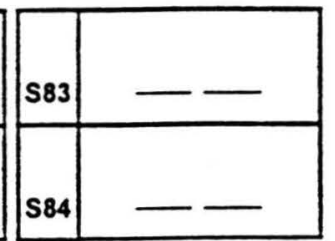

ASSINALE O MÁXIMO DE DUAS OPÇÕES:

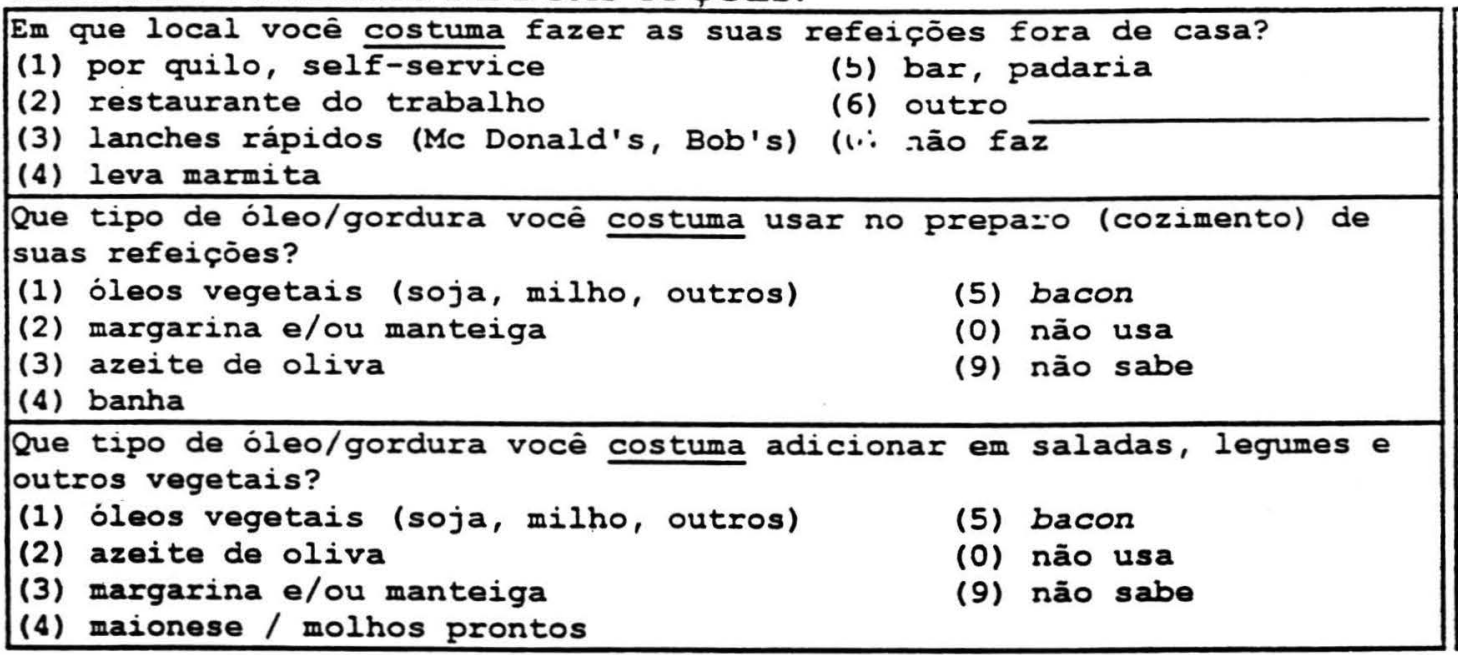

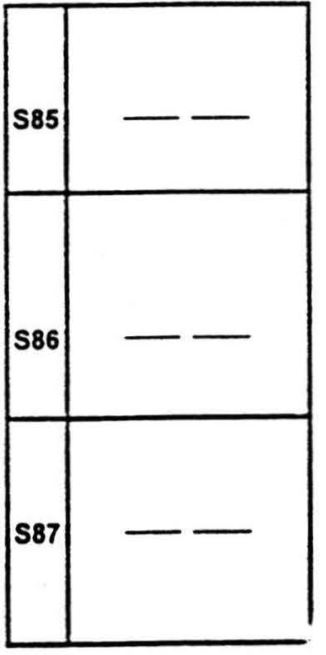

\begin{tabular}{|l|l|l|l|}
\cline { 2 - 4 } \multicolumn{1}{c|}{} & $\begin{array}{c}\text { (1) nunca l } \\
\text { raramente }\end{array}$ & $\begin{array}{c}\text { (2) algumas } \\
\text { vezes. }\end{array}$ & $\begin{array}{c}\text { (3) sempre I } \\
\text { freqüentemente }\end{array}$ \\
\hline $\begin{array}{l}\text { Quanco vocé come carne de boi/vaca ou de porco, vocè } \\
\text { costuma comer a gordura visivel? }\end{array}$ & & & \\
\hline $\begin{array}{l}\text { Quanco vocé come carne de frango, vocé costuma comer a } \\
\text { pele? }\end{array}$ & & & \\
\hline Vocè costuma acrescentar sal na comida, depois de pronta? & & & \\
\hline Vocè costuma usar pimenta em suas refeiçóes? & & & \\
\hline $\begin{array}{l}\text { Com que freqüència vocè come carnes fritas/assadas ou } \\
\text { grelhadas? }\end{array}$ & & & \\
\hline
\end{tabular}

Quando você come os seguintes aiimentos, com que freqüência você consome produtos light

\begin{tabular}{|l|c|c|c|}
\cline { 2 - 4 } (com baixo teor de gordura)? & $\begin{array}{c}\text { (1) sempre I } \\
\text { freaüentemente }\end{array}$ & $\begin{array}{c}\text { (2) algumas } \\
\text { vezes }\end{array}$ & $\begin{array}{c}\text { (3) nunca I } \\
\text { raramente }\end{array}$ \\
\hline Queijo/requeijå̀ & & & \\
\hline logune/sorvete & & & \\
\hline Molnos para salada & & & \\
\hline
\end{tabular}

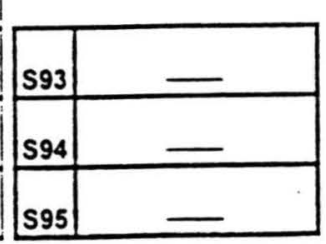




\section{Anexo 4.}

Carta enviada aos entrevistados contendo os resultados dos exames realizados. 


\section{ANEXO 7}

SECRETARIA DE ESTADO DA SAÚDE DE SÃO PAULO

Centro de Vigilância Epidemiológica "Prof. Alexandre Vranjac"

DIVISÃO DE DOENÇAS CRÔNICAS NÃO-TRANSMISSÍVEIS

Avenida Doutor Amaldo, 351 - $6^{\circ}$ andar - sala 613 - São Paulo, SP - CEP 01246-901

Telefax: 0xx11-3082.2172 Telefone: 0xx11-3066.8295

S.Paulo, 20-set-01

Pesquisa: FATORES DE RISCO PARA DOENCCAS

CRÔNICAS NÃO-TRANSMISSIVEIS

NO MUNICÍPIO DE SÃo PAULO

Ilmo(a). Sr(a). DxIxa Xexdxn Txrxex

R. Xuxs Xaxixs Xextx|x dx Lxex, 1X6X - Xoxtx XIxrxsxax

0X3X8-X0X S.Paulo, SP

$1 \times 5 X$

$\mathrm{Na}$ entrevista realizada em 08-set-01 foram feitas as seguintes medidas de seu interesse:

Peso: $56,2 \mathrm{~kg} \quad$ Cintura: $73,5 \mathrm{~cm}$

Altura: $1,70 \mathrm{~m} \quad$ Quadril: $94,0 \mathrm{~cm}$

Pressão arterial: $105 \times 68 \mathrm{~mm} \mathrm{Hg}$

Os exames feitos no sangue colhido em 12-set-01 tiveram os seguintes resultados:

Glicemia de jejum: $92 \mathrm{mg} / \mathrm{dL}$

Colesterol total: $\quad 198 \mathrm{mg} / \mathrm{dL}$

Fração HDL: $\quad \mathbf{7 4} \mathrm{mg} / \mathrm{dL}$

Triglicérides: $\quad 53 \mathrm{mg} / \mathrm{dL}$

De acordo com critérios internacionais, seu peso está dentro do esperado.

Para sua idade de 49,3 anos, sua pressão arterial está boa

Seu exame de açúcar no sangue (glicemia de jejum) está normal

Seus exames de colesterol (colesterol total e fração HDL), no conjunto, estão bons

e o exame de outras gorduras no sangue (triglicérides) está normal

Assim, recomendamos parar de fumar

Se necessitar de qualquer esclarecimento sobre este assunto, por favor ligue 3068-2967 ou 3082-2172

Atenciosamente,

Coordenação da Pesquisa sobre

Fatores de Risco para Doenças Crônicas

Não-Transmissiveis no Municipio de São Paulo 


\section{Anexo 4.}

Carta enviada aos entrevistados contendo os resultados dos exames realizados. 


\section{Anexo 5.}

Parecer do Conselho de Ética em Pesquisa da UNIFESP.

Parecer do Conselho de Ética em Pesquisa da FSP/USP. 
IImo.(a) Sr.(a)

Prof(a) Dr(a) LUIZ FRANCISCO MARCOPITO

Departamento de Medicina Preventiva da UNIFESP

Prezado(a) Professor (a),

O Comitê de Ética em Pesquisa do Hospital São Paulo/Universidade Federal de São Paulo analisou e aprovou o Projeto de Pesquisa intitulado: "Fatores de risco para doenças crônicas não-transmissíveis. Inquérito domiciliar no município de São Paulon.

Atenciosamente,

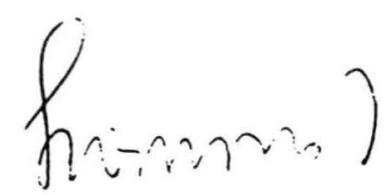

Prof. Dr. José Osmar Medina Pestana

Presidente do Comitê de Ética em Pesquisa do

Hospital São Paulo/Universidade Federal de São Paulo

cc.: Prof(a). Dr(a). Laércio Joel Franco

Chefe do Departamento de Medicina Preventiva da UNIFESP 


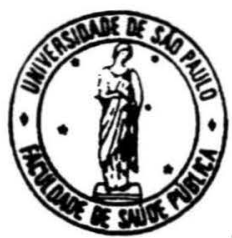

\section{Universidade de São Paulo}

Faculdade de Saúde Pública

COMITÊ DE ÉTICA - COEP

Av. Dr. Arnaldo, 715 - CEP $01246-904$ - São Paulo - Brasil

Telefones: (55-11) 3066-7779/7742 -0 - e-mail: coep@fsp.usp.br

\section{Of.COEP/60/05}

07 de março de 2004

Pelo presente, informo que o Comitê de Ética em Pesquisa da Faculdade de Saúde Pública da Universidade de São Paulo-COEP, analisou e aprovou, o Protocolo de Pesquisa n. ${ }^{\circ}$ 1306, intitulado: "PADRÕES DE CONSUMO ALIMENTAR E OUTROS FATORES DE RISCO PARA DOENÇAS CARDIOVASCLLARES DA POPULAÇÃO URBANA DO MUNICÍPIO DE SÃO PAULO", apresentado pela pesquisadora Africa Isabel De La Cruz Perez Neumann e, por se tratar de uma pesquisa utilizando banco de dados e baseada em dados secundários não fere a nenhum aspecto ético.

Atenciosamente,

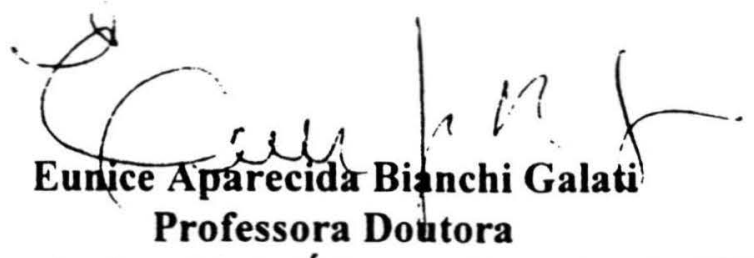

Coordenadora do Comitê de Ética em Pesquisa da FSP-COEP 


\section{SECRETARIA DE ESTADO DA SAÚDE DE SÃO PAULO \\ TERMO DE CONSENTIMENTO ESCLARECIDO}

Projeto: FATORES DE RISCO PARA DOENÇAS CRÔNICAS NÄO-TRANSMISSIVEIS:

INQUERITO DOMICILIAR NO MUNICIPIO DE SÃO PAULO

Fui informado(a) de que

- a Secretaria de Estado da Saúde de São Paulo está realizando estudo em cerca de 2.000 domicilios da Capital;

- esses domicilios foram selecionados por sorteio;

- o domicilio onde resido foi um dos selecionados;

- dentre as pessoas entre 15 e 59 anos de idade que nele residem uma foi selecionada por sorteio para participar desse estudo;

- eu fui essa pessoa selecionada.

Também fui informado(a) de que

- o estudo consiste de uma entrevista, medidas de pressão, de peso, de altura, da cintura e do quadril;

- a entrevista obedecerá a um questionário contendo perguntas sobre: dados de identificação, instrução escolar, trabalho, renda, pressão alta, diabetes (açúcar no sangue), gorduras no sangue, remédios em uso, fumo, bebida, exercicio, nervosismo.

Tambèm fui informado(a) de que

- em um terço dos entrevistados, também escolhidos por sorteio,

1) serão feitas perguntas sobre alimentos (comidas e bebidas); $e$

2) será feito um exame colhendo amostra de sangue após 12 de jejum que será perfurada com uma lanceta;

- nessa amostra de sangue serão dosados o açúcar e as gorduras;

- eu $\square$ fui / $\square$ não fui sorteado(a) para essa parte do estudo.

A Secretaria da Saúde gostaria muito que eu participasse do estudo, porque

- eu estaria contribuindo para a saúde da população;

- eu me beneficiaria diretamente com os resultados das medidas (e dosagens) feitas em casa,

mas a Secretaria da Saúde garante meu direito de recusar.

Se eu aceitar participar do estudo, a Secretaria da Saúde garante que

- eu não serei obrigado(a) a responder a qualquer pergunta que não quiser;

- todas as respostas que eu der serão mantidas confidenciajs;

- minha identidade jamais será revelada.

Assim sendo, eu a CONCORDO EM PARTICIPAR.

eu $\square$ não concordo em participar.

São Paulo, de de

Nome:

Documento de identidade

Assinatura

Documento de identidade

Assinatura do responsaivel legal, se menor de 18 anos de ictade

Deciaro que ootive de forma apropriada e voluntária o Consentimento Livre e Esclarecido deste paciente ou

representante legal para a participação neste estudo.

Assinatura do responsável pelo estudo

Luiz Francisco Marcopito -

Coordenador da Pesquisa (fone para contato: 3068-2967)

Data ......................... 


\section{Anexo 6.}

\section{MATRIZ DE CORRELAÇÃO ANTIIMAGEM.}

As seguintes correlações anti-imagem foram obtidas para cada variável no presente estudo:

\begin{tabular}{|l|l|}
\hline LEITE INTEGRAL & 0,899 \\
\hline LEITE DESNATADO & 0,817 \\
\hline PÄES & 0,870 \\
\hline CEREAIS & 0,813 \\
\hline MASSAS & 0,867 \\
\hline SALGADOS & 0,877 \\
\hline MAIONESE & 0,861 \\
\hline GORDURAS & 0,878 \\
\hline DOCES & 0,884 \\
\hline FEIJŐES & 0,804 \\
\hline FEIJOADA & 0,839 \\
\hline FOLHOSOS & 0,770 \\
\hline NÄO FOLHOSOS+ SOPAS & 0,776 \\
\hline FRUTAS & 0,887 \\
\hline SUCOS NATURAIS & 0,861 \\
\hline CARNE BOI+ MIÚDOS & 0,833 \\
\hline PORCO & 0,800 \\
\hline FRANGO & 0,598 \\
\hline PEIXES & 0,896 \\
\hline LINGÜIÇA & 0,813 \\
\hline PRESUNTO & 0,895 \\
\hline OVO & 0,715 \\
\hline INFUSÃO & 0,801 \\
\hline BEBIDAS alcoólicas & 0,722 \\
\hline SUCOS artificiais & 0,810 \\
\hline REFRI DIET & 0,614 \\
\hline ADOÇANTE no café & 0,522 \\
\hline REFRI COMUM & 0,785 \\
\hline SAL & 0,698 \\
\hline & \\
\hline
\end{tabular}




\section{Anexo 7. Fatores definidos pela análise fatorial}

VARIÂNCIA TOTAL

\begin{tabular}{|c|c|c|c|c|c|c|c|c|c|}
\hline \multirow[b]{2}{*}{ COMPONENTES } & \multicolumn{3}{|c|}{ AUTOVALORES INICIAIS } & \multicolumn{3}{|c|}{$\begin{array}{l}\text { Extraction Sums of Squared } \\
\text { Loadings }\end{array}$} & \multicolumn{3}{|c|}{$\begin{array}{c}\text { Rotation Sums of Squared } \\
\text { Loadings }\end{array}$} \\
\hline & 丞 & 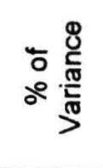 & 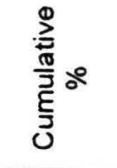 & 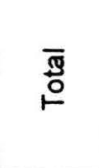 & 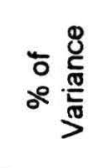 & 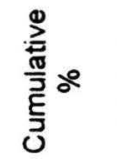 & 要 & 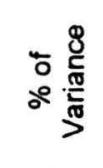 & 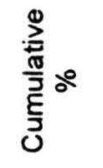 \\
\hline 1 & 5,258 & 18,130 & 18.130 & 5,258 & 18,130 & 18.130 & 3,380 & 11,654 & 11.654 \\
\hline 2 & 2,182 & 7,525 & 25,655 & 2,182 & 7,525 & 25,655 & 2,833 & 9,769 & 21,423 \\
\hline 3 & 1,517 & 5,230 & 30.885 & 1,517 & 5,230 & 30,885 & 2.143 & 7,388 & 28.811 \\
\hline 4 & 1,383 & 4,767 & 35,653 & 1,383 & 4,767 & 35,653 & 1,984 & 6,841 & 35,653 \\
\hline 5 & 1,304 & 4,496 & 40,148 & & & & & & \\
\hline 6 & 1,202 & 4,146 & 44,295 & & & & & & \\
\hline 7 & 1,120 & 3,861 & 48,156 & & & & & & \\
\hline 8 & 1,047 & 3,611 & 51.767 & & & & & & \\
\hline 9 & 1,039 & 3,584 & 55,351 & & & & & & \\
\hline 10 & .935 & 3.224 & 58.575 & & & & & & \\
\hline 11 & ,913 & 3,150 & 61,724 & & & & & & \\
\hline 12 & ,879 & 3,030 & 64.754 & & & & & & \\
\hline 13 & 871 & 3,004 & 67,758 & & & & & & \\
\hline 14 & ,786 & 2,710 & 70,468 & & & & & & \\
\hline 15 & ,754 & 2,599 & 73,067 & & & & & & \\
\hline 16 & ,742 & 2,559 & 75,626 & & & & & & \\
\hline 17 & ,721 & 2,487 & 78,112 & & & & & & \\
\hline 18 & ,713 & 2,457 & 80,570 & & & & & & \\
\hline 19 & 685 & 2.363 & 82.933 & & & & & & \\
\hline 20 & ,676 & 2,332 & 85,265 & & & & & & \\
\hline 21 & .613 & 2,113 & 87.378 & & & & & & \\
\hline 22 & ,576 & 1,988 & 89,365 & & & & & & \\
\hline 23 & ,546 & 1,881 & 91,247 & & & & & & \\
\hline 24 & ,515 & $1, \pi 77$ & 93.024 & & & & & & \\
\hline 25 & ,484 & 1,668 & 94,692 & & & & & & \\
\hline 26 & .459 & 1,581 & 96,273 & & & & & & \\
\hline 27 & .428 & 1,477 & 97,750 & & & & & & \\
\hline 28 & 337 & 1.161 & 98.911 & & & & & & \\
\hline 29 & 316 & 1,089 & 100.000 & & & & & & \\
\hline
\end{tabular}

Extraction Method: Principal Component Analysis. 